IZA DP No. 10165

Teacher Expectations Matter

Nicholas W. Papageorge

Seth Gershenson

Kyungmin Kang

August 2016

Forschungsinstitut zur Zukunft der Arbeit Institute for the Study of Labor 


\title{
Teacher Expectations Matter
}

\author{
Nicholas W. Papageorge \\ Johns Hopkins University \\ and IZA \\ Seth Gershenson \\ American University \\ and IZA \\ Kyungmin Kang \\ Johns Hopkins University
}

\section{Discussion Paper No. 10165 \\ August 2016}

\author{
IZA \\ P.O. Box 7240 \\ 53072 Bonn \\ Germany \\ Phone: +49-228-3894-0 \\ Fax: +49-228-3894-180 \\ E-mail: iza@iza.org
}

\begin{abstract}
Any opinions expressed here are those of the author(s) and not those of IZA. Research published in this series may include views on policy, but the institute itself takes no institutional policy positions. The IZA research network is committed to the IZA Guiding Principles of Research Integrity.

The Institute for the Study of Labor (IZA) in Bonn is a local and virtual international research center and a place of communication between science, politics and business. IZA is an independent nonprofit organization supported by Deutsche Post Foundation. The center is associated with the University of Bonn and offers a stimulating research environment through its international network, workshops and conferences, data service, project support, research visits and doctoral program. IZA engages in (i) original and internationally competitive research in all fields of labor economics, (ii) development of policy concepts, and (iii) dissemination of research results and concepts to the interested public.
\end{abstract}

IZA Discussion Papers often represent preliminary work and are circulated to encourage discussion. Citation of such a paper should account for its provisional character. A revised version may be available directly from the author. 


\section{ABSTRACT}

\section{Teacher Expectations Matter}

We develop and estimate a joint model of the education and teacher-expectation production functions that identifies both the distribution of biases in teacher expectations and the impact of those biases on student outcomes via self-fulfilling prophecies. The identification strategy leverages insights from the measurement-error literature and a unique feature of a nationally representative dataset: two teachers provided their educational expectations for each student. We provide novel, arguably causal evidence that teacher expectations affect students' educational attainment. Estimates suggest that the elasticity of the likelihood of college completion with respect to teachers' expectations is about 0.12. On average, teachers are overly optimistic about students' ability to complete a four-year college degree. However, the degree of over-optimism of white teachers is significantly larger for white students than for black students. This highlights a nuance that is frequently overlooked in discussions of biased beliefs: unbiased (i.e., accurate) beliefs can be counterproductive if there are positive returns to optimism or if there are socio-demographic gaps in the degree of teachers' over-optimism, both of which we find evidence of. We use the estimated model to assess the effects of two policies on black students' college completion: hiring more black teachers and "de-biasing" white teachers so that they are similarly optimistic about black and white students.

JEL Classification: I2, D84, J15

Keywords: education, educational attainment, teachers, subjective expectations, human capital accumulation

Corresponding author:

Nicholas W. Papageorge

Department of Economics

Johns Hopkins University

Wyman 521, 3400 N. Charles St

Baltimore, MD 21218

USA

E-mail: papageorge@jhu.edu

\footnotetext{
${ }^{*}$ We gratefully acknowledge helpful comments from conference participants at the North American Meetings of the Econometric Society and the IZA Junior-Senior Labor Economics Symposium. Stephen B. Holt provided able research assistance. For helpful suggestions and conversations, we thank Barton Hamilton, Robert Pollak, Yingao Hu, Victor Ronda and Richard Spady. The usual caveats apply. Papageorge acknowledges that this research was supported in part by a grant from the American Educational Research Association (AERA). AERA receives funds for its "AERA Grants Program" from the National Science Foundation under NSF Grant \# DRL-0941014. Opinions reflect those of the authors and do not necessarily reflect those of the granting agencies.
} 


\section{Introduction}

At least since Becker (1964) cast schooling as an investment in human capital, economists have sought to understand the factors that drive variation in educational outcomes. Sociodemographic gaps in educational attainment have received particular attention, since education facilitates upward economic and social mobility across generations (Bailey and Dynarski, 2011), increases earnings (Card, 1999), and has a direct, causal effect on a number of important social and behavioral outcomes such as civic engagement (Dee, 2004a; Milligan et al. 2004), health (Grossman, 2006), and crime (Lochner and Moretti, 2004, Machin et al. 2011). Moreover, there are numerous social benefits of a more educated population (Moretti, 2004). Such gaps are especially concerning if they reflect sub-optimal investments in human capital by under-represented or historically disadvantaged groups (e.g., racial minorities). Teacher expectations constitute one potentially important, but relatively understudied, educational input that might contribute to socio-demographic gaps in educational attainment. Despite pervasive views that teacher expectations matter, however, it is difficult to credibly identify their causal effects on student outcomes (Brophy, 1983; Jussim and Harber, 2005; Ferguson, 2003). The reason is that teacher expectations may simply reflect accurate forecasts about educational attainment. If so, then teacher expectations do not influence outcomes, but instead reflect the information teachers have about true student potential. Alternatively, a causal impact arises if incorrect (i.e., biased) teacher expectations create self-fulfilling prophecies in which investments made in or by students are altered, thereby leading to outcomes that resemble teachers' initially incorrect beliefs. 1

In this paper, we develop and estimate a structural econometric model of the teacherexpectation and education production functions. ${ }^{2}$ The model identifies both the distribution of biases in teacher expectations and the impacts of those biases on students' educational attainment. Specifically, we estimate each student's objective probability (upon entering the tenth grade) of completing a college degree and compare these probabilities to the student's teachers' stated educational expectations. We then allow discrepancies (biases) to directly

\footnotetext{
${ }^{1}$ We are not the first to examine how self-fulfilling prophecies can perpetuate negative bias against demographic groups. Loury (2009) develops an informal model where taxi drivers' racial biases against black passengers lead to adverse selection in which blacks wait for a taxi such that the original biases become true. In an earlier observational study, Rist (1970) provides a rather harrowing account of how subjective teacher perceptions, driven largely by social class, affected how both teachers and students behaved in the classroom. Eventually, these behaviors produced student outcomes that corresponded to the teachers' initial and negative beliefs about students from lower social classes. Both Jussim and Eccles (1992) and Jussim and Harber (2005) recognize how accuracy and self-fulfilling prophecies could contribute to a correlation between expectations and outcomes.

${ }^{2}$ We refer to the model as "structural" since we assign an explicit economic interpretation to some model parameters.
} 
enter as inputs in the education production function. In doing so, we solve the fundamental endogeneity problem that plagues previous research on the importance of teacher expectations (Gregory and Huang, 2013; Boser et al., 2014) by distinguishing between accurate forecasts and inaccurate forecasts that generate self-fulfilling prophecies. The econometric analysis exploits a unique feature of a nationally-representative longitudinal dataset: two teachers provide their educational expectations for each student 3 When teachers disagree about a particular student, which they frequently do, this provides within-student variation in expectations. In both the formal model and analogous reduced-form instrumental variables (IV) analyses, we leverage this within-student variation to identify the impact of expectations on educational attainment. Both the structural and IV estimates suggest that teachers' expectations have sizable, arguably causal impacts on the likelihood that students complete a college degree.

Prior to specifying and estimating a formal model that disentangles accurate forecasts from biased beliefs that fuel self-fulfilling prophecies, the current study begins by documenting several interesting patterns in the teacher expectations data. First, teacher expectations are informative, and remain so even after conditioning on a rich set of academic, demographic, and socioeconomic controls, as well as school fixed effects and the other teacher's expectation. Second, on average, teacher expectations are optimistic: teachers expect more college degrees than are earned. Third, teacher expectations respond to information that would presumably affect college-going, such as family income, standardized test scores, and ninth-grade GPA. Fourth, teachers frequently disagree about how far a given student will go in school. The most common margin for disagreements is between teachers who expect "some college" and teachers who expect a four-year college degree. Finally, and key to our identification strategy, teacher disagreements appear to be driven by transitory, relatively unimportant factors that are arguably excluded from the education production function. For example, when a student behaves passively in English class but not in math class, this affects the English teacher's expectation but not the math teacher's expectation. This type of within-student, within-semester variation in passiveness represents transitory, arguably random departures from the student's steady-state level of passiveness. Moreover, when two teachers disagree about a particular students' expected educational attainment, at least one (but perhaps both) must be wrong. Both the structural and IV estimates are identified off of conditionally random, exogenous disagreements between teachers. Intuitively, this is akin to using one teacher's expectation to control for the important factors that do directly affect attainment. We investigate the production of teacher expectations and the sources of

\footnotetext{
${ }^{3}$ Previous research has leveraged this feature to estimate the effect of student-teacher racial match on teachers' perceptions and expectations via student-fixed effects models (Dee, 2005, Gershenson et al., 2016).
} 
disagreements in greater detail below.

The structural model formalizes the common factors that drive teacher expectations and directly enter the education production function as a latent factor, which is interpreted as a student's objective probability, absent teacher bias, of obtaining a four-year college degree. Borrowing from the measurement error literature, we treat each teacher's expectation as a possibly mis-measured unobserved or "latent" factor 4 The latent factor is identified off of two teacher expectations along with the observed student outcome. Since the latent factor also enters the teacher-expectation production function, it encompasses the common factors observed by both teachers that influence both teacher expectations and educational attainment. Providing this sort of economic interpretation to a latent factor using lessons from the measurement error literature is similar to Heckman et al. (2006), who develop a model where latent factors capture both cognitive and non-cognitive skills. However, an innovation of our approach is that we also provide an economic interpretation of the measurement error (error terms in teacher expectations equations) that lead to disagreements between teachers. Specifically, we interpret those errors as biases in teachers' expectations, which we then allow to enter the education production function. The main identifying assumption is that the transitory or subject-specific shocks that cause teachers to disagree about a student's potential do not directly affect attainment. To continue the example from the preceding paragraph, this means that while a student's baseline level of passiveness can directly affect educational attainment (since it is captured by the latent factor), classroomspecific deviations from this baseline level that might affect individual teachers' expectations do not. We provide empirical evidence in support of this assumption (i.e., that factors that might directly affect attainment but only be observed by one teacher do not predict teacher disagreements).

In demonstrating that teacher expectations matter, this paper contributes to several separate, but related literatures. First, a large literature has shown that teachers are important inputs in the education production function (Chetty et al., 2013; Hanushek and Rivkin, 2010). However, it remains unclear what specific behaviors and characteristics make teachers effective. Our study discusses one possible mechanism: teachers' expectations might affect student outcomes. A second, related literature has established robust evidence that on average, nonwhite students perform better and are more engaged when paired with same-race teachers (Dee, 2004b; Fairlie et al., 2014; Holt and Gershenson, 2015). Again, we offer one possible mechanism through which such mismatch effects operate, since Gershenson et al. (2016) find that student-teacher racial mismatch affects teachers' expectations.

\footnotetext{
${ }^{4}$ The use of multiple measures to recover the distribution of latent factors goes back to the psychometric literature (Jöreskog and Goldberger, 1972).
} 
We also contribute to a nascent literature in the economics of education that investigates how teachers' biases affect student outcomes. For example, Lavy and Sand (2015) identify primary school teachers in Israel who have "pro-boy" grading bias by comparing students' scores on "blind" and "non-blind" exams. The authors then show that random assignment to a "pro-boy"-biased teacher improves boys' middle- and high-school exam scores and increases boys' advanced math/science course-taking in high school. Such teachers have negative effects on these outcomes for female students, particularly for females from low-SES backgrounds. Terrier (2015) finds similar effects of gender-based grading bias on short-run achievement and subsequent course-taking in France. We contribute to this line of work by explicitly estimating the production of expectations and by considering the role that teacher expectations play in the education production function.

Another line of research to which we contribute has considered several reasons why teacher expectations might influence (rather than simply reflect) student outcomes. Generally, teachers might shape students' academic self-concepts (Burgess and Greaves, 2013; Dee, 2014). These effects might be particularly salient for relatively disadvantaged students who rarely interact with college-educated adults outside of school settings (Jussim and Harber, 2005 , Lareau, 2011; Lareau and Weininger, 2008), since a model of costly information acquisition would predict that such students rely on teacher expectations as a primary source of information. These effects could be transmitted in two ways. First, teachers might directly impart their potentially biased expectations to students or do so indirectly by modifying how they teach, evaluate, and advise stigmatized students (Ferguson, 2003). For example, teachers likely influence students' beliefs via the grades they assign (Mechtenberg, 2009). Second, stigmatized groups may modify their own expectations and behavior to conform to negative biases (Ferguson, 2003). Indeed, perceived low expectations for performance may exacerbate the harmful effects of stereotype threat, whereby low expectations either cause emotional responses that directly harm performance or cause students to disidentify with educational environments (Steele, 1997). In either case, biased expectations can create a feedback loop that functions like a self-fulfilling prophecy that perpetuates the educational attainment gap. Our study does not identify which of the reasons discussed above is the key mechanism explaining why teacher expectations drive outcomes. However, our empirical framework formalizes the idea that biases function as self-fulfilling prophecies by allowing these biases to enter the education production function. Therefore, the model is able to disentangle two potential sources of correlation between expectations and student outcomes: expectations may be accurate forecasts, but may also influence student outcomes through self-fulfilling prophecies.

More generally, we contribute to literature on the importance of subjective expectations 
in understanding economic behavior. The idea that subjective beliefs rather than objective probabilities drive individual behavior is not new (Savage, 1954, Manski, 1993). Indeed, Suen (2004) presents a number of theoretical insights into how biased expectations are perpetuated, particularly when information acquisition is costly and provided in coarse increments. Similarly, Van den Steen (2004) shows how people tend to over-weight information that is consistent with the information that they already have. The trouble with this is exemplified in the following example. Suppose a black student has pessimistic views about his or her ability to earn a four-year college degree. Upon meeting a black college graduate, the student might update his or her beliefs about the feasibility of earning a degree. Alternatively, the student might view the black college graduate as a fluke and essentially ignore the new information provided by this data point (Suen, 2004; Van den Steen, 2004). Despite their importance, subjective expectations are only recently entering into economic analyses of decision-making. One reason is that data on subjective expectations have rarely been collected. Another reason is that it is difficult to assess whether beliefs have causal effects on outcomes absent experimentally-induced exogenous variation 5 Our approach addresses this issue by using lessons from measurement error literature and, moreover, by leveraging multiple reported subjective expectations about a single objective probability. We therefore offer a methodology to use observational data to assess how beliefs affect behavior. We also contribute to literature studying how beliefs form and affect economically important behavior. For example, several studies have examined how biased media influences voter behavior (Chiang and Knight, 2011; DellaVigna and Kaplan, 2007; Gentzkow and Shapiro, 2006). In the education context, Fortin et al. (2015) and Jacob and Wilder (2010) examine how students' expectations evolve over time and might explain demographic gaps in achievement. The current study contributes to this literature by (i) suggesting that teacher biases may be one reason that certain groups make sub-optimal decisions due to lack of information and (ii) providing one way to identify arguably causal effects of biased beliefs using longitudinal observational data in a non-experimental setting.

We provide compelling evidence of a causal impact of teachers' expectations on the likelihood of college completion. Specifically, the model captures three distinct reasons for the racial gap in outcomes. The most important of which is that black and white students enter tenth grade with very different objective probabilities of completing a college degree. This

\footnotetext{
${ }^{5}$ In a famous contribution, Rosenthal and Jacobson (1968) report effects of informing teachers that some randomly selected students are high-aptitude. These students perform better on tests. This paper provides some basis for the view that teacher expectations matter in that biases can become self-fulfilling prophecies. Our paper shows that these so-called "Pygmalion Effects" exist in the absences of experimentally-induced variation, have long-run impacts on educational attainment, and contribute to black-white gaps in college completion.
} 
is not necessarily due to ability differences, but also by differences in the full complement of educational inputs received from birth to grade nine (Todd and Wolpin, 2007). Related to this are differences in how those initial conditions, including race, map into teacher expectations (Gershenson et al., 2016). Finally, there are racial differences in how biases and initial conditions map into educational attainment (Cameron and Heckman, 2001).

The structural model also addresses an open question raised in Gershenson et al. (2016): when white and black teachers systematically disagree about black students' potential, who is correct? It turns out that neither is correct, in the sense that both teachers' expectations diverge from the objective probability of college completion. However, a focus on who is correct misses the policy-relevant point, as all teachers are optimistic, on average, and high expectations have a positive impact on the likelihood of college completion. Instead, white teachers' optimism is systematically greater for white students than for black students. Such differences matter and contribute to racial gaps in college completion, due to the positive impact of high expectations on educational attainment.

We use the model to explore two social policies that could attenuate the attainment gap between black and white students. The first policy, which has been hotly debated, is to hire more black teachers (Putman et al., 2016). This would increase the probability that black students face a black teacher, which in turn would increase the likelihood that a black student faces higher expectations (Gershenson et al., 2016). One potential drawback is that black teachers might favor black students at the expense of white students; however, we show little evidence that this is true ${ }^{6}$ Another policy we consider is the de-biasing of white teachers. A number of interventions have shown promise in reducing racially-based unconscious bias (Devine et al., 2012), including some in the education context Carnes et al., 2015; Okonofua et al. 2016). Additionally, Dobbie and Fryer Jr. (2015) provide suggestive evidence that some pre-service teacher training programs can reduce teachers' racial biases and increase their educational expectations for children from disadvantaged backgrounds. We operationalize this counterfactual by simulating white teachers who, regardless of student race, form the same expectations for a given objective probability of college completion.

Four main results emerge from these counterfactual simulations. First, hiring more black math teachers is somewhat more effective at raising college completion versus hiring more black ELA teachers. Second, hiring more black math teachers is considerably more effective than de-biasing white teachers for students entering the tenth grade with low probabilities

\footnotetext{
${ }^{6}$ There are many other reasons why this policy is debated. For one, it suggests segregating students. Second, it would require the hiring of so many black teachers that the current rate of college-educated blacks going into the teacher profession would need to rise dramatically. Achieving this would likely require increasing teacher salaries and would pull college-educated blacks from other professions.
} 
of college completion. Third, de-biasing white teachers becomes relatively more effective for black students who enter with relatively high probabilities of college completion. Finally, both policies are generally more effective for students entering with higher objective probabilities. For example, raising the probability that a black student in the top quartile sees a black math teacher from $18 \%$ to $84 \%$ raises the probabilty of college graduation from $62.9 \%$ to $65.2 \%$. Doing the same in the lowest quartile raises graduation probability from $3.70 \%$ to $3.89 \%$. Moreover, de-biasing an equivalent number of white teachers has a similar effect at the upper quartile and no effect at all on the bottom quartile. Among other conclusions, our results show that plausible policies can help some black students, especially those who are above the median objective probability of college completion upon entering the 10th grade. However, our results suggest that disadvantaged blacks barely respond to these policies, suggesting that earlier interventions are necessary.

The paper proceeds as follows. Section 2 describes the data set used in the project and documents some basic facts about the information contained in teacher expectations and how and why teachers disagree. Section 3 develops the structural model and describes identification and estimation. Sections 4 and 5 present the main results and policy simulations, respectively. Section 6 concludes.

\section{Data Set and Preliminary Data Analysis}

In this section, we discuss the data set used in the project and describe some basic patterns in the data. Section 2.1 introduces the 2002 Education Longitudinal Study (ELS 2002). Section 2.2 establishes that teacher expectations are informative, i.e., that they are strongly predictive of student outcomes. This empirical pattern could reflect that teacher expectations are accurate forecasts of student outcomes or alternatively that they influence student outcomes through self-fulfilling prophecies. To examine these alternatives further, Section 2.3 studies how teacher expectations are produced. We pay particular attention to understanding why two teachers disagree (in terms of reported expectations) about the same student. We also discuss how we exploit teacher disagreements to estimate causal effects.

\section{$2.1 \quad$ ELS 2002}

The ELS 2002 is a nationally representative survey of the cohort of U.S. students who entered 10th grade in 2002.7 The ELS data contain rich information on students' socio-demographic

\footnotetext{
${ }^{7}$ The ELS data are collected, maintained, and made available to researchers by the National Center for Education Statistics. See https://nces.ed.gov/surveys/els2002.
} 
backgrounds as well as secondary and postsecondary schooling outcomes (including educational attainment through 2012, or within 8 years of an "on time" high school graduation). Students were sampled within schools and school identifiers facilitate within-school (school fixed effects) analyses. The data also contain a number of observed school and teacher characteristics, including teachers' experience, demographic background, credentials, and expectations and perceptions of specific students.

The main analytic sample is restricted to the 6,060 students for whom the above-mentioned variables are observed 8 Because there are two teacher expectations per student, the analytic sample contains 12,130 teachers. Table 1 summarizes the students who comprise the analytic sample. Column (1) does so for the full sample and columns (2)-(5) do so separately by student race and sex. The outcome of interest, students' educational attainment, is summarized in three ways: percentage of students who earn a four-year college degree (or more), percentage of students who fail to complete high school, and average years of schooling. About $45 \%$ of students in the sample completed a four-year degree, though whites and females were significantly more likely to do so than blacks and males, respectively. This is consistent with demographic gaps in educational attainment observed in other datasets (Bailey and Dynarski, 2011; Bound and Turner, 2011; Cameron and Heckman, 2001). The racial gaps in educational attainment are particularly stark, as whites were about 20 percentage points (50\%) more likely to graduate from college than blacks while blacks were twice as likely as whites to fail to complete high school. Racial differences in educational attainment are also apparent in Figure 1, which provides a histogram for educational attainment categories across for the full sample and then separately for blacks, whites, males, and females.

Our primary analysis focuses on racial differences in teachers' expectations and student outcomes, along with the role of student-teacher racial mismatch. This is because black-white gaps in expectations and college completion are substantively large. Moreover, Gershenson et al. (2016) find statistically and economically significant differences between white and black teachers' expectations for black students. Our aim is to assess whether this type of mismatch effect, and biases in teacher expectations more generally, influence students' educational outcomes. We focus on the college-completion margin due to the striking patterns observed in Figure 1; blacks are significantly more likely than whites to only complete "some college." This suggests that college completion, relative to college entrance, is an important margin to consider in the analysis of racial attainment gaps.9 We define students' educational

\footnotetext{
${ }^{8}$ All sample sizes are rounded to nearest ten in accordance with NCES regulations for restricted data. The instrumental variables analysis described below uses a further restricted sample, for whom a wider range of teacher-perception variables are observed.

${ }^{9}$ Recent research explicitly notes that individuals with some college, but less than a four-year degree, have socioeconomic trajectories that closely resemble those of high school graduates (Lundberg et al., 2016).
} 
attainment and teachers' educational expectations for the student in the same way: the student outcome of interest in the primary analyses is an indicator for "student completed a four-year college degree or more" (as of 2012, 8 years removed from an on-time high-school graduation) and the independent variable of interest is an indicator for "teacher expects a four-year college degree or more."

We exploit a unique feature of the ELS 2002's design: two teachers, one math and one English Language Arts (ELA), provided their subjective expectations and perceptions of each student. The key teacher-expectation variable is based on teachers' responses to the following question: "How far do you think [STUDENT] will go in school?" Teachers answered this question by selecting one of seven mutually exclusive categories ${ }^{10}$ Teachers' expectations are summarized in the next section of Table 1. Overall, about $64 \%$ of teachers expected the student to complete a four-year college degree. This suggests that teachers, on average, are too optimistic about students' college success, since only $45 \%$ of students complete a four-year degree. This over-optimism is apparent in each demographic group, though teachers' expectations for black students are significantly lower than for white students, as are expectations for male students relative to females. This points to an interesting feature in the data that foreshadows our results: black students are put at a disadvantage in terms of teacher expectations not because teachers' expectations are too low, but due to a lack of teacher over-optimism. These racial and sex gaps in expectations are consistent with the patterns in actual educational attainment described above, suggesting that teachers' expectations are informative. However, while math and ELA teachers' expectations are similar on average, ELA teachers' expectations tend to be slightly higher, particularly among black students. This shows that teachers occasionally disagree about how far a particular student will go in school. Below, we further investigate the sources of teacher disagreements and consider how such disagreements can be leveraged to identify the impact of expectations on student outcomes.

The final two panels of Table 1 summarize students' academic and socioeconomic characteristics. A comparison of columns (2) and (3) shows that white students have significantly higher test scores, GPAs, and household incomes than black students, as well as better educated mothers, all of which is consistent with longstanding racial disparities in academic performance and socioeconomic status (Fryer, 2010). Another notable difference by student race is in their assigned teacher's race: black students are four to five times as likely as white students to be assigned a black teacher, which is due to non-white teachers being more likely

\footnotetext{
${ }^{10}$ Options were Less than high school graduation; High school graduation or GED only; Attend or complete 2-year college/school; Attend college, 4-year degree incomplete; Graduate from college; Obtain Master's degree or equivalent; Obtain $\mathrm{PhD}, \mathrm{MD}$, other advanced degree.
} 
to teach in majority non-white schools (Hanushek et al., 2004; Jackson, 2009). Nonetheless, the majority of students, white and black, have white teachers. This is troubling in the context of the current study, as Gershenson et al. (2016) show that student-teacher racial mismatch has significant, arguably causal effects on teachers' educational expectations for students. Columns (4) and (5) of Table 1 show that girls have higher GPAs and perform better on reading assessments than boys, while boys perform better on math assessments. This is consistent with the literature (Jacob, 2002). Unsurprisingly, there are no significant differences in SES by sex, since boys and girls live in the same neighborhoods and attend the same schools.

Table 2 similarly summarizes the teachers represented in the analytic sample. Overall, $11 \%$ of teachers are nonwhite and nonwhite teachers are evenly represented across subjects

and sex. The average teacher has about 15 years of experience though $16 \%$ of teachers have $\leq 3$ years of teaching experience. Math teachers are more experienced than English teachers, on average, as are black teachers relative to white teachers. Almost half of teachers have an undergraduate degree in the subject they teach. A similar percentage hold a graduate degree. The bottom panel of Table 2 confirms that black teachers are significantly more likely to teach black students than are teachers from other racial backgrounds.

\subsection{Teacher Expectations are Predictive}

Are teacher expectations informative? This section demonstrates how teacher expectations about educational attainment are predictive and, moreover, that they remain so even after controlling for a number of factors that jointly determine teacher forecasts and student outcomes. Figure 2 plots the percentage of students who complete a four-year college degree for each category of teacher expectations, separately for math and ELA teachers. According to the figure, higher expectations are associated with a higher probability of college completion. Interestingly, however, teacher forecasts are subject to error. For example, of students for whom ELA teachers expect some college, roughly $15 \%$ go on to obtain a 4 -year degree. Forecast errors tend to be in the opposite direction, however. Fewer than $60 \%$ of students whose math or ELA teachers expect a 4-year degree actually obtain one. This pattern extends to students for whom teachers expect a Masters or other higher degree, who obtain at least a 4-year degree roughly $80 \%$ and $85 \%$ of the time, respectively. In other words, though teacher expectations are predictive of student outcomes, on average teachers seem to over-estimate educational attainment, which is consistent with patterns found in Table 1 .

One reason teacher expectations predict student outcomes is that teachers use information they have on students, such as student performance in class or socioeconomic back- 
ground, to generate accurate forecasts. Therefore, we would expect expectations to become less predictive of outcomes once we control for factors that potentially affect both. Table 3 presents estimates of linear regressions of the form

$$
y_{i}=\gamma_{E} T_{E i}+\gamma_{M} T_{M i}+X_{i} \beta+\epsilon_{i}
$$

where the T's denote teacher expectations, $y$ denotes student outcomes, and $i$ indexes students 11 Either $\gamma_{E}$ or $\gamma_{M}$ can be restricted to equal zero, where $E$ and $M$ index ELA and math teachers, respectively. The vector $X$ includes a progressively richer set of statistical controls, up to and including school fixed effects (FE). Standard errors are clustered by school, as teachers and students are nested in schools.

Columns (1) and (2) of Table 3 report simple bivariate regressions of $y$ on the ELA and math teachers' expectations, respectively. The point estimates are nearly identical, positive, and strongly statistically significant. Of course, these positive correlations cannot be given causal interpretations since there are many omitted factors that jointly predict student outcomes and teachers' expectations (e.g., household income). In subsequent columns of Table 3 we attempt to reduce this omitted-variables bias by explicitly controlling for such factors. In column (3), we simultaneously condition on both teachers' expectations. Interestingly, though both estimates of $\gamma$ decrease in magnitude, they remain nearly identical to one another and both remain individually statistically significant. That both teachers' expectations remain individually significant indicates that there is substantial within-student variation in teacher expectations (i.e., teachers frequently disagree). Intuitively, one teacher's expectation can be viewed as a proxy for many of the other factors that influence $y$; indeed, this idea foreshadows the formal identification strategy introduced in Section 3.

Subsequent columns of Table 3 continue to add covariates to the model, which lead to a similar pattern in the estimated $\gamma$ : the estimated effects of expectations decrease in magnitude, but remain positive, similar in size to one another, and individually statistically significant. The richest (and our preferred) specification, which conditions on students' socio-demographic background, past academic performance, and school FE, is reported in column (7). These estimates suggest that conditional on the other teacher's expectation and a rich set of observed student characteristics including sex, race, household income, mother's educational attainment, 9th grade GPA, and performance on math and ELA standardized

\footnotetext{
${ }^{11}$ To allay concerns that these results are driven by students with extreme levels of attainment, Appendix Table S1 reports OLS estimates of equation 1 for the restricted sample that excludes students who either did not complete high school or who earned a graduate degree. We present OLS estimates of these linear probability models (LPM) for ease of interpretation and to facilitate the inclusion of school fixed effects. However, estimates of the probit analog to equation (1) yield qualitatively similar patterns. Probit estimates are reported in Appendix Table S2.
} 
tests, the average marginal effect of changing a teacher's expectation that a student will complete college from zero to one increases the student's likelihood of earning a college degree by about 15 percentage points. Columns (8) and (9) show that the point estimates are similar in magnitude for white and black students, though the black-sample estimates are less precisely estimated, likely due to the significantly smaller sample size.

At first blush, 0.15 might seem like an implausibly large effect, since $45 \%$ of students in the sample earned a four-year degree. But it is unlikely that the policy-relevant counterfactual is changing a teacher's expectation of the probability that a student earns a college degree from zero to one. Instead, consider the average marginal effect of more modest 10- or 20percentage point increases in the probability that a teacher places on a student completing college, which correspond to the estimated effect of having a different-race teacher on teacher expectations (Gershenson et al. 2016) and the unconditional black-white gap in expectations shown in Table 1, respectively. The effects of these changes are about 1.5 and 3.0 percentage points, respectively. From the base college-completion rate of $45 \%$, these represent modest, but nontrivial, increases of 3.3 to $6.7 \%$. These effect sizes are remarkably similar to those found in other evaluations of K-12 inputs' impacts on post-secondary outcomes. For example, Dynarski et al. (2013) find that assignment to small classes in primary-school increased the probability that students earned a college degree by 1.6 percentage points. Similarly, Chetty et al. (2013) find that a one-SD increase in teacher effectiveness increases the probability that a student attends at least four years of college between the ages of 18 and 22 by about $3.2 \%$ Still, even with these rich controls and conditioning on the other teacher's expectation, the threat of omitted-variables bias remains. We discuss alternatives to OLS estimation of equation (1) that address this concern below.

\subsection{The Teacher Expectations Production Function}

To understand whether teacher expectations have a causal impact on student outcomes, we must first understand what drives variation in teacher expectations. In this section, we examine the teacher-expectation production function. Teacher expectations reflect information that is important for college-going, which means that they reflect accurate forecasts of student outcomes. However, we also discuss evidence that teachers disagree about particular students, and why such disagreements might arise. Teacher disagreements offer one possible way to identify causal effects of expectations on outcomes. The reason is that disagreements may arise because of transitory shocks that do not directly affect student outcomes (i.e., shocks that are excluded from the education production function shown in equation (11)).

\footnotetext{
${ }^{12}$ Chetty et al. (2013) do not observe actual college completion and instead use this as a proxy.
} 
To assess this possibility, we examine teacher responses to questions that appear to reflect transitory shocks. Such factors include, for example, a teacher's perception that a student is "passive in class" or "likes math." These variables, which are summarized in Appendix Table S3, tend to predict disagreements in teachers' expectations for the same student, rather than proxying for important underlying student attributes or traits observed by both teachers. We argue, therefore, that these factors can be used as instruments for teacher expectations that aid in the estimation of causal effects. We implement this strategy by estimating equation (1) by 2SLS, where the first stage represents the production function for teacher expectations.

Consider equations describing the production of teacher expectations of the form

$$
T_{i j}=X_{i} \beta_{j}+Z_{i M} \pi_{j M}+Z_{i E} \pi_{j E}+\nu_{i j}, j \in\{M, E\}
$$

where $X_{i}$ are the factors included in equation (1) that affect teacher expectations and student outcomes. In constrast, $Z_{j}$ are vectors of possibly transitory, subject-specific factors that each teacher reports separately for each student. These variables are arguably excluded from equation (1), indicating that equation (2) represents a potentially valid first-stage for 2SLS estimation of equation (1). One of the key implications of Section 2.2 is that teacher expectations seem to reflect information that would presumably matter for college completion, such as ninth grade GPA, test scores, parental income and education, and the unobserved school and neighborhood characteristics captured by school fixed effects. Specifically, as we added controls to equation (1), the explanatory power of teacher expectations decreased, which suggests that expectations reflect much of this information. This is consistent with the estimates of pooled (across subjects) versions of equation (2) reported in Gershenson et al. (2016) and with the differences observed in Table 3 there are positive socioeconomic, GPA, and ability gradients in teacher expectations and a gender gap that favors females. ${ }^{13}$ The relationship between students' performance on standardized math and ELA exams, which were conducted by the ELS and not shown to teachers, and teachers' expectations is approximately linear. Moreover, Panel A of Figure 3 shows that math and ELA teachers' expectations respond nearly identically to math scores. Panel B shows that the same is true for ELA scores. Importantly, this suggests that differences in students' subject-specific abilities do not drive teacher disagreements, which is a key identifying assumption of the econometric model presented in Section 3. More generally, Figure 3 reinforces the idea that teachers' expectations are informative and reflect information, in this case information about students' cognitive ability, that is likely important for college completion and observed by both teachers.

\footnotetext{
${ }^{13}$ Specifically, see Table 3 in Gershenson et al. $(2016)$.
} 
Still, expectations may reflect information that we have not accounted for in $X$, but which also matter for student outcomes, in which case OLS estimates of equation (1) would be biased. To motivate a potential instrumental-variables solution to this endogeneity problem, recall from Table 3 that teacher expectations predict $y$ independently of one another. This arises because there is some within-student variation (i.e., disagreements) in teacher expectations. Again, this variation alone does not solve the potential endogeneity problem. For example, one teacher may have higher expectations if she observes skills that matter for college that the other teacher does not. One obvious potential source of such "important" (endogenous) disagreements is legitimate differences in subject-specific aptitudes that are only observed by one teacher. However, this is not borne out in Figure 3, which shows that both teachers respond similarly to both math and reading test scores 14

To further investigate the types and sources of disagreements, the transition matrices in Table 4 show that the majority of disagreements about whether or not a student will earn a 4-year college degree are between teachers who expect a degree and teachers who expect the student to complete some college, rather than more substantive disagreements. This suggests that disagreements are often subtle, and might hinge on transitory or relatively unimportant factors. For example, chance encounters between teachers and students in the hallway might affect the teacher's expectations for that student, even though the behavior was unrepresentative of the student and will not affect college going. Such factors are normally unobserved by the econometrician. However, the ELS includes a battery of teacherspecific perceptions of each student that might affect one teacher's expectations, but not the other's 15

Specifically, teachers were asked whether each student was "passive" and "attentive" in class. Similarly, students were asked whether they found math and reading to be "fun." While students' steady-state levels of passiveness, attentiveness, and enjoyment of learning are non-cognitive skills that likely affect educational attainment (Cunha et al., 2010), subtle differences in the expression of these traits between 10th-grade math and English classrooms should not influence students' educational attainment. Of course, high-school students may behave differently in different classrooms for myriad reasons, including but not limited to the peer-composition of the classroom and the time of day the class meets (Carrell and Hoekstra, 2010; Figlio, 2007; Imberman et al., 2012; Shapiro et al., 2015). Such differences might well affect teachers' expectations, however, since English teachers do not typically observe students' behavior in math classrooms, and vice versa.

\footnotetext{
${ }^{14} \mathrm{We}$ return to this point and formally test whether test score differences drive differences in teacher expectations in Section 3.2 when we discuss identification of our main econometric model.

${ }^{15}$ These variables are summarized in Appendix Table S4. These variables are missing for $<5 \%$ of students.
} 
We investigate this hypothesis, and the production of teacher expectations more generally, by estimating a fully-specified version of equation (2). Results are presented in Table 5 . For context, regressing ELA and math teachers' expectations on $X$ alone yields $R^{2}$ of about 0.5, meaning that this set of fairly standard measures of socio-demographic background, achievement, and school quality explains about half the variation in teacher expectations. Columns (1) and (2) of Table 5 report estimates of equation (2) for the full analytic sample. Two results are immediately apparent. First, the classroom-specific variables $(Z)$ are informative: adding them increases the adjusted- $R^{2}$ by $0.05(11 \%)$ and they are strongly jointly significant. Second, they tend to be individually significant, and intuitively signed. For example, column (1) shows that being perceived as passive in English class significantly reduces the likelihood that the English teacher expects a college degree, but has no effect on the math teacher's expectation. The reverse is true for being perceived as passive in math class (column 2). This is fascinating, as it implies that teachers are not responding to the student's steady-state (underlying) demeanor, but rather that teachers are forming expectations based on within-semester, within-student, between-class variation in students' passiveness. Similar differences are observed in teachers' perceptions of students' "attentiveness." Most remarkable are English teachers' negative responses to whether students "find math fun."

The estimates of the teacher-expectation production functions reported in columns (1) and (2) highlight some of the transitory shocks that likely affect expectations but not student outcomes (except through their effects on teachers' expectations). Of course there are many others, which are not observed in the data. The model developed in section 3 , which explicitly accounts for such unobserved factors, is motivated by the teacher-expectation production functions. Specifically, since the transitory, between-classroom variation in students' demeanor affects teachers' expectations but arguably does not affect students' educational attainment, these variables are potential instruments for the endogenous teacher expectations in equation (1). Indeed, the teacher-expectation production functions in columns (1) and (2) can be interpreted as first-stage regressions. The instruments are strong, as evidenced by the first-stage $F$ statistics of 16 and 20 (Stock and Yogo, 2002). The rank condition is likely satisfied as well, since the "passive in English" indicator affects the English teacher's expectation, but not that of the math teacher, and vice versa for the "passive in math" indicator. The resulting 2SLS estimates of the impact of teacher expectations on college-going are positive and statistically significant, and are similar in magnitude to the corresponding OLS estimates, both of which are reported in the top panel of Table 5

\footnotetext{
${ }^{16}$ Indeed, control-function Hausman Tests find no significant differences between the OLS and 2SLS estimates for the full, white, or black samples in Table 5. The estimates for the black sample are particularly
} 
In the following section, we develop an econometric model to assess the causal effect of teacher expectations on student outcomes. The econometric model relies on a similar identification strategy to the instrumental-variables procedure employed here: teachers might disagree about a given student due to factors that do not influence student outcomes directly (e.g., a chance positive encounter after class) but could do so indirectly by leaving a teacher with an unduly favorable perception of the student's prospects. Our aim in this section was to find such factors. A key weakness of this approach, however, is that the majority of these types of factors, by virtue of being subtle and transitory, are unlikely to be measured and thus unobserved by the econometrician. Another limitation is that the IV procedure provides no information about the distribution of biases in teacher expectations or how expectations relate to students' objective probabilities of completing college. This leads us to develop an econometric model where we use lessons from the measurement error literature ( $\mathrm{Hu}$ and Schennach, 2008) to estimate a distribution of forecast error that not only leads teachers to disagree, but can also affect student outcomes through the mechanism of self-fulfilling prophecies.

\section{A Model of Expectations and Outcomes}

We develop an econometric model to isolate the causal impact of teacher expectations on college completion. The key identification challenge is that the observed correlation between teacher expectations and students' educational attainment can reflect a causal impact (via self-fulfilling prophecies), but might also reflect that teacher expectations are accurate forecasts of student outcomes. The model disentangles these two sources of correlation. To allow teacher expectations to be accurate forecasts, we model them as functions of the same latent factor that produces student outcomes. This latent variable captures factors that produce student outcomes and that teachers use to form expectations. However, we also allow teacher expectations to incorporate forecast error, which is identified off of teacher disagreements regarding the same student. These forecast errors, in turn, are permitted to influence student outcomes, which captures the idea of self-fulfilling prophecies.

The key identifying assumption is that teacher forecast error arises from factors that do not directly affect the objective probability of college completion, but might do so indirectly through their impact on teacher beliefs. This is similar to the exclusion restriction for the IV estimates discussed in section 2.3. However, by their nature, many such factors (e.g., chance positive or negative encounters with a student) are unlikely to be recorded in the

imprecise, again due to the small sample. 
data set. The framework we develop here draws upon lessons from the measurement error literature to capture these unobserved factors by estimating a distribution of teacher forecast errors, which can jointly affect teachers' expectations and student outcomes ${ }^{17}$ Section 3.1 introduces the baseline model. Section 3.2 discusses identification. Section 3.3 describes estimation.

\subsection{The Econometric Model}

College completion is a binary variable denoted $y_{i}$, which takes the value 1 if student $i$ graduates from a 4 -year college and 0 otherwise. The probability that $y_{i}=1$ is given by:

$$
\operatorname{Pr}\left(y_{i}=1\right)=\Phi\left(c+\theta_{i}+G_{i} \beta+b_{E i} \gamma_{E}+b_{M i} \gamma_{M}\right)
$$

where $\Phi$ is the standard normal cdf. According to equation (3), college completion is a function of a constant $c$ and a latent factor $\theta_{i}$, where we assume that

$$
\theta_{i} \sim N\left(0, \sigma_{\theta}^{2}\right)
$$

Together, $c, \theta_{i}$, and 9th-grade GPA $(G)$ determine the objective probability that student $i$, absent teacher bias (b), will attain a four-year college degree. Similar to Cunha et al. (2010), we assign an economic interpretation to $\theta_{i}$. However, it is neither a student fixed effect nor a measure of student ability. Rather, it is a latent variable that captures heterogeneity in the objective probability that a student observed in the 10th grade will eventually graduate college. It is the same latent variable that will be used in the production function of teacher expectations to capture how teachers observe many of the factors that determine this objective probability.

The model will be separately estimated for black and white students, though we suppress race subscripts to avoid additional notation. This means that blacks and whites may exhibit different distributions of completing a college degree, which would be captured by racespecific differences in $c$ (mean) and $\sigma_{\theta}$. Given our interpretation of $\theta$, these differences are

${ }^{17}$ The techniques used in this literature draw upon the psychometric literature (see e.g., Goldberger (1972) and Jöreskog and Goldberger (1975)), where an aim is to separate measurement error from an underlying latent factor (e.g., depression) captured imperfectly by a set of measurements. These methods were later incorporated into economics where the latent factor is assigned an economic meaning. A key example is Cunha et al. (2010) who use multiple test scores to identify a latent factor capturing cognition along with measures to identify a non-cognitive skill factor. Both factors are then used in a model of human capital accumulation and labor market outcomes. $\mathrm{Hu}$ and Schennach (2008) extend this literature by generating conditions under which parametric assumptions can be relaxed and identification is still achieved. We rely on arguments in Cunha et al. (2010) and $\mathrm{Hu}$ and Schennach (2008) when we discuss identification. 
not purely ability differences, but also reflect variation in the inputs received by students that could affect long-run educational outcomes, such as early childhood investments and school quality. Teacher biases, expressions for which are derived below, are given by $b_{j i}$, where $j \in\{E, M\}$ indexes the teacher and the $\gamma$ parameters map biases to outcomes. Including biases in teachers' expectations in the education production function is an innovation of the current study that formally allows for self-fulfilling prophecies.

The econometric model jointly estimates teacher-expectation and student-outcome equations as functions of $\theta_{i}$ and $G_{i}$. Teacher expectations, denoted $T_{j i}$ for teachers $j \in\{E, M\}$, are given by:

$$
\operatorname{Pr}\left(T_{j i}=1\right)=\Phi\left(c_{j}+\phi_{j} \theta_{i}+G_{i} \beta_{j}+D_{j i} \times\left[c_{j, D}+\phi_{j, D} \theta_{i}+G_{i} \beta_{j, D}\right]\right) .
$$

The indicator $D_{j i}$ takes the value of one if student $i$ faces an other-race subject- $j$ teacher, and zero otherwise. This captures how teacher-student racial mismatch can change how teachers form expectations for a given student with a singular objective probability of college completion (Gershenson et al., 2016). In other words, racial mismatch between teachers and students can affect whether and to what degree teachers are biased.

We define bias by combining equations (3) and (5):

$$
b_{j i} \equiv T_{j i}-\Phi\left(c+\theta_{i}+G_{i} \beta\right)
$$

so that bias is simply the difference between what a teacher reports $\left(T_{i j}\right)$ and the objective probability that the student would complete a college degree given $\theta_{i}$ and $G_{i}$. This definition of bias implies that $b_{j i}$ is continuous, increases $1: 1$ with $T_{j i}$, and is $\in(-1,1)$.

According to equation (6), teacher bias arises when teachers diverge from information that is common to both of them, including ninth-grade GPA and the latent factor $\theta_{i}$. The model captures several potential sources of bias in teacher expectations. Based on the patterns observed in section 2.1, we allow teachers to be wrong on average, meaning $c_{j}$ and $c_{j, D}$ can deviate from $c$. Teachers may also be wrong about how $\theta_{i}$ maps into outcomes, which occurs if $\phi_{j} \neq 1$. For example, the reduced form finding that teachers seem to over-estimate low and high educational attainment outcomes despite our controlling for a host of observables could mean that $\phi_{j}>11^{18}$ Teachers may also be biased in how they map observable grades $G_{i}$ to

\footnotetext{
${ }^{18}$ The term $\left(\phi_{j}-1\right)$ may capture how teachers have biased beliefs about how a given $\theta_{i}$ affects outcomes. It may also capture that teachers correctly map ability to outcomes, but mis-estimate $\theta_{i}$. We cannot separately identify these effects. Similarly, the term $\beta_{j}$ may represent that teachers are biased in the mapping or in their observation of $G_{i}$. Again, we are unable to separately identify these mechanisms. For ease of interpretation, we will assume that teachers observe $G_{i}$ and $\theta_{i}$, but incorrectly map these to outcomes when forming expectations.
} 
outcomes, in which case $\beta_{j} \neq \beta$. Finally, teachers may be wrong for idiosyncratic reasons, which is captured by the standard-normal disturbances that lead to the probit functional form in equation (5) 19

\subsection{Identification of the Econometric Model}

There are two points to discuss regarding identification of the econometric model defined by equations (3)-(6). The first is whether the estimated $\gamma$ are accurately interpreted as causal. Analogous to what is required for identification of the reduced form models estimated in Section 2.2, the argument is that teacher bias be exogenous in the production function of student outcomes. The second is that we need sufficient data to estimate the distribution of the latent factor, which is not a trivial condition. We discuss each in point in turn.

\subsubsection{Exogeneity of Teacher Bias}

For the $\gamma_{j}$ to be given causal interpretations in equation (3), the biases (denoted $b$ ) must be exogenous, conditional on $\theta, c$, and $G$. The $b$, in turn, are the factors that drive teacher expectations to diverge for the same student. Intuitively, this means that information that teachers use to form expectations, but which is not used in both teachers' expectations, does not directly affect college-going. Information about student $i$ that is commonly used by both teachers to form expectations is captured in $\theta_{i}, c$, and ninth-grade GPA.

A threat to identification, then, is that differences in teacher expectations are due to factors that are not observed by both teachers, but do matter for college going. For example, consider a student who is exceptionally strong in math, but mediocre in English. A math teacher may recognize this skill when the English teacher does not. This would lead to variation in teacher expectations that is based upon differences in teacher observations of skills that might matter for college. However, the data suggest that this is not true: Figure 3 shows that the expectation gradients with respect to test scores for both teachers (ELA and math) are nearly identical for both ELA and math tests, even though these tests were not administered by teachers and the teachers did not see the students' scores. If teacher disagreements were explained by skills differences, we would expect math teachers to respond to reading test scores less strongly than would ELA teachers, and vice versa.

\footnotetext{
${ }^{19}$ In the model we estimate, we assume probit errors are independent across teachers. In Section 3.2, we introduce additional data to identify the econometric model. Using additional data, it becomes possible to relax this independence assumption. Results from a model where we do this are available from the authors and indicate that although there is some positive correlation between teacher biases, accounting for it does not affect other results.
} 
We formally test whether differences in students' subject-specific skills predict teacher disagreements by estimating linear probability models of the form

$$
1\left\{T_{E i} \neq T_{M i}\right\}=\delta_{1}\left|S_{E i}-S_{M i}\right|+\delta_{2} G_{i}+X_{i} \delta_{3}+e_{i}
$$

where $S_{j}$ are subject- $j$ test scores, $1\{\cdot\}$ is the indicator function, $G$ is 9th-grade GPA, and $X$ is the vector of socio-demographic controls and school fixed effects from equation (1). Estimates of $\delta_{1}$ and $\delta_{2}$ are reported in the top rows of Table 6. Row 1, which restricts $\delta_{1}$ to equal zero, shows that disagreements are decreasing in 9th-grade GPA. This is intuitive, since there is more ambiguity regarding the future outcomes of moderate and low-performing ninth graders. Importantly, this is why we explicitly allow for $G$ to enter in both the education and teacher-expectation production functions, and is thus not a threat to identification. However, rows 2 and 3 of Table 6 show that subject-specific skill differences, whether included in levels or a quadratic, do not significantly predict teacher disagreements. This is consistent with the nearly overlapping plots in Figure 3 and reinforces the idea that teacher disagreements are not driven by actual differences in students' subject-specific aptitudes, which might directly enter the education production function.

Another possibility is that variation in expectations is due to large shocks that might eventually affect college completion, but that only one teacher observes. For example, one teacher may learn that a student has a learning disability and revise her expectations accordingly ${ }^{20}$ If this information is not known by the other teacher, then it is not in $\theta_{i}$, which means it would be captured in $b$, which would undermine the exogeneity of the biases in equation (3). Of course, if both teachers are aware of the learning disability, then that information is captured by $\theta_{i}$ and is therefore controlled for in equation (3), which means that, conditional on $\theta_{i}$, the $\gamma$ are identified. To assess whether large shocks or pieces of information are known to only one teacher and accordingly drive differences in teacher expectations, we estimate variants of equation (7) that replace $\left|S_{E i}-S_{M i}\right|$ with student-specific information about problems, skills, and inputs that might (i) affect college completion and (ii) only be known by one teacher. These factors include: whether the student is being bullied, has been in a fight, participated in the science fair, finds classes interesting, participated in a "test prep" course for college applications, and whether the parent thinks the student might have an un-diagnosed learning disability and are summarized in Appendix Table S4. Rows 4-9

\footnotetext{
${ }^{20}$ The character Pastor Tim in the popular television show The Americans provides an extreme, yet illustrative, example. In the show, a student confides in Pastor Tim that her parents are Russian spies. This information would likely affect both Pastor Tim's expectations and the student's educational attainment. If other teachers are unaware that the student's parents are Russian spies, $\theta$ will fail to fully capture this relevant information, and model estimates will be subject to omitted variables bias. Of course, the absurdity of this situation highlights the low likelihood that such problems plague the ELS data.
} 
of Table 6 show that none of these variables significantly predict disagreements in teacher expectations. Together, the tests discussed in this section and reported in Table 6 suggest that the identifying assumption is valid: teacher disagreements are not driven by factors that might directly affect educational attainment.

\subsubsection{Rank Condition and Additional Measurements}

As written, the model described in equations (3)-(6) in the previous section is not econometrically identified in that there are not enough measurements to identify all model parameters. There are two reasons. First, we cannot identify latent factors with discrete outcomes absent further data. Second, the two expectation equations, which are used as imperfect measurements of student abililty, are also included as regressors (via the $b$ ) in the outcome equation. One way to achieve identification is to place additional restrictions on parameters as in Heckman et al. (2006) and replace the probit functional forms with linear probability models (LPM). In Appendix A, we show that if we restrict $\gamma_{E}=\gamma_{M} \equiv \gamma$ and $\phi_{E}=\phi_{M} \equiv \phi$, we obtain an identified system of equations, and that the resulting LPM estimates of the impact of bias remain similar to the APE reported in Table 7.

Parameter restrictions are a useful alternative when there are not obvious exclusion restrictions on additional data, i.e., variables that only enter either the expectations or the outcome equations, but not both. Typically, it is difficult to defend such exclusions. Fortunately, two exams (a math and a reading test) were administered to all ELS-2002 students. Results from these exams were not revealed to students or teachers. Therefore, the exams can be used as additional (mis)measurements of student ability, but do not enter into the student outcome equation once we have conditioned on $\theta_{i}$. In other words, scores on these exams should only be associated with educational attainment because they reflect factors that would likewise affect college completion, but not because teachers observe them.

We also control for 9th grade grades in the outcome equation, allow grades to affect teacher expectations, and also use grades to identify $\theta_{i}$. This is useful for a couple of reasons. First, we might be concerned that math and reading test scores do not contain the full set of skills that teachers observe, in which case there would be bias in the impact of teacher forecast error on $y$. Several papers (e.g., Cunha et al., 2012) argue that test scores might not contain non-cognitive skills, such as motivation or grit, but that grades would. Moreover, we do not want to see grades as independent of $\theta$, which requires that we model its relationship

with $\theta$. Finally, we want to illustrate how teacher bias can be due to a mis-reading of the mapping of skills to outcomes, where some skills are observed by the econometrician and some are not. 
Formally, we add three equations:

$$
\begin{aligned}
S_{j i} & =c_{S j}+\phi_{S j} \theta_{i}+e_{S j i}, j \in\{E, M\} \\
G_{i} & =c_{G}+\phi_{G} \theta_{i}+e_{G i}
\end{aligned}
$$

where $S_{j}$ is the test score in subject $j$. In the equations, $e_{S E i}, e_{S M i}$ follow normal distribution with $N\left(0, \sigma_{S, j}\right)$ for $j \in\{E, M\}$, independent across $i$ and $j$. Further, $e_{G i}$ are assumed to be independent of $e_{S E i}$ and $e_{S M i}$ and to follow a truncated normal distribution with mean 0 and standard deviation $\sigma_{G}$, where the upper and lower cutoff values are equal to the draw of $e_{G i}$ that equate GPA to 4.0 and 0, respectively. Appendix D (available from the authors) shows formally that the addition of these three measurement equations identifies the system of equations (3)-(9).

\subsection{Estimation}

The econometric model is described in equations (3)-(9). We collect the parameters to be estimated into a vector denoted $\Xi$ :

$$
\Xi=\left\langle c, \sigma_{\theta}, \beta,\left\{\gamma_{j}, c_{j}, \phi_{j}, \beta_{j}, c_{j, D}, \phi_{j, D}, \beta_{j, D}, c_{S, j}, \phi_{S, j}, \sigma_{S, j}\right\}_{j \in\{E, M\}}, c_{G}, \phi_{G}, \sigma_{G}\right\rangle .
$$

We estimate $\Xi$ using simulated maximum likelihood (Hajivassiliou and Ruud, 1994). In the inner loop of the estimation algorithm, we compute the likelihood for a particular set of candidate parameters, which are indexed by $(g)$ and denoted $\Xi^{(g)}$. To calculate the log likelihood for a given set of candidate parameters $\Xi^{(g)}$, we first draw the latent factor $K$ times for each individual $i$. We denote each draw $\theta_{i k}^{(g)}\left[{ }^{21}\right.$ For each $\theta_{i k}^{(g)}$, we use distributional assumptions on the error terms, additional candidate parameters, and data to calculate the likelihood contribution for teacher expectations $\left(P_{T_{\tau}}\left(T_{i, j} \mid \theta_{i k}^{(g)}\right), j \in\{E, M\}\right)$. Next, for each draw, we calculate bias using equation (6). Then, we calculate the likelihood contribution for college completion, denoting the probability $P_{y}\left(y_{i} \mid \theta_{i k}^{(g)}\right)$. Similarly, we compute the likelihood contributions for the test scores and for ninth-grade GPA, denoting these densities $f_{E}\left(S_{E, i} \mid \theta_{i k}^{(g)}\right)$, $f_{M}\left(S_{M, i} \mid \theta_{i k}^{(g)}\right)$, and $f_{G}\left(G_{i} \mid \theta_{i k}^{(g)}\right)$, respectively. Using these components, we calculate the value

\footnotetext{
${ }^{21}$ Prior to estimating, we draw a block matrix of size $N \times K$ from a standard normal distribution once and denote it $\Psi$, where $N$ is the number of individuals in the sample and $K$ is the number of simulation draws, set to 1,000 . At each draw, $\theta_{i k}^{(g)}$ denotes the value of the latent factor for individual $i$ and draw $k$. It is element $i, k$ in $\Psi$ multiplied by $\sigma_{\theta}^{(g)}$. This helps to avoid the so-called "chattering" effect, which can lead to different values of the likelihood function given the same parameters due to differences in random draws at each parameter set.
} 
of the likelihood for each draw of the latent factor $\theta_{i k}^{(g)}$ as:

$$
\begin{aligned}
L_{i k}^{(g)} & =P_{y}\left(y_{i} \mid \theta_{i k}^{(g)}\right) \times \prod_{\tau \in\{E, M\}} P_{T_{\tau}}\left(T_{\tau i} \mid \theta_{i k}^{(g)}\right) \\
& \times f_{E}\left(S_{E i} \mid \theta_{i k}^{(g)}\right) \times f_{M}\left(S_{M i} \mid \theta_{i k}^{(g)}\right) \times f_{G}\left(G_{i} \mid \theta_{i k}^{(g)}\right) .
\end{aligned}
$$

After constructing $L_{i k}^{(g)}$ for each individual $i$ and draw $k$, we then average $L_{i k}^{(g)}$ over the $K$ draws for each individual. Finally, we take the log and then sum over all $N$ individuals to obtain the log-likelihood, i.e., we compute:

$$
l^{(g)}=\sum_{i=1}^{N} \log \left(\frac{1}{K} \sum_{k=1}^{K} L_{i k}^{(g)}\right)
$$

In the outer loop, we repeat the inner loop for different sets of candidate parameters until the log likelihood function is maximized. We use quasi-newton methods to choose candidate parameters ${ }^{22}$

\section{Do Teacher Expectations Matter?}

This section discusses the estimated model. Section 4.1 presents parameter estimates and average partial effects. Section 4.2 examines teacher biases, focusing on how biases differ by teacher and student race. Section 4.3 illustrates how the model explains black and white attainment gaps as a function of factors occurring prior to the tenth grade, but also as a function of how teachers use these factors to form expectations and how these expectations affect students through the mechanism of self-fulfilling prophecies. This exercise motivates analyses of policies, which are examined in Section 5 .

\subsection{Parameter Estimates and Average Partial Effects}

Tables 7 and 8 report parameter estimates of the education and teacher-expectation production functions defined by equations (3) and (5), respectively ${ }^{23}$ Column (1) of Table 7 reports parameter estimates for white students, and the estimated $\gamma$ suggest that teacher expectations have positive, statistically significant effects on the probability that white students complete a 4-year degree 24 The estimated $\beta$ is positive and statistically significant,

\footnotetext{
${ }^{22}$ We also repeat the estimation algorithm for different sets of starting values to help ensure that we have not found a local maximum.

${ }^{23}$ Appendix Table S5 reports the "nuisance parameter" estimates from measurement equation (9).

${ }^{24}$ We refer to effects of bias and teacher expectations interchangeably since there is a 1:1 relationship between these constructs, by definition, in equation (5).
} 
indicating that students with higher 9th-grade GPAs are significantly more likely to earn a four-year college degree than their counterparts with lower GPAs. This result is intuitive and provides a useful check of the model, since GPA is a known proxy for academic ability that predicts college completion (Bound and Turner, 2011). The magnitudes of these probit coefficients cannot be directly interpreted, so the bottom panel of Table 7 reports average partial effects (APE) of teachers' expectations, the main independent variables of interest, on the likelihood of earning a four-year degree ${ }^{25}$ The APEs indicate that for white students, on average, the impact of either teacher changing from not expecting to expecting a college degree is about a 20 percentage point increase in the likelihood of the student completing a four-year degree. These effects translate into statistically significant elasticities of college completion with respect to biases of about 0.12. The effects of math and ELA teachers' biases are not significantly different from one another, and are remarkably similar in size to the corresponding linear 2SLS estimates for white students reported in columns (3) and (4) of Table 5. The similarity between these two approaches lends additional credence to the interpretation of these estimates as causal effects of teacher expectations on students' long-run educational attainment.

Column (2) of Table 7 reports parameter estimates for black students, and the estimated $\gamma$ once again suggest that teacher expectations have positive effects on educational attainment. However, only the ELA teacher's expectation is statistically significant at traditional confidence levels, and this coefficient is similar in size to that for white students ${ }^{26}$ The estimated $\beta$ is once again positive and statistically significant, though smaller in magnitude than that for white students.

The variance and mean (as it relates to college completion) of $\theta$ capture the objective probability (absent teacher bias and conditional on GPA) that a student will complete college. Consistent with realized educational outcomes, a comparison of columns (1) and (2) show that the distribution of $\theta$ for black students is centered to the left of that for white students, and exhibits greater variance. This means that upon reaching the tenth grade, black students are already disadvantaged relative to their white counterparts in terms of college potential. Again, this does not reflect their ability, but instead captures racial disparities in the multitude of investments over the lifecycle, including factors such as school quality, neighborhood effects, and early childhood environments and resources. Our model is designed to separate this objective probability (which teachers use to form their expectations) from the impact of teacher expectations via self-fulfilling prophecies.

\footnotetext{
${ }^{25}$ Standard errors for the average partial effects (APE) are computed via the Delta Method. The APE are evaluated at the mean value of $\theta$, which is zero by construction.

${ }^{26}$ However, the math and ELA $\gamma$ are not significantly different from one another.
} 
The bottom panel of column (2) shows that the APE of ELA teachers' expectations on the probability that black students earn a four-year college degree is strongly statistically significant and similar in size to the APE of ELA teachers' expectations on white students' educational attainment. The APE of math teachers' expectations on the probability that black students complete college is positive, but only about half as large and imprecisely estimated. The lack of precision may be partly due to the relatively small number of blacks in the sample. Nonetheless, the main implications of Table 7 are that (i) teacher expectations have a positive, arguably causal impact on college completion and (ii) the structural model yields estimates of these effects that are qualitatively similar to linear 2SLS estimates of the reduced-form equation (1).

Table 8 similarly reports the parameter estimates of the teacher-expectation production functions. The first two columns report the parameter estimates for white students' ELA and math teachers, respectively. The production of teacher expectations for white students is broadly similar across subjects: the other-race teacher indicators are both statistically insignificant, as are their corresponding APE, which is consistent with the lack of a racialmismatch effect on teachers' expectations for white students in Gershenson et al. (2016). Also, intuitively, teachers' expectations are increasing in both $\theta$ and 9th-grade GPA. The results for black students, reported in columns (3) and (4), are broadly similar. However, there is one notable difference: for black students, there are negative, significant effects of student-teacher racial mismatch on teachers' expectations. This is again consistent with the student-fixed effects estimates reported in Gershenson et al. (2016). Specifically, pooled estimates of student-FE LPMs in Gershenson et al. (2016) find that racial mismatch reduces the probability that teachers expect a black student will complete a college degree by 0.09. However, when allowing the effect to vary by subject, the authors find that the racialmismatch effect is about twice as large for math teachers (0.15) as for ELA teachers (0.07). This pattern, and the effect sizes, are remarkably similar to those reported in columns (3) and (4) of Table 8. That the structural model estimated here produces similar evidence regarding the impact of student-teacher racial mismatch on teachers' educational expectations for black students, despite using a demonstrably different identification strategy and estimation procedure, cross-validates the structural model and lends additional support to the causal interpretation of the parameter estimates of interest.

\subsection{Race Differences in Teacher Biases}

Thus far, we have documented an arguably causal relationship between teacher expectations and educational attainment and confirmed previous results suggesting that student-teacher 
racial mismatch reduces teachers' educational expectations for black students Gershenson et al., 2016). However, neither the results in Table 8 nor those in Gershenson et al. (2016) speak directly to long-debated questions about whether, to what extent, and in what direction teacher expectations are biased. The model developed in section 3.1, and specifically equation (6), provide answers to these questions. Figure 4 plots kernel density estimates of the distributions of the biases in teachers' expectations separately by student race, subject, and student-teacher race congruence 27

Panel A shows the distributions of ELA teachers' biases. For both same- and other-race ELA teachers of both white and black students, the average bias is positive. In other words, teachers are overly optimistic on average, which is consistent with patterns observed in the raw ELS data documented in Table 1 and in Figure 2. Also, for both same- and otherrace ELA teachers the average amount of bias is similar for both white and black students. However, the average positive bias (overoptimism) is slightly larger for black students when evaluated by a black teacher. This is consistent with evidence of smaller effects of studentteacher racial mismatch on ELA teachers' expectations for black students. The similarity in means is somewhat misleading, however, as if obfuscates more pronounced differences across the distribution. Specifically, there is more mass at zero bias for blacks than for whites, as many teachers accurately predict that black students will not complete college, and this is true for both same- and other-race teachers. There is similarly more mass at one (the upper bound of bias) for blacks than whites, which is due to both same- and other-race teachers being more likely to expect black students to complete college, even when the objective probability of them doing so is nil. White students, meanwhile, are more likely than blacks to receive positive bias in the range of about 0.1 to 0.7 , which means that both same- and other-race teachers are more likely to give white students the "benefit of the doubt" and expect a four-year degree when their objective probability of completing college is in the $30-90 \%$ range.

Panel B of Figure 4 similarly plots the distributions of math teachers' biases. Many of the qualitative patterns observed in Panel A for ELA teachers are present here: biases are positive on average for all students, blacks are more likely than whites to receive zero bias, and on average, black students receive more positive bias (overoptimism) than white students when evaluated by black teachers, while the opposite is true for white teachers' expectations. However, differences in the bias distributions of same- and other-race math teachers are significantly more pronounced than the corresponding differences for ELA teachers. This is to be expected, given the result in Table 8 that the effect of racial mismatch on expecta-

\footnotetext{
${ }^{27}$ Another way to illustrate these differences is using contour plots, which are presented in Appendix Figure S1. These plots (heat maps) depict higher concentrations as brighter colors.
} 
tions is significantly larger for math teachers than for ELA teachers. Indeed, these mean differences are driven by a notable increase in the frequency of objectively correct (zero-bias) expectations and a flattening of the right tail of the bias distribution for other-race teachers' expectations for black students. This raises a nuanced, but important point: other-race math teachers' expectations for black students may be more accurate (less biased) than those made by black math teachers. However, this accuracy has the potential to propagate racial gaps in educational attainment, since we have shown that high expectations, even overly optimistic ones, have an arguably causal, positive impact on college completion. In terms of the main result in Gershenson et al. (2016), which is that white teachers have lower expectations than black teachers when evaluating the same student, the results in Figure 4 indicate that on average, all teachers are too optimistic about students' college-completion potential, but the degree of overoptimism is greater for black students assessed by black teachers relative to white teachers. We explore these ideas in greater detail below.

\subsection{Race Mismatch and Teacher Expectations}

We have demonstrated a causal impact of teacher expectations on student outcomes along with racial differences in the production of bias. However, we have yet to investigate how these two mechanisms interact and contribute to the racial gap in college completion. We begin to do so here, by noting that the model distinguishes between three types of racial differences that can influence racial gaps in educational attainment:

1. Initial conditions, including ninth-grade GPA and the latent factor $\theta_{i}$, which combine to identify the objective likelihood of college completion (net of the impact of bias) at the time tenth-grade teachers form expectations.

2. The mapping between initial conditions and teacher expectations governed by the parameters in equation (5), i.e., racial disparities in the teacher expectations faced by students with the same $\theta_{i}$ and $G_{i}$

3. The production function of student outcomes governed by parameters in equation (3).

Figure 5 illustrates how each of these factors contributes to racial disparities ${ }^{28}$ The figure plots the CDF of the probability that black and white students will obtain a four-year college

\footnotetext{
${ }^{28}$ For each counterfactual simulation, this is done by drawing $e_{G i}, e_{E i}, e_{M i}$, and $\theta 100,000$ times using the distributional assumptions outlined in subsection 3.2 .2 given our parameter estimates and simulating GPA, as well as ELA and math teacher expectations using equations (5) and (9). The probability that black and white students will obtain a four-year college degree is then calculated using equation (3).
} 
degree, assuming that all students have white teachers 29 In the upper-right panel, we plot the objective distributions for black and white students. Immediately apparent are large gaps between blacks and whites produced by the model, which occur across the distribution.

In the upper-right panel of Figure 5, we simulate the black-white college completion gap under the counterfactual in which blacks are assigned the same initial conditions as whites, i.e., the same distribution of $\theta_{i}$ and of $G_{i}$. Not surprisingly, this closes much of the attainment gap, as many of the differences in the distribution of educational attainment arise from factors occurring prior to the tenth grade. Still, even with the same initial conditions, black students do not face the same distribution of college completion as white students. This means that some of the gap can be explained by how initial conditions map to expectations along with racial differences in how expectations produce outcomes.

One interesting feature of the upper right panel of Figure 5 is that students with initial conditions suggesting a low probability of college completion might do better than their white counterparts if assigned the same initial conditions. The reason is that some black students with lower initial conditions may face higher positive bias. This can be seen in Figure 4 . where black students are more likely to face optimistic teachers. Nonetheless, towards the upper end of the distribution, whites outperform blacks despite having the same ninth-grade GPA and the same objective probability of completing college. Again, since $\theta_{i}$ does not represent innate ability, these results suggest that two students enter the tenth grade having the same objective probabilities (net of bias) of finishing college might experience different outcomes. This discrepancy is due to racial differences in the production and impact of biases, which exacerbates existing gaps.

To illustrate this point, the lower-left panel of Figure 5 shows what happens if black and white students not only have the same initial conditions, but also the same mapping from initial conditions to teacher expectations. This has a relatively small additional impact on the gap, which can be seen in the lower right panel, where both counterfactuals are simulated. Notice, for individuals with relatively low or relatively high objective probabilities of college completion, the impact of the production of teacher bias is nearly zero. In fact, some black students in the lower tails are harmed if they face the same production of bias as white students. This is because black students with low $\theta_{i}$ tend to face higher expectations from white teachers. For blacks in the middle of the distribution, however, facing the same mapping from initial conditions to teacher expectations as whites is helpful in promoting college completion. This finding is consistent with the distributions of bias plotted in Figure 4, which indicate that white students who begin with objective probabilities of college

\footnotetext{
${ }^{29}$ We consider the implications of assigning more black teachers to black students in Section 5
} 
completion that are neither very high nor very low are more likely to be given the "benefit of the doubt" than are black students. Given that expectations matter, this can raise the attainment gap through self-fulfilling prophecies.

The lower right panel of Figure 5 also illustrates that the remainder of the gap is closed when blacks counterfactually face the same education production function as whites (governed by the parameters in equation (3p). Part of the production function difference is due to differences in $\gamma$, particularly differences in math teachers' $\gamma$ s across races. Another difference is in $\beta$, which may reflect disparities in school quality 30 In general, Figure 5 demonstrates that most of the attainment gap between blacks and whites arises from factors that occur prior to our observing them in the tenth grade, which is not surprising and underscores the importance of interventions in early-childhood and primary-school education. Still, initial conditions do not account for the entire gap, which is concerning since it means that teacher expectations widen the gap. This is due to racial differences in the impact of bias on outcomes, but also due to differences in the production of bias. In the following section, we ask whether policies that affect the production of bias can reduce the student attainment gap.

\section{Policy: Teacher Diversity versus Teacher De-Biasing}

In this section, we discuss two counterfactual simulations designed to assess policies that modify the expectations faced by black students. We treat initial conditions $\theta_{i}$ and $G_{i}$ as given, and therefore not as policy relevant, since our focus is on how teacher expectations respond to those conditions and ultimately affect student outcomes. Of course, these initial conditions are not fixed and can likely be shaped by other earlier interventions such as class size reductions (Dynarski et al., 2013), improved teacher quality (Chetty et al., 2013), and early childhood investments (Currie, 2001; Heckman, 2006). However, the current study's aim is to assess whether changes in the production and impact of bias on student outcomes can affect the black-white college completion gap. We consider two policies, both of which can be evaluated using our model: hiring more black teachers, thereby increasing the probability that students of all races have a black teacher, and modifying how white teachers form expectations about black students. We operationalize the latter by imposing that white teachers, for a given $\theta_{i}$ and $G_{i}$, form "race blind" expectations for students.

We motivate these counterfactual simulations by simply plotting teachers' expectations for black students as a function of $\theta_{i}$ while making different assumptions about how their expectations are formed. The top panels of Figure 6] show how white ELA and math teachers'

\footnotetext{
${ }^{30}$ Indeed, if black students face white $\gamma$, but different $\beta$, a small gap remains.
} 
expectations change when we de-bias white teachers (i.e., when for a given $\theta$, the black student receives the expectation normally given to a white student). It is immediately apparent that not all black students are helped by such a policy. Indeed, at low levels of $\theta$ white teachers have higher expectations for black students than for white students. However, at high levels of $\theta$, black students benefit from this policy. This is consistent with the distributions of bias presented in Figure 4. The policy-relevant implication here is that de-biasing white teachers in this fashion would likely hurt some black students. Therefore, in the formal policy simulation, we impose that white teachers' expectations take the envelope of the two curves.

The bottom panels of Figure 6 show how the expectations of ELA and math teachers for black students change when the expectation is formed by a black-rather than whiteteacher. Among ELA teachers there is a muted increase in expectations at all levels of $\theta$ of hiring more black teachers. For math, the effect is much larger due to the larger impact of racial mismatch on math teachers' expectations. Importantly, white students are not hurt by this policy, as shown in the corresponding Appendix Figure S2 for white students.

In Figure 7, we directly compare de-biasing to hiring more black teachers. These "equivalent policy lines" report the combinations of de-biased and black teachers necessary to maintain the black college completion rate. Both the math and ELA teacher lines are upward sloping, which simply means that de-biasing white teachers and increasing the probability that black students have black teachers both increase black college completion on average. Both lines are steeper than the 45-degree line, indicating that raising the probability that a black student faces a black teacher is more effective at achieving college graduation for a given number of black students in relation to de-biasing an equivalent percentage of white teachers. Interestingly, the slope of the line is steeper and to the left for black math teachers. This means that to achieve the same effect of de-biasing a given number of white teachers, fewer black math versus ELA teachers would need to be hired. This is because of the relatively high expectations that black math teachers have for black students versus white math teachers. Of course, the similarity of the lines and slopes for math versus ELA teachers shows that hiring more black ELA teachers is also a policy worth considering. Nonetheless, this result underscores the need to identify the inputs and interventions that promote black student success in STEM fields and highlights the policy-relevance of black-white achievement gaps in STEM fields (Anderson and Kim, 2006; Arcidiacono et al., 2016; Harper, 2010).

Figure 7 compares the two policies as mutually exclusive interventions. In reality, they likely would not be. Policy makers might consider mixtures, such as simultaneously hiring more black teachers and attempting to de-bias white teachers. To understand how these two policies interact, we use the production function in equation (3) to plot isoquants. 
Specifically, for different combinations of de-biasing and hiring (e.g., de-bias $25 \%$ of white teachers and set the probability that black students face black teachers at 30\%) we use the model to simulate college completion 100,000 times. Next, we assess which combinations of policies lead on average to the same probability of college completion. We plot resulting isoquants where the inputs are equivalent to de-biasing zero white teachers and setting the probability that black students face black teachers at 5 equidistant points along the distribution: $1 / 6,2 / 6,3 / 6,4 / 6$ and $5 / 6$. The isoquants are constructed separately for each quartile of the distribution of $\theta$ since we know that these policies have different effects on individuals with different objective probabilities of completing college.

The four panels of Figure 8 highlight the heterogeneity by $\theta$ in the tradeoffs between the two policies. At one extreme, panel A shows that for students in the lowest quartile, debiasing white teachers has no effect, as evidenced by the vertical isoquants. This is because white teachers tend to have higher expectations for students with low objective probabilities of completing college. Since the policy we consider takes the maximum of actual versus simulated expectations, the de-biasing policy literally does not affect students in the bottom quartile. Hiring more black teachers has some effect, though it is modest: increasing the fraction of black teachers from $1 / 6$ to $5 / 6$ raises the probability of college-going from $3.7 \%$ to $3.9 \%$. This is troubling as it shows that students with low objective probabilities of completing college degrees by the time they reach the tenth grade are difficult to help, at least via changing teachers' expectations. This underscores the limits of the policies we are considering here and the importance of interventions for students earlier on, as well as outside the traditional school setting.

Panel B of Figure 8 considers the second quartile. For this group, de-biasing of teachers seems to have some effect, though it is small. De-biasing all white teachers is equivalent to raising the proportion of black teachers from about $12 \%$ to about $16 \%$. Panel $\mathrm{C}$ shows that de-biasing white teachers (compared to hiring more black teachers) becomes increasingly effective at increasing black-student graduation rates among students who already have relatively high objective probabilities of graduating, as the marginal rate of substitution is about 2.1. For example, to raise the probability of college completion from $33.9 \%$ to $34.6 \%$, hiring practices would need to increase the likelihood of facing a black math teacher from $15 \%$ to $32 \%$. Alternatively, the proportion of debiased white teachers would need to rise from $32 \%$ to $68 \%$. The isoquant illustrates that some mixture of the two policies would also work, where linearity is due to the specification of the production function 41 Moreover, for individuals in the third quartile, policies become more effective, raising the graduation

\footnotetext{
${ }^{31}$ In the Conclusion, we discuss possible extensions to this work, including estimation of a production function with non-constant marginal rates of substitution.
} 
probability from $33.9 \%$ to $36.6 \%$.

Among individuals with the highest objective probability of completing college (panel D of Figure 8), it is apparent that (i) policies are relatively more effective in general, raising college completion rates from $62.9 \%$ to $65.2 \%$ and (ii) the relative productivity of de-biasing white teachers rises, as the MRS is now about 1 . The reason is that white teachers have especially low expectations for black students with high initial conditions in comparison to white students with the same initial conditions. In other words, white teachers tend to underestimate the potential of black students relative to white students, particularly for black students with high objective probabilities of earning a college degree. This is concerning, as the black students with the most college potential face the largest penalties via teacher expectations. Panel D also shows that hiring more black teachers would be beneficial. For example, raising the probability that a black student faces a black math teacher from $15 \%$ to $35 \%$ raises college completion from $62.9 \%$ to $63.5 \%$. Recall, this result conditions on the objective probability starting in the tenth grade. Earlier interventions could have stronger effects.

\section{Conclusion}

We jointly estimate education and teacher-expectation production functions using data from a nationally representative longitudinal survey of U.S. high school students. The identification strategy leverages insights from the measurement-error literature and a unique feature of these data: two teachers provided their educational expectations for each student.

Our analysis yields four main results. First, we provide novel, arguably causal evidence that teacher expectations matter in the sense that they affect students' educational attainment. Estimates from both reduced-form instrumental variables models and structural measurement-error models suggest that the elasticity of the likelihood of college completion with respect to teachers' expectations is about 0.12 , which is consistent with the impact of other K-12 educational inputs on college completion (Dynarski et al., 2013). Moreover, this finding provides insights into the mechanisms through which the long-run effects of K-12 teachers documented by Chetty et al. (2013) might operate.

Second, when comparing expectations for black versus white students, we show that assessing which teachers are more accurate is not necessarily the most salient question. We identify the distribution of biases in teacher expectations, and find that on average, all teachers are overly optimistic about students' ability to complete a four-year college degree. However, the degree of over-optimism is significantly larger for white students than for black 
students, especially when black students are evaluated by white teachers. This answers the unresolved question in Gershenson et al. (2016) of "which teachers are wrong," and more generally highlights an important nuance that is frequently overlooked in discussions of biased beliefs: unbiased (i.e., accurate) beliefs can be counterproductive if there are positive returns to optimism or if there are socio-demographic gaps in the degree of teachers' over-optimism, both of which we find evidence of.

Third, we consider two counterfactual, but realistic policies: hiring more black teachers and de-biasing white teachers. For black students with low objective probabilities of college completion upon entering the tenth grade, hiring more black teachers is more effective. For black students with high objective probabilities, both policies are about equally effective. In other words, the most effective mix of policies implemented for high school students depends on whether college completion is already highly likely or unlikely for these students. This information, paired with relative costs, could inform decision-makers as to the optimal mixture of policies.

Finally, the paper makes makes a methodological contribution to the measurement error literature by assigning a structural meaning not only to the common latent factor that enters all equations, but also to the measurement error itself, which we interpret as teacher bias and allow to enter as in input in the education production function. We believe that our approach could fruitfully be applied to estimate causal effects of beliefs on behavior or outcomes in non-experimental settings and using observational data where multiple beliefs about a similar economic object are collected.

Several generalizations of the measurement error model, and particularly of the education production function (equation (3)), might be considered in future work. For example, the education production function assumes that the math and ELA teachers' expectations are perfect substitutes, but this need not be the case. Similarly, there could be heterogeneity by student, teacher, and school characteristics in the impact of teacher expectations on student outcomes. For example, low-achieving (as of 9th grade) students might be particularly influenced by teacher expectations, expectations of same-race teachers might be particularly salient to students, or teachers' abilities to pass on beliefs might be limited in under-resourced schools or depending on school characteristics, such as the racial composition of students or teachers.

\section{References}

Anderson, E. and D. Kim, "Increasing the Success of Minority Students in Science and 
Technology," American Council on Education. Washington, DC, 2006.

Arcidiacono, Peter, Esteban M. Aucejo, and V. Joseph Hotz, "University Differences in the Graduation of Minorities in STEM fields: Evidence from California," The American Economic Review, 2016, 106 (3), 525-562.

Bailey, Martha J. and Susan M. Dynarski, "Inequality in Postsecondary Education," in G. Duncan and R. Murnane, eds., Whither Opportunity?: Rising Inequality, Schools, and Children's Life Chances, New York, NY: Russell Sage Foundation, 2011, pp. pp. 171-132.

Becker, G.S., Human Capital: A Theoretical Analysis with Special Reference to Education, Columbia University Press, 1964.

Boser, Ulrich, Megan Wilhelm, and Robert Hanna, "The Power of the Pygmalion Effect: Teachers Expectations Strongly Predict College Completion," The Center for American Progress, 2014, pp. 1-7.

Bound, John and Sarah Turner, "Dropouts and Diplomas: The Divergence in Collegiate Outcomes," in E. Hanushek, S. Machin, and L. Woessmann, eds., Handbook of the Economics of Education, Vol. 4, New York, NY: Russell Sage Foundation, 2011, pp. 573-613.

Brophy, Jere E., "Research on the Self-Fulfilling Prophecy and Teacher Expectations," Journal of Educational Psychology, 1983, 75 (5), 631.

Burgess, Simon and Ellen Greaves, "Test Scores, Subjective Assessment, and Stereotyping of Ethnic Minorities," Journal of Labor Economics, 2013, 31 (3), 535-576.

Cameron, Stephen V. and James J. Heckman, "The Dynamics of Educational Attainment for Black, Hispanic, and White Males," Journal of Political Economy, 2001, 109 (3), 455-499.

Card, David, "The Causal Effect of Education on Earnings," Handbook of Labor Economics, 1999, 3, 1801-1863.

Carnes, Molly, Patricia G. Devine, Linda Baier Manwell, Angela Byars-Winston, Eve Fine, Cecilia E. Ford, Patrick Forscher, Carol Isaac, Anna Kaatz, Wairimu Magua et al., "Effect of an Intervention to Break the Gender Bias Habit for Faculty at One Institution: A Cluster Randomized, Controlled Trial," Academic Medicine: Journal of the Association of American Medical Colleges, 2015, 90 (2), 221-230. 
Carrell, Scott E. and Mark L. Hoekstra, "Externalities in the Classroom: How Children Exposed to Domestic Violence Affect Everyone's Kids," American Economic Journal: Applied Economics, 2010, 2 (1), 211-228.

Chetty, Raj, John N. Friedman, and Jonah E. Rockoff, "Measuring the Impacts of Teachers II: Teacher Value-Added and Student Outcomes in Adulthood," American Economic Review, 2013, 104 (9), 2633-79.

Chiang, Chun-Fang and Brian Knight, "Media bias and Influence: Evidence from Newspaper Endorsements," The Review of Economic Studies, 2011, pp. 795-820.

Cunha, Flavio, James J. Heckman, and Susanne M. Schennach, "Estimating the Technology of Cognitive and Noncognitive skill formation," Econometrica, 2010, 78 (3), 883-931.

Currie, Janet, "Early Childhood Education Programs," The Journal of Economic Perspectives, 2001, 15 (2), 213-238.

Dee, Thomas S., "Are There Civic Returns to Education?," Journal of Public Economics, 2004a, 88 (9), 1697-1720.

_ , "Teachers, Race, and Student Achievement in a Randomized Experiment," Review of Economics and Statistics, 2004b, 86 (1), 195-210.

_ , "A Teacher Like Me: Does Race, Ethnicity, or Gender Matter?," American Economic Review, 2005, 95 (2), 158-165.

_. "Social Identity and Achievement Gaps: Evidence from an Affirmation Intervention," Journal of Research on Educational Effectiveness, 2014, 8 (2), 149-168.

DellaVigna, S. and E. Kaplan, "The Fox News Effect: Media Bias and Voting," Quarterly Journal of Economics, 2007, 122 (3), 1187-1234.

den Steen, Eric Van, "Rational Overoptimism (and Other Biases)," American Economic Review, 2004, 94 (4), 1141-1151.

Devine, Patricia G., Patrick S. Forscher, Anthony J. Austin, and William T.L. Cox, "Long-Term Reduction in Implicit Race Bias: A Prejudice Habit-Breaking Intervention," Journal of Experimental Social Psychology, 2012, 48 (6), 1267-1278. 
Dobbie, Will and Roland G. Fryer Jr., "The Impact of Voluntary Youth Service on Future Outcomes: Evidence from Teach For America," The BE Journal of Economic Analysis \& Policy, 2015, 15 (3), 1031-1065.

Dynarski, Susan, Joshua Hyman, and Diane Whitmore Schanzenbach, "Experimental Evidence on the Effect of Childhood Investments on Postsecondary Attainment and Degree Completion," Journal of Policy Analysis and Management, 2013, 32 (4), 692-717.

Fairlie, Robert W., Florian Hoffmann, and Philip Oreopoulos, "A Community College Instructor Like Me: Race and Ethnicity Interactions in the Classroom," The American Economic Review, 2014, 104 (8), 2567-2591.

Ferguson, Ronald F., "Teachers' Perceptions and Expectations and the Black-White Test Score Gap," Urban Education, 2003, 38 (4), 460-507.

Figlio, David N., "Boys named Sue: Disruptive Children and their Peers," Education Finance and Policy, 2007, 2 (4), 376-394.

Fortin, Nicole M., Philip Oreopoulos, and Shelley Phipps, "Leaving Boys Behind: Gender Disparities in High Academic Achievement," Journal of Human Resources, 2015, 50 (3), 549-579.

Fryer, Roland G., "Racial Inequality in the 21st century: The Declining Significance of Discrimination," NBER Working Paper 2010.

Gentzkow, Matthew and Jesse M. Shapiro, "Media Bias and Reputation," Journal of Political Economy, 2006, 114 (2), 280-316.

Gershenson, Seth, Stephen B. Holt, and Nicholas W. Papageorge, "Who Believes in Me? The Effect of Student-Teacher Demographic Match on Teacher Expectations," Economics of Education Review, 2016, 52, 209-224.

Goldberger, Arthur S., "Structural Equation Methods in the Social Sciences," Econometrica, 1972, 40 (6), 979-1001.

Gregory, Anne and Francis Huang, "It Takes a Village: The Effects of 10th Grade College-Going Expectations of Students, Parents, and Teachers Four Years Later," American Journal of Community Psychology, 2013, 52 (1-2), 41-55.

Grossman, Michael, "Education and Nonmarket Outcomes," Handbook of the Economics of Education, 2006, 1, 577-633. 
Hajivassiliou, Vassilis A. and Paul A. Ruud, "Classical Estimation Methods for LDV Models Using Simulation," Handbook of Econometrics, 1994, 4, 2383-2441.

Hanushek, Eric A. and Steven G. Rivkin, "Generalizations about Using Value-Added Measures of Teacher Quality," American Economic Review, 2010, 100 (2), 267-271.

_ , John F. Kain, and Steven G. Rivkin, "Why Public Schools Lose Teachers," Journal of Human Resources, 2004, 39 (2), 326-354.

Harper, Shaun R., "An Anti-Deficit Achievement Framework for Research on Students of Color in STEM," New Directions for Institutional Research, 2010, 2010 (148), 63-74.

Heckman, James J., "Skill Formation and the Economics of Investing in Disadvantaged Children," Science, 2006, 312 (5782), 1900-1902.

_ , Jora Stixrud, and Sergio Urzua, "The Effects of Cognitive and Noncognitive Abilities on Labor Market Outcomes and Social Behavior," Journal of Labor Economics, 2006, 24 (3), 411.

Holt, Stephen B. and Seth Gershenson, "The Impact of Teacher Demographic Representation on Student Attendance and Suspensions," IZA Discussion Paper No. 9554, 2015.

Hu, Yingyao and Susanne M. Schennach, "Instrumental Variable Treatment of Nonclassical Measurement Error Models," Econometrica, 2008, 76 (1), 195-216.

Imberman, Scott A., Adriana D. Kugler, and Bruce I. Sacerdote, "Katrina's Children: Evidence on the Structure of Peer Effects from Hurricane Evacuees," American Economic Review, 2012, 102 (5), 2048-2082.

Jackson, C. Kirabo, "Student Demographics, Teacher Sorting, and Teacher Quality: Evidence from the End of School Desegregation," Journal of Labor Economics, 2009, 27 (2), $213-256$.

Jacob, Brian A., "Where the Boys Aren't: Non-Cognitive Skills, Returns to School and the Gender Gap in Higher Education," Economics of Education Review, 2002, 21 (6), $589-598$.

Jacob, Brian A and Tamara Wilder, "Educational expectations and attainment," Technical Report, National Bureau of Economic Research 2010. 
Jöreskog, Karl G and Arthur S. Goldberger, "Factor Analysis by Generalized Least Squares," Psychometrika, 1972, 37 (3), 243-260.

Jöreskog, Karl G. and Arthur S. Goldberger, "Estimation of a Model with Multiple Indicators and Multiple Causes of a Single Latent Variable," Journal of the American Statistical Association, 1975, 70 (351a), 631-639.

Jussim, L. and J.S. Eccles, "Teacher Expectations: II. Construction and Reflection of Student Achievement.," Journal of Personality and Social Psychology, 1992, 63 (6), 947961.

Jussim, Lee and Kent D. Harber, "Teacher Expectations and Self-Fulfilling Prophecies: Knowns and Unknowns, Resolved and Unresolved Controversies," Personality and Social Psychology Review, 2005, 9 (2), 131-155.

Lareau, Annette, Unequal Childhoods: Class, Race, and Family Life, Univ of California Press, 2011.

- and Elliot B. Weininger, "Class and the Transition to Adulthood," in G. Lareau and E. B. Weininger, eds., Social Class: How Does It Work, New York, NY: Russell Sage Foundation, 2008, pp. 118-151.

Lavy, Victor and Edith Sand, "On The Origins of Gender Human Capital Gaps: Short and Long Term Consequences of Teachers' Stereotypical Biases," NBER Working Paper No. 209092015.

Lochner, Lance and Enrico Moretti, "The Effect of Education on Crime: Evidence from Prison Inmates, Arrests, and Self-Reports," American Economic Review, 2004, 94 (1), 155-189.

Loury, Glenn C., The Anatomy of Racial Inequality, Harvard University Press, 2009.

Lundberg, Shelly, Robert A. Pollak, and Jenna Stearns, "Family Inequality: Diverging Patterns in Marriage, Cohabitation, and Childbearing," The Journal of Economic Perspectives, 2016, 30 (2), 79-101.

Machin, Stephen, Olivier Marie, and Sunčica Vujić, "The Crime Reducing Effect of Education," Economic Journal, 2011, 121 (552), 463-484.

Manski, Charles F, "Adolescent Econometricians: How Do Youth Infer the Returns to Schooling?" in "Studies of Supply and Demand in Higher Education," University of Chicago Press, 1993, pp. 43-60. 
Mechtenberg, Lydia, "Cheap Talk in the Classroom: How Biased Grading at School Explains Gender Differences in Achievements, Career Choices and Wages," The Review of Economic Studies, 2009, 76 (4), 1431-1459.

Milligan, Kevin, Enrico Moretti, and Philip Oreopoulos, "Does Education Improve Citizenship? Evidence from the United States and the United Kingdom," Journal of Public Economics, 2004, 88 (9), 1667-1695.

Moretti, Enrico, "Human Capital Externalities in Cities," Handbook of Regional and Urban Economics, 2004, 4, 2243-2291.

Okonofua, Jason A., David Paunesku, and Gregory M. Walton, "Brief Intervention to Encourage Empathic Discipline Cuts Suspension Rates in Half Among Adolescents," Proceedings of the National Academy of Sciences, 2016, pp. 5221-5226.

Putman, Hannah, Michael Hansen, Kate Walsh, and Diana Quintero, "High Hopes and Harsh Realities: The Real Challenges to Building a Diverse Workforce," Brookings Brown Center for Education. Washington, DC, 2016.

Rist, Ray, "Student Social Class and Teacher Expectations: The Self-Fulfilling Prophecy in Ghetto Education," Harvard Educational Review, 1970, 40 (3), 411-451.

Rosenthal, Robert and Lenore Jacobson, "Pygmalion in the Classroom," The Urban Review, 1968, 3 (1), 16-20.

Savage, L.J., The Foundations of Statistics, Wiley, 1954.

Shapiro, Teny Maghakian, Kevin M. Williams, and James E. West, "Cognitive Function and Human Capital Accumulation Across the Day: Evidence from Randomized School Schedules," Mimeo, Santa Clara University 2015.

Steele, Claude M., "A Threat in the Air: How Stereotypes Shape Intellectual Identity and Performance.," American Psychologist, 1997, 52 (6), 613.

Stock, James H. and Motohiro Yogo, "Testing for Weak Instruments in Linear IV Regression," NBER Working Paper 2002.

Suen, Wing, "The Self-Perpetuation of Biased Beliefs," The Economic Journal, 2004, 114 (495), 377-396. 
Terrier, Camille, "Giving a Little Help to Girls? Evidence on Grade Discrimination and its Effect on Students' Achievement," Centre for Economic Performance Discussion Paper No. 13412015.

Todd, Petra E. and Kenneth I. Wolpin, "The Production of Cognitive Achievement in Children: Home, School, and Racial Test Score Gaps," Journal of Human Capital, 2007, $1(1), 91-136$. 


\section{Figures and Tables}

Table 1: Analytic Sample Means - Students

\begin{tabular}{lccccc}
\hline \hline Sample (Students) : & $\begin{array}{c}\text { All } \\
(1)\end{array}$ & $\begin{array}{c}\text { White } \\
(2)\end{array}$ & $\begin{array}{c}\text { Black } \\
(3)\end{array}$ & $\begin{array}{c}\text { Male } \\
(4)\end{array}$ & $\begin{array}{c}\text { Female } \\
(5)\end{array}$ \\
\hline Educational Attainment & & & & & \\
Completed College or more & 0.45 & 0.49 & 0.29 & 0.43 & 0.47 \\
Completed < HS Diploma & 0.01 & 0.01 & 0.02 & 0.01 & 0.01 \\
Education Completed, Years & 14.67 & 14.83 & 14.08 & 14.51 & 14.81 \\
& $(2.06)$ & $(2.06)$ & $(1.84)$ & $(2.05)$ & $(2.07)$ \\
Teacher Expectations & & & & & \\
College or More, English & 0.64 & 0.67 & 0.48 & 0.60 & 0.67 \\
Expect < HS, English & 0.01 & 0.01 & 0.03 & 0.02 & 0.01 \\
ELA Teacher Expected Years & 15.65 & 15.78 & 14.86 & 15.48 & 15.80 \\
& $(2.23)$ & $(2.14)$ & $(2.21)$ & $(2.29)$ & $(2.16)$ \\
College or More, Math & 0.63 & 0.66 & 0.44 & 0.61 & 0.65 \\
Expect < HS, Math & 0.01 & 0.01 & 0.03 & 0.01 & 0.01 \\
Math Teacher Expected Years & 15.51 & 15.65 & 14.66 & 15.43 & 15.59 \\
& $(2.09)$ & $(1.99)$ & $(2.07)$ & $(2.16)$ & $(2.03)$ \\
Academic Background & & & & & \\
Reading Assessment & 52.82 & 54.67 & 46.71 & 52.39 & 53.21 \\
& $(9.83)$ & $(9.26)$ & $(8.99)$ & $(10.20)$ & $(9.47)$ \\
Math Assessment & 53.01 & 54.71 & 45.77 & 54.00 & 52.12 \\
& $(9.67)$ & $(8.78)$ & $(8.88)$ & $(10.13)$ & $(9.15)$ \\
9th grade GPA & 2.92 & 3.02 & 2.44 & 2.82 & 3.01 \\
& $(0.78)$ & $(0.73)$ & $(0.76)$ & $(0.78)$ & $(0.77)$ \\
Demographics and Socioeconomic Status & & & & & \\
Household Income < 20K & 0.11 & 0.06 & 0.26 & 0.09 & 0.13 \\
Household Income $>$ 100K & 0.18 & 0.21 & 0.08 & 0.19 & 0.17 \\
Mother has $\leq$ HS diploma & 0.34 & 0.29 & 0.39 & 0.32 & 0.35 \\
Mother has a Bachelor's or More & 0.31 & 0.34 & 0.23 & 0.33 & 0.29 \\
Teacher & & & & & \\
ELA Teacher Non-White & 0.10 & 0.05 & 0.26 & 0.10 & 0.10 \\
Math Teacher Non-White & 0.11 & 0.06 & 0.21 & 0.11 & 0.11 \\
ELA Teacher Black & 0.04 & 0.02 & 0.20 & 0.04 & 0.04 \\
Math Teacher Black & 0.04 & 0.02 & 0.16 & 0.03 & 0.04 \\
\hline Observations & 6060 & 3970 & 610 & 2870 & 3190 \\
\hline \hline & & & & & \\
\hline & & &
\end{tabular}

Note: Students are the unit of analysis. Standard deviations for non-binary variables are reported in parentheses. HS is high school. 9th-grade GPAs are on a 4.0 scale. Math and reading assessment scores are on a 0-100 scale. All sample sizes are rounded to the nearest 10 in accordance with NCES regulations for restricted data. 
Table 2: Analytic Sample Means - Teachers

\begin{tabular}{lccccccc}
\hline \hline Sample (Teachers): & $\begin{array}{c}\text { All } \\
\text { Teachers } \\
(1)\end{array}$ & $\begin{array}{c}\text { Math } \\
\text { Teachers } \\
(2)\end{array}$ & $\begin{array}{c}\text { English } \\
\text { Teachers } \\
(3)\end{array}$ & $\begin{array}{c}\text { White } \\
\text { Teachers } \\
(4)\end{array}$ & $\begin{array}{c}\text { Black } \\
\text { Teachers } \\
(5)\end{array}$ & $\begin{array}{c}\text { Male } \\
\text { Teachers } \\
(6)\end{array}$ & $\begin{array}{c}\text { Female } \\
\text { Teachers } \\
(7)\end{array}$ \\
\hline Teacher Characteristics & & & & & & & \\
$\quad$ Non-White & 0.11 & 0.11 & 0.10 & 0.00 & 1.00 & 0.10 & 0.11 \\
Math Teacher & 0.50 & 1.00 & 0.00 & 0.50 & 0.47 & 0.62 & 0.43 \\
Male & 0.35 & 0.44 & 0.27 & 0.36 & 0.26 & 1.00 & 0.00 \\
Years of Experience & 14.89 & 15.35 & 14.44 & 15.17 & 15.01 & 15.56 & 14.53 \\
& $(10.76)$ & $(10.74)$ & $(10.77)$ & $(10.80)$ & $(11.28)$ & $(11.61)$ & $(10.25)$ \\
S three years of experience & 0.16 & 0.14 & 0.19 & 0.15 & 0.21 & 0.16 & 0.16 \\
No teaching certificate & 0.17 & 0.15 & 0.18 & 0.16 & 0.21 & 0.21 & 0.14 \\
Major in subject taught & 0.48 & 0.47 & 0.49 & 0.49 & 0.48 & 0.42 & 0.51 \\
Has graduate degree & 0.47 & 0.48 & 0.47 & 0.49 & 0.45 & 0.51 & 0.46 \\
Student Demographics & & & & & & & 0.00 \\
American Indian & 0.00 & 0.00 & 0.00 & 0.00 & 0.00 & 0.01 & 0.00 \\
Asian & 0.08 & 0.08 & 0.08 & 0.07 & 0.05 & 0.09 & 0.07 \\
Black & 0.10 & 0.10 & 0.10 & 0.09 & 0.47 & 0.09 & 0.11 \\
Hispanic & 0.12 & 0.12 & 0.12 & 0.10 & 0.12 & 0.13 & 0.11 \\
Multiple Race & 0.04 & 0.04 & 0.04 & 0.04 & 0.04 & 0.05 & 0.04 \\
Male & 0.47 & 0.47 & 0.47 & 0.47 & 0.44 & 0.51 & 0.45 \\
\hline Observations & 12130 & 6060 & 6060 & 10830 & 470 & 4300 & 7820 \\
\hline \hline
\end{tabular}

Note: Teachers are the unit of analysis. Standard deviations for non-binary variables are reported in parentheses. All sample sizes are rounded to the nearest 10 in accordance with NCES regulations for restricted data. 
Table 3: OLS Estimates of Effect of Expectations on Educational Attainment

\begin{tabular}{lccccccccc}
\hline \hline & & \multicolumn{4}{c}{ All Students } & \multicolumn{4}{c}{ White } \\
& $(1)$ & $(2)$ & $(3)$ & $(4)$ & $(5)$ & $(6)$ & $(7)$ & $(8)$ & $(9)$ \\
\hline Expect College (ELA) & $0.48^{* * *}$ & & $0.31^{* * *}$ & $0.31^{* * *}$ & $0.26^{* * *}$ & $0.18^{* * *}$ & $0.16^{* * *}$ & $0.15^{* * *}$ & $0.17^{*}$ \\
& $(0.01)$ & & $(0.02)$ & $(0.02)$ & $(0.02)$ & $(0.02)$ & $(0.02)$ & $(0.02)$ & $(0.08)$ \\
Expect College (Math) & & $0.48^{* * *}$ & $0.31^{* * *}$ & $0.31^{* * *}$ & $0.26^{* * *}$ & $0.19^{* * *}$ & $0.15^{* * *}$ & $0.16^{* * *}$ & 0.13 \\
& & $(0.01)$ & $(0.02)$ & $(0.02)$ & $(0.02)$ & $(0.02)$ & $(0.02)$ & $(0.02)$ & $(0.07)$ \\
Teacher Controls & No & No & No & Yes & Yes & Yes & Yes & Yes & Yes \\
Student SES & No & No & No & No & Yes & Yes & Yes & Yes & Yes \\
9th Grade GPA & No & No & No & No & No & Yes & Yes & Yes & Yes \\
School FE & No & No & No & No & No & No & Yes & Yes & Yes \\
\hline Observations & 6060 & 6060 & 6060 & 6060 & 6060 & 6060 & 6060 & 3970 & 610 \\
$R^{2}$ & 0.22 & 0.22 & 0.28 & 0.28 & 0.33 & 0.35 & 0.44 & 0.47 & 0.63 \\
Adjusted $R^{2}$ & 0.22 & 0.22 & 0.28 & 0.28 & 0.32 & 0.35 & 0.37 & 0.37 & 0.31 \\
\hline \hline
\end{tabular}

Note: ${ }^{*} p<0.10,{ }^{* *} p<0.05,{ }^{* * *} p<0.01$. The dependent variable is a binary indicator equal to one if the student completed a four-year college degree or more, and zero otherwise. Parentheses contain standard errors that are robust to clustering at the school level. These are OLS estimates of Equation 1. Student socioeconomic status (SES) controls include indicators for household income and mother's educational attainment as well as indicators for student race, sex, and if a language other than English is spoken at home. Teacher controls include teacher race and gender dummies, years of experience, and whether or not the teacher majored in the subject he or she teaches. School FE refers to school fixed effects. 
Table 4: Transition Matricies of Disagreements in Teacher Expectations

\begin{tabular}{l|cccc}
\hline \hline Math & \multicolumn{4}{|c}{ English Teacher Expectation } \\
Teacher Expectation & HS or Less & Some College & Bachelor's or More & Total \\
\hline & \multicolumn{4}{c}{ All Students $(\mathrm{N}=6060)$} \\
\hline HS or Less & 7.12 & 4.79 & 1.62 & 13.54 \\
Some College & 4.32 & 9.90 & 9.27 & 23.49 \\
Bachelor's or More & 1.62 & 8.36 & 52.99 & 62.97 \\
Total & 13.06 & 23.06 & 63.88 & 100.00 \\
\hline & \multicolumn{4}{c}{ White Students (N = 3970) } \\
\hline HS or Less & 5.47 & 4.16 & 1.21 & 10.82 \\
Some College & 4.18 & 9.56 & 9.09 & 22.83 \\
Bachelor's or More & 1.33 & 8.31 & 56.71 & 66.35 \\
Total & 10.97 & 22.02 & 67.00 & 100.00 \\
\hline & \multicolumn{4}{c}{ Black Students (N = 610) } \\
\hline HS or Less & 13.18 & 8.07 & 2.63 \\
Some College & 7.08 & 12.52 & 12.03 & 23.88 \\
Bachelor's or More & 2.63 & 8.07 & 33.77 \\
Total & 22.90 & 28.67 & 48.43 \\
\hline \hline
\end{tabular}

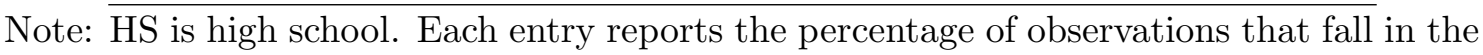
particular math teacher expectation-ELA teacher expectation category. 
Table 5: 2SLS Estimates of Effect of Expectations on Educational Attainment

\begin{tabular}{|c|c|c|c|c|c|c|}
\hline & \multicolumn{2}{|c|}{ All } & \multicolumn{2}{|c|}{ Whites } & \multicolumn{2}{|c|}{ Blacks } \\
\hline & $\begin{array}{l}\text { English } \\
\text { (1) }\end{array}$ & $\begin{array}{c}\text { Math } \\
(2)\end{array}$ & $\begin{array}{c}\text { English } \\
(3)\end{array}$ & $\begin{array}{c}\text { Math } \\
(4)\end{array}$ & $\begin{array}{l}\text { English } \\
(5)\end{array}$ & $\begin{array}{l}\text { Math } \\
(6)\end{array}$ \\
\hline Expects college (OLS) & $\begin{array}{c}0.15^{* * *} \\
(0.02)\end{array}$ & $\begin{array}{c}0.14^{* * *} \\
(0.02)\end{array}$ & $\begin{array}{c}0.14^{* * *} \\
(0.02)\end{array}$ & $\begin{array}{c}0.15^{* * *} \\
(0.02)\end{array}$ & $\begin{array}{c}0.18^{* * *} \\
(0.06)\end{array}$ & $\begin{array}{l}0.10^{*} \\
(0.05)\end{array}$ \\
\hline Expects college (2SLS) & $\begin{array}{c}0.24^{* * *} \\
(0.06)\end{array}$ & $\begin{array}{c}0.19^{* * *} \\
(0.06)\end{array}$ & $\begin{array}{c}0.24^{* * *} \\
(0.08)\end{array}$ & $\begin{array}{c}0.16^{* *} \\
(0.07)\end{array}$ & $\begin{array}{c}0.00 \\
(0.17)\end{array}$ & $\begin{array}{c}0.20 \\
(0.17)\end{array}$ \\
\hline First-Stage Estimates & & & & & & \\
\hline Passive (English) & $\begin{array}{c}-0.13^{* * *} \\
(0.02)\end{array}$ & $\begin{array}{c}-0.02 \\
(0.02)\end{array}$ & $\begin{array}{c}-0.12^{* * *} \\
(0.03)\end{array}$ & $\begin{array}{c}0.01 \\
(0.03)\end{array}$ & $\begin{array}{c}0.04 \\
(0.11)\end{array}$ & $\begin{array}{l}-0.14 \\
(0.09)\end{array}$ \\
\hline Passive (Math) & $\begin{array}{c}-0.02 \\
(0.02)\end{array}$ & $\begin{array}{c}-0.07^{* * *} \\
(0.02)\end{array}$ & $\begin{array}{c}-0.01 \\
(0.03)\end{array}$ & $\begin{array}{c}-0.07^{* *} \\
(0.03)\end{array}$ & $\begin{array}{l}-0.12 \\
(0.09)\end{array}$ & $\begin{array}{c}0.01 \\
(0.11)\end{array}$ \\
\hline Never attentive (English) & $\begin{array}{c}-0.29^{* * *} \\
(0.06)\end{array}$ & $\begin{array}{l}-0.05 \\
(0.06)\end{array}$ & $\begin{array}{c}-0.42^{* * *} \\
(0.06)\end{array}$ & $\begin{array}{c}-0.15^{* *} \\
(0.08)\end{array}$ & $\begin{array}{c}-0.86^{* * *} \\
(0.21)\end{array}$ & $\begin{array}{c}0.14 \\
(0.22)\end{array}$ \\
\hline Rarely attentive (English) & $\begin{array}{c}-0.32^{* * *} \\
(0.04)\end{array}$ & $\begin{array}{l}-0.04 \\
(0.03)\end{array}$ & $\begin{array}{c}-0.34^{* * *} \\
(0.04)\end{array}$ & $\begin{array}{l}-0.05 \\
(0.04)\end{array}$ & $\begin{array}{c}-0.54^{* * *} \\
(0.16)\end{array}$ & $\begin{array}{c}-0.28^{* *} \\
(0.13)\end{array}$ \\
\hline Sometimes attentive (English) & $\begin{array}{c}-0.31^{* * *} \\
(0.02)\end{array}$ & $\begin{array}{c}-0.04^{*} \\
(0.02)\end{array}$ & $\begin{array}{c}-0.28^{* * *} \\
(0.03)\end{array}$ & $\begin{array}{l}-0.04 \\
(0.03)\end{array}$ & $\begin{array}{c}-0.53^{* * *} \\
(0.08)\end{array}$ & $\begin{array}{l}-0.06 \\
(0.10)\end{array}$ \\
\hline Mostly attentive (English) & $\begin{array}{c}-0.10^{* * *} \\
(0.01)\end{array}$ & $\begin{array}{c}-0.03^{* *} \\
(0.01)\end{array}$ & $\begin{array}{c}-0.09^{* * *} \\
(0.02)\end{array}$ & $\begin{array}{c}-0.03^{*} \\
(0.02)\end{array}$ & $\begin{array}{c}-0.29^{* * *} \\
(0.08)\end{array}$ & $\begin{array}{l}-0.11 \\
(0.10)\end{array}$ \\
\hline Never attentive (Math) & $\begin{array}{l}-0.05 \\
(0.07)\end{array}$ & $\begin{array}{c}-0.36^{* * *} \\
(0.10)\end{array}$ & $\begin{array}{c}-0.06 \\
(0.10)\end{array}$ & $\begin{array}{c}-0.40^{* * *} \\
(0.11)\end{array}$ & $\begin{array}{c}0.01 \\
(0.15)\end{array}$ & $\begin{array}{l}-0.23 \\
(0.34)\end{array}$ \\
\hline Rarely attentive (Math) & $\begin{array}{c}-0.10^{* * *} \\
(0.03)\end{array}$ & $\begin{array}{c}-0.35^{* * *} \\
(0.03)\end{array}$ & $\begin{array}{l}-0.04 \\
(0.04)\end{array}$ & $\begin{array}{c}-0.34^{* * *} \\
(0.04)\end{array}$ & $\begin{array}{c}0.08 \\
(0.15)\end{array}$ & $\begin{array}{c}-0.31^{* *} \\
(0.15)\end{array}$ \\
\hline Sometimes attentive (Math) & $\begin{array}{c}-0.08^{* * *} \\
(0.02)\end{array}$ & $\begin{array}{c}-0.32^{* * *} \\
(0.02)\end{array}$ & $\begin{array}{c}-0.07^{* * *} \\
(0.03)\end{array}$ & $\begin{array}{c}-0.32^{* * *} \\
(0.03)\end{array}$ & $\begin{array}{l}-0.12 \\
(0.10)\end{array}$ & $\begin{array}{c}-0.45^{* * *} \\
(0.09)\end{array}$ \\
\hline Mostly attentive (Math) & $\begin{array}{l}-0.02 \\
(0.01)\end{array}$ & $\begin{array}{c}-0.09 * * * \\
(0.01)\end{array}$ & $\begin{array}{c}-0.01 \\
(0.02)\end{array}$ & $\begin{array}{c}-0.09^{* * *} \\
(0.02)\end{array}$ & $\begin{array}{l}-0.10 \\
(0.10)\end{array}$ & $\begin{array}{l}-0.08 \\
(0.09)\end{array}$ \\
\hline Strongly agree reading is fun & $\begin{array}{c}0.08^{* * *} \\
(0.02)\end{array}$ & $\begin{array}{l}-0.02 \\
(0.02)\end{array}$ & $\begin{array}{c}0.07^{* *} \\
(0.03)\end{array}$ & $\begin{array}{c}-0.02 \\
(0.03)\end{array}$ & $\begin{array}{c}-0.24^{*} \\
(0.12)\end{array}$ & $\begin{array}{c}0.20 \\
(0.14)\end{array}$ \\
\hline Agree reading is fun & $\begin{array}{c}0.05^{* *} \\
(0.02)\end{array}$ & $\begin{array}{l}-0.02 \\
(0.02)\end{array}$ & $\begin{array}{c}0.04 \\
(0.02)\end{array}$ & $\begin{array}{l}-0.02 \\
(0.03)\end{array}$ & $\begin{array}{c}-0.34^{* * *} \\
(0.12)\end{array}$ & $\begin{array}{c}0.10 \\
(0.15)\end{array}$ \\
\hline Disagree reading is fun & $\begin{array}{c}0.05^{* * *} \\
(0.02)\end{array}$ & $\begin{array}{l}-0.00 \\
(0.02)\end{array}$ & $\begin{array}{c}0.04 \\
(0.02)\end{array}$ & $\begin{array}{l}-0.01 \\
(0.02)\end{array}$ & $\begin{array}{c}-0.25^{* *} \\
(0.12)\end{array}$ & $\begin{array}{c}0.15 \\
(0.14)\end{array}$ \\
\hline Strongly agree math is fun & $\begin{array}{c}-0.06^{* *} \\
(0.02)\end{array}$ & $\begin{array}{c}0.07^{* * *} \\
(0.02)\end{array}$ & $\begin{array}{c}-0.11^{* * *} \\
(0.03)\end{array}$ & $\begin{array}{c}0.08^{* * *} \\
(0.03)\end{array}$ & $\begin{array}{l}-0.19^{*} \\
(0.11)\end{array}$ & $\begin{array}{l}-0.12 \\
(0.10)\end{array}$ \\
\hline Agree math is fun & $\begin{array}{c}-0.05^{* *} \\
(0.02)\end{array}$ & $\begin{array}{c}0.05^{* * *} \\
(0.02)\end{array}$ & $\begin{array}{l}-0.02 \\
(0.02)\end{array}$ & $\begin{array}{c}0.05^{* *} \\
(0.02)\end{array}$ & $\begin{array}{l}-0.13 \\
(0.09)\end{array}$ & $\begin{array}{c}0.01 \\
(0.10)\end{array}$ \\
\hline Disagree math is fun & $\begin{array}{c}-0.04^{* *} \\
(0.02) \\
\end{array}$ & $\begin{array}{c}0.00 \\
(0.02) \\
\end{array}$ & $\begin{array}{l}-0.03 \\
(0.02) \\
\end{array}$ & $\begin{array}{c}0.02 \\
(0.02) \\
\end{array}$ & $\begin{array}{c}-0.06 \\
(0.07) \\
\end{array}$ & $\begin{array}{l}-0.14 \\
(0.09) \\
\end{array}$ \\
\hline$R^{2}$ & 0.59 & 0.59 & 0.60 & 0.60 & 0.78 & 0.74 \\
\hline $\mathrm{Adj}-R^{2}$ & 0.52 & 0.52 & 0.52 & 0.52 & 0.54 & 0.48 \\
\hline $\mathrm{N}$ & 4420 & 4420 & 2960 & 2960 & 250 & 250 \\
\hline F-test(1st Stage) & $19.92^{* * *}$ & $23.46^{* * *}$ & $13.54^{* * *}$ & $13.75^{* * *}$ & $5.39^{* * *}$ & $4.81^{* * *}$ \\
\hline
\end{tabular}

Note: ${ }^{*} p<0.10,{ }^{* *} p<0.05,{ }^{* * *} p<0.01$. The dependent variable is a binary indicator equal to one if the student completed a four-year college degree or more, and zero otherwise. Parentheses contain standard errors that are robust to clustering at the school level. The first two rows present OLS and 2SLS estimates, respectively, of Equation 1, for the analytic sample for which all instruments are observed. All regressions control for student race, sex, 9th-grade GPA, math and ELA scores, household income, indicator for single parent family, mother's educational attainment, school fixed effects, and teacher race, sex, and educational attainment. 
Table 6: Testing the Exogeneity of Teacher Bias

\begin{tabular}{|c|c|c|}
\hline Regression No. & Variable & Estimates \\
\hline 1 & 9th-grade GPA & $\begin{array}{c}-0.0723^{* * *} \\
(0.0097)\end{array}$ \\
\hline 2 & $\left|S_{E}-S_{M}\right|$ & $\begin{array}{c}0.0023 \\
(0.0014)\end{array}$ \\
\hline 3 & $\left|S_{E}-S_{M}\right|$ & $\begin{array}{l}-0.0005 \\
(0.0031)\end{array}$ \\
\hline & $\left|S_{E}-S_{M}\right|^{2}$ & $\begin{array}{c}0.0002 \\
(0.0002)\end{array}$ \\
\hline 4 & S Ever Bullied & $\begin{array}{c}0.0012 \\
(0.0147)\end{array}$ \\
\hline 5 & $\mathrm{~S}$ Got in Fight & $\begin{array}{l}-0.0023 \\
(0.0205)\end{array}$ \\
\hline 6 & S Participated in Science Fair & $\begin{array}{l}-0.0126 \\
(0.0191)\end{array}$ \\
\hline 7 & $\mathrm{~S}$ finds class interesting & $\begin{array}{l}-0.0032 \\
(0.0130)\end{array}$ \\
\hline 8 & $\mathrm{~S}$ Ever in college prep & $\begin{array}{c}0.0160 \\
(0.0147)\end{array}$ \\
\hline 9 & $\mathrm{P}$ thinks $\mathrm{S}$ has disability & $\begin{array}{l}-0.0376 \\
(0.0243)\end{array}$ \\
\hline
\end{tabular}

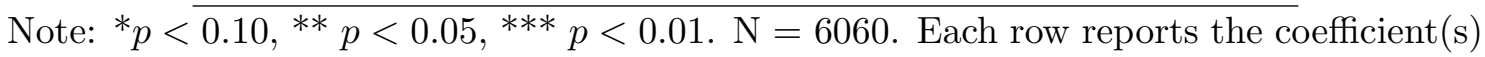
of interest from a unique regression. When necessary, a dummy for "variable of interest is missing" is included in the regression. These "missing" indicators are never statistically significant. $\mathrm{S}$ is student and $\mathrm{P}$ is parent. $S_{E}$ and $S_{M}$ are ELA and math standardized test scores. All regressions control for student race, sex, 9th-grade GPA, household income and mother's educational attainment, indicators for single parent household and if a language other than English is spoken at home, and school fixed effects. In regression 3 , the quadratic terms are jointly insignificant $(\mathrm{F}$-stat $=1.63, p$-value $=0.20$. $)$ 
Table 7: Education Production Function Estimates

\begin{tabular}{c|cc}
\hline \hline & Whites & Blacks \\
\hline$\gamma_{E}$ & $0.52^{* * *}$ & $0.50^{* * *}$ \\
& $(0.06)$ & $(0.16)$ \\
$\gamma_{M}$ & $0.55^{* * *}$ & 0.23 \\
& $(0.06)$ & $(0.16)$ \\
$\beta$ & $0.50^{* * *}$ & $0.27^{* *}$ \\
& $(0.05)$ & $(0.11)$ \\
$c$ & $-0.46^{* * *}$ & $-0.83^{* * *}$ \\
& $(0.05)$ & $(0.14)$ \\
$\sigma_{\theta}$ & $0.51^{* * *}$ & $0.80^{* * *}$ \\
& $(0.05)$ & $(0.14)$ \\
APE & & \\
\hline$b_{E}$ & $0.18^{* * *}$ & $0.14^{* * *}$ \\
& $(0.02)$ & $(0.05)$ \\
$b_{M}$ & $0.20^{* * *}$ & 0.07 \\
& $(0.02)$ & $(0.04)$ \\
Elasticities & & \\
\hline$b_{E}$ & $0.1221^{* * *}$ & $0.18^{* * *}$ \\
& $(0.02)$ & $(0.06)$ \\
$b_{M}$ & $0.13^{* * *}$ & 0.08 \\
& $(0.02)$ & $(0.05)$ \\
\hline $\mathrm{N}$ & 3970 & 610 \\
\hline \hline
\end{tabular}

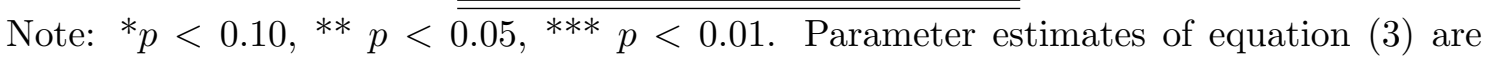
reported. The dependent variable is a binary indicator equal to one if the student completed a four-year college degree or more, and zero otherwise. Standard errors are computed by constructing the Hessian of the likelihood function using outer product measure. To compute the outer product measure, we calculate two-sided numerical derivatives of the likelihood function for each estimated parameter. In each direction, the derivative is calculated by perturbing each parameter and then computing the likelihood. Standard errors for the average partial effects (APE) and elasticities are calculated using the delta method. 
Table 8: Teacher Expectation Production Function Estimates

\begin{tabular}{c|cccc}
\hline \hline \multirow{4}{*}{} & \multicolumn{2}{|c}{ Whites } & \multicolumn{2}{c}{ Blacks } \\
& ELA & Math & ELA & Math \\
& $(1)$ & $(2)$ & $(3)$ & $(4)$ \\
\hline$c$ & $0.58^{* * *}$ & $0.56^{* * *}$ & $0.47^{* *}$ & $0.53^{* * *}$ \\
& $(0.03)$ & $(0.03)$ & $(0.19)$ & $(0.19)$ \\
$c_{D}$ & -0.09 & 0.23 & -0.26 & $-0.53^{* * *}$ \\
& $(0.13)$ & $(0.15)$ & $(0.21)$ & $(0.2)$ \\
$\phi$ & $1.47^{* * *}$ & $1.68^{* * *}$ & $0.94^{* * *}$ & $1.38^{* *}$ \\
& $(0.18)$ & $(0.2)$ & $(0.32)$ & $(0.55)$ \\
$\phi_{D}$ & -0.45 & 0.00 & -0.21 & -0.52 \\
& $(0.45)$ & $(0.39)$ & $(0.32)$ & $(0.51)$ \\
$\beta$ & $0.55^{* * *}$ & $0.5^{* * *}$ & $0.44^{* *}$ & 0.14 \\
& $(0.04)$ & $(0.04)$ & $(0.18)$ & $(0.21)$ \\
$\beta_{D}$ & 0.23 & 0.16 & 0.05 & 0.31 \\
& $(0.19)$ & $(0.14)$ & $(0.2)$ & $(0.23)$ \\
$\mathrm{APE}$ & \multicolumn{3}{c}{} \\
\hline$D$ & -0.03 & 0.06 & $-0.10^{*}$ & $-0.27^{* * *}$ \\
& $(0.04)$ & $(0.04)$ & $(0.06)$ & $(0.07)$ \\
\hline $\mathrm{N}$ & \multicolumn{3}{|c}{3970} & \multicolumn{3}{c}{610} \\
\hline
\end{tabular}

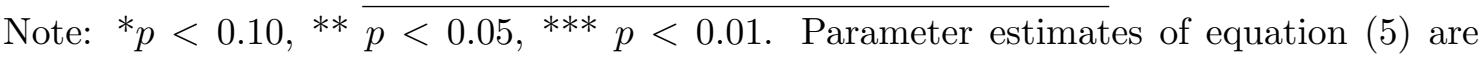
reported. Standard errors are computed by constructing the Hessian of the likelihood function using outer product measure. To compute the outer product measure, we calculate two-sided numerical derivatives of the likelihood function for each estimated parameter. In each direction, the derivative is calculated by perturbing each parameter and then computing the likelihood. Standard errors for the average partial effects (APE) are calculated using the delta method. 


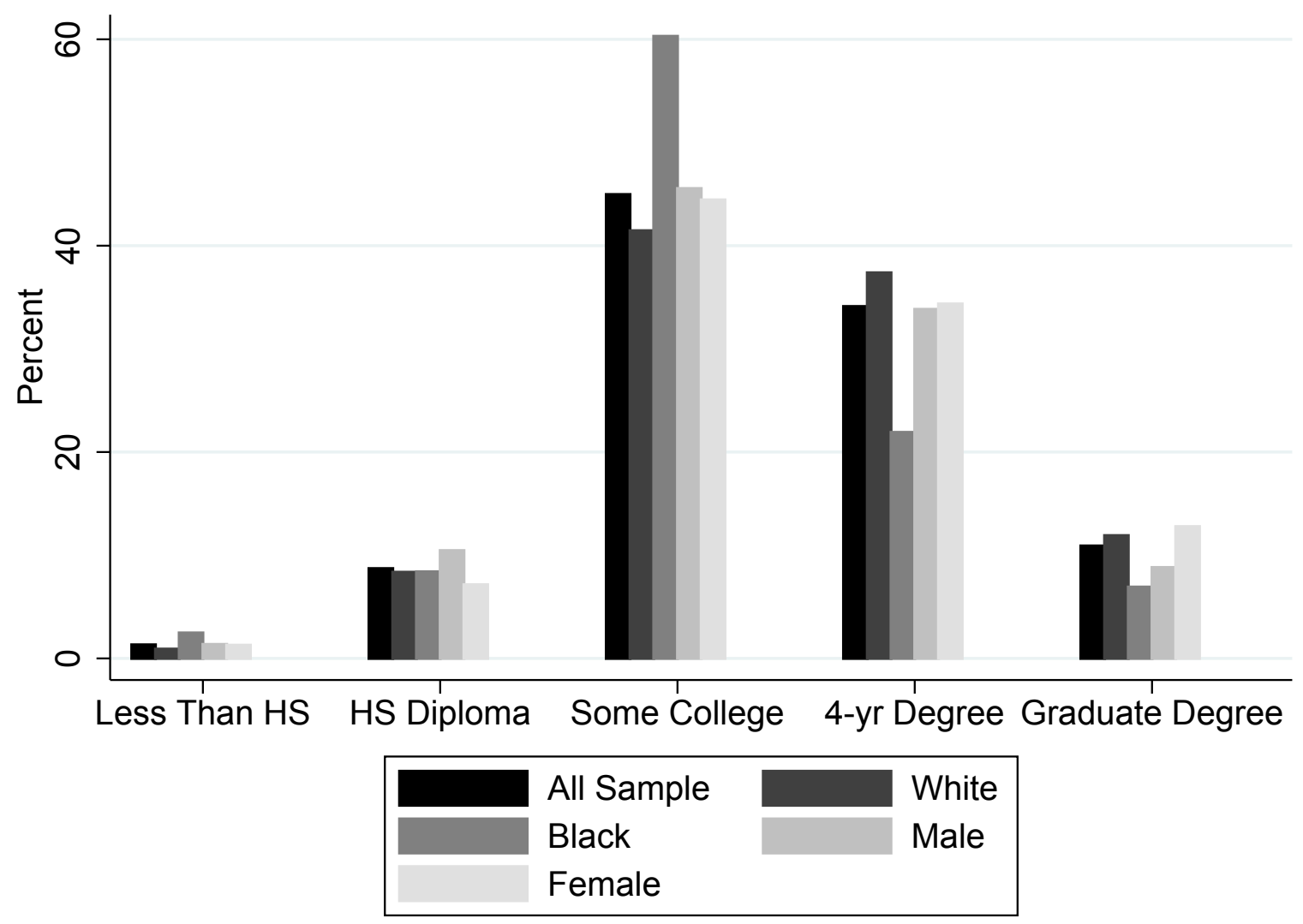

Figure 1: Educational Attainment, By Subgroup. Histogram of percentage of subsample of students who fall in the given educational attainment category is plotted. HS is high school. Graduate degree includes masters, Ph.D., or professional degrees 


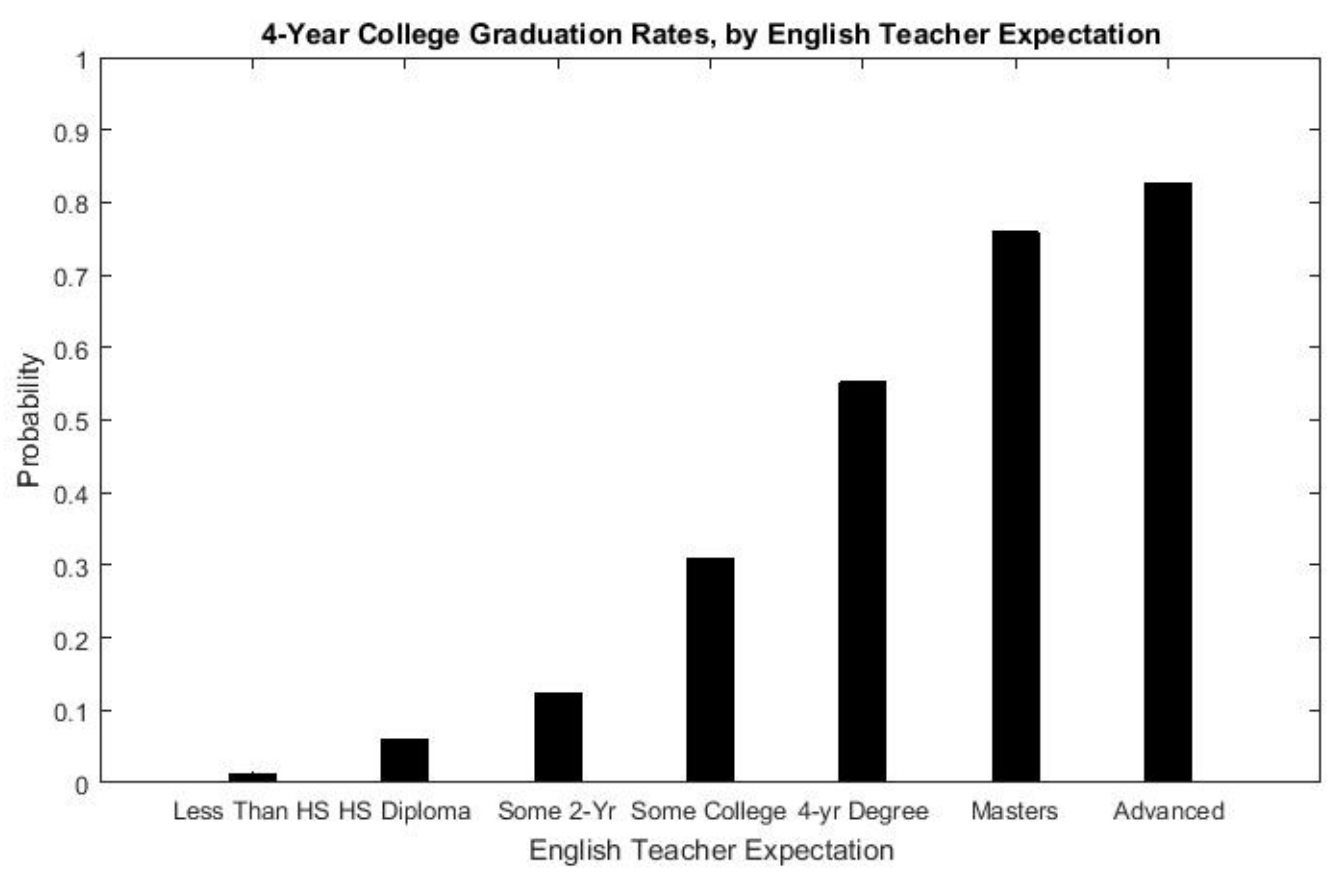

(a)

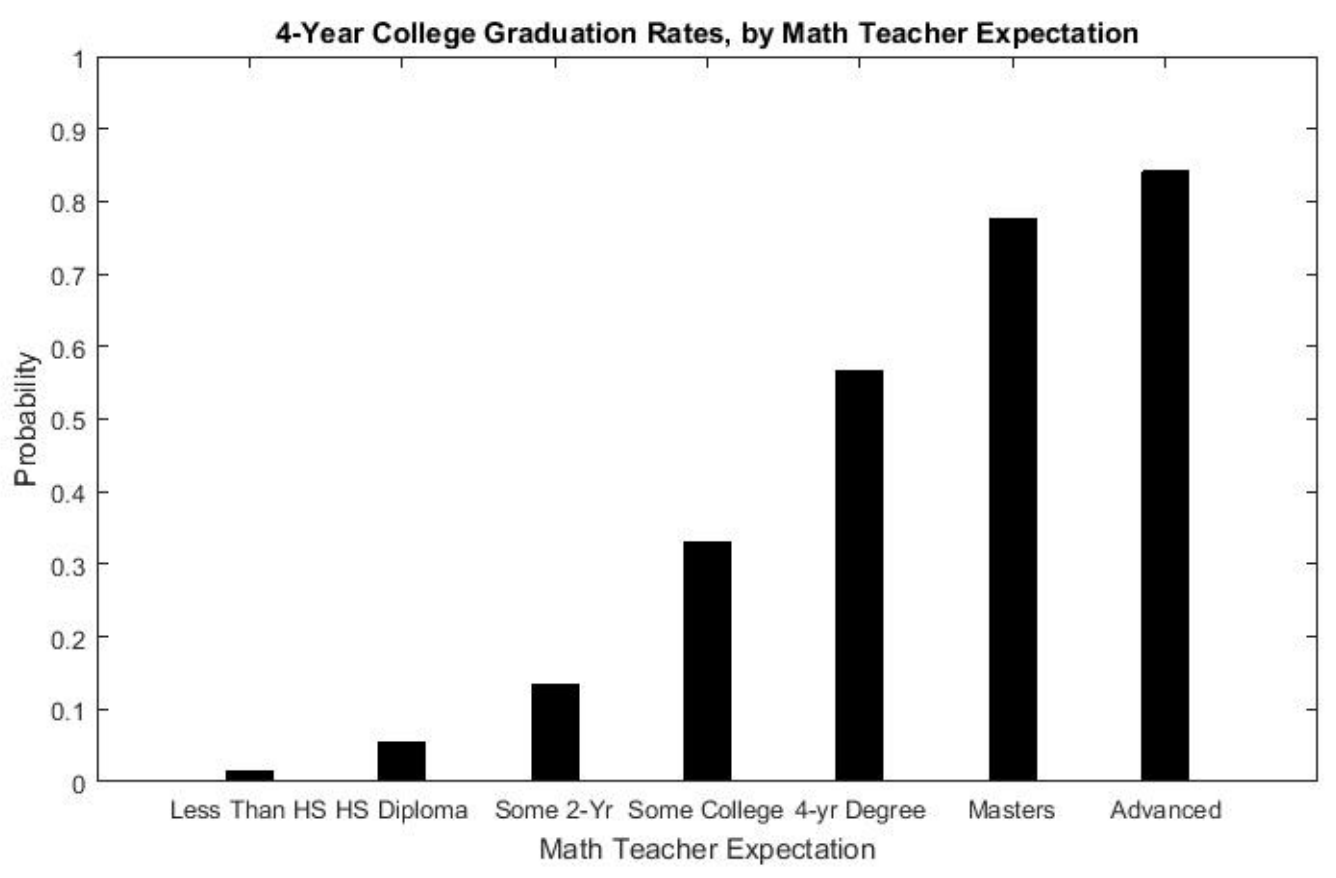

(b)

Figure 2: Teacher expectations and student outcomes. Panel 2(a) shows the percentage of students who complete a four year college degree by ELA teacher expectations. Panel 2(b) plots respective percentages by math teacher expectations. 


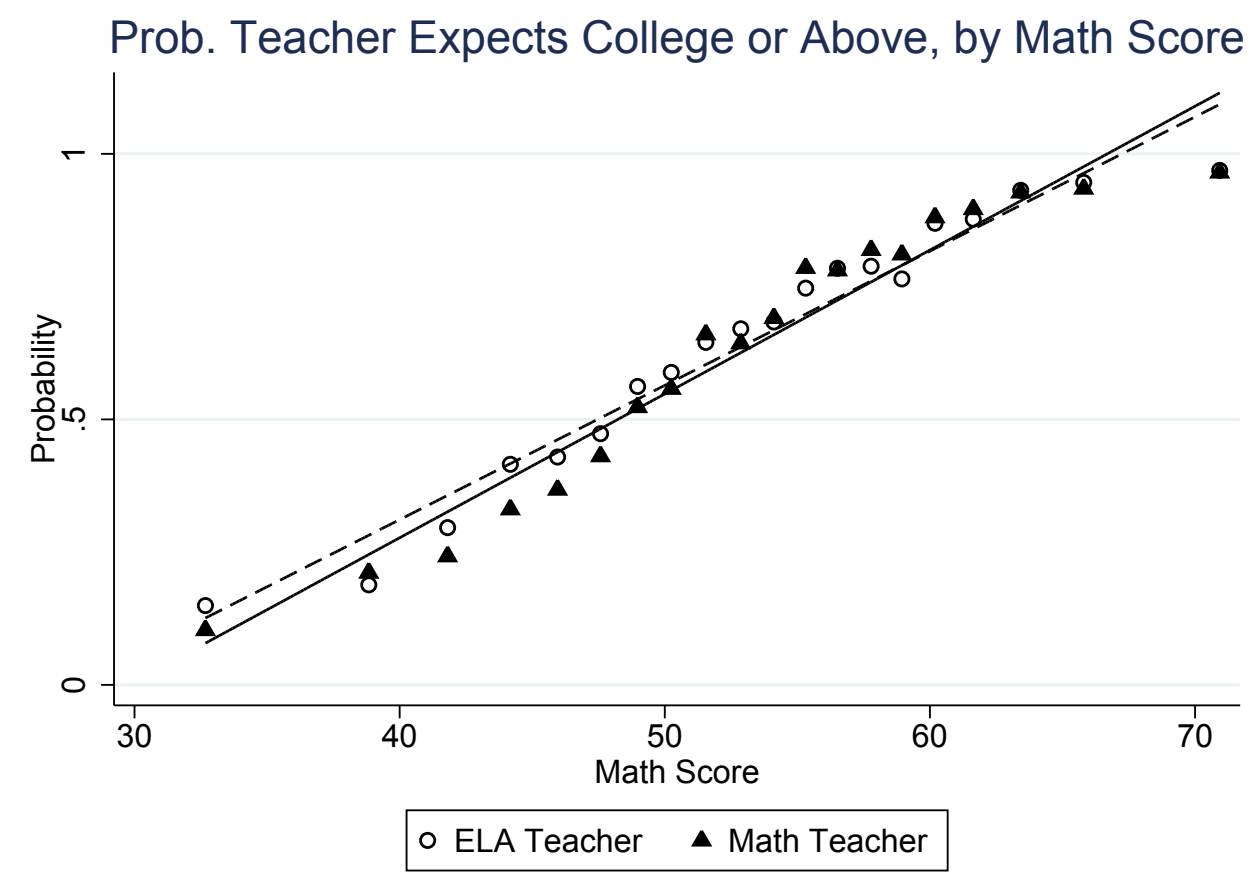

(a)

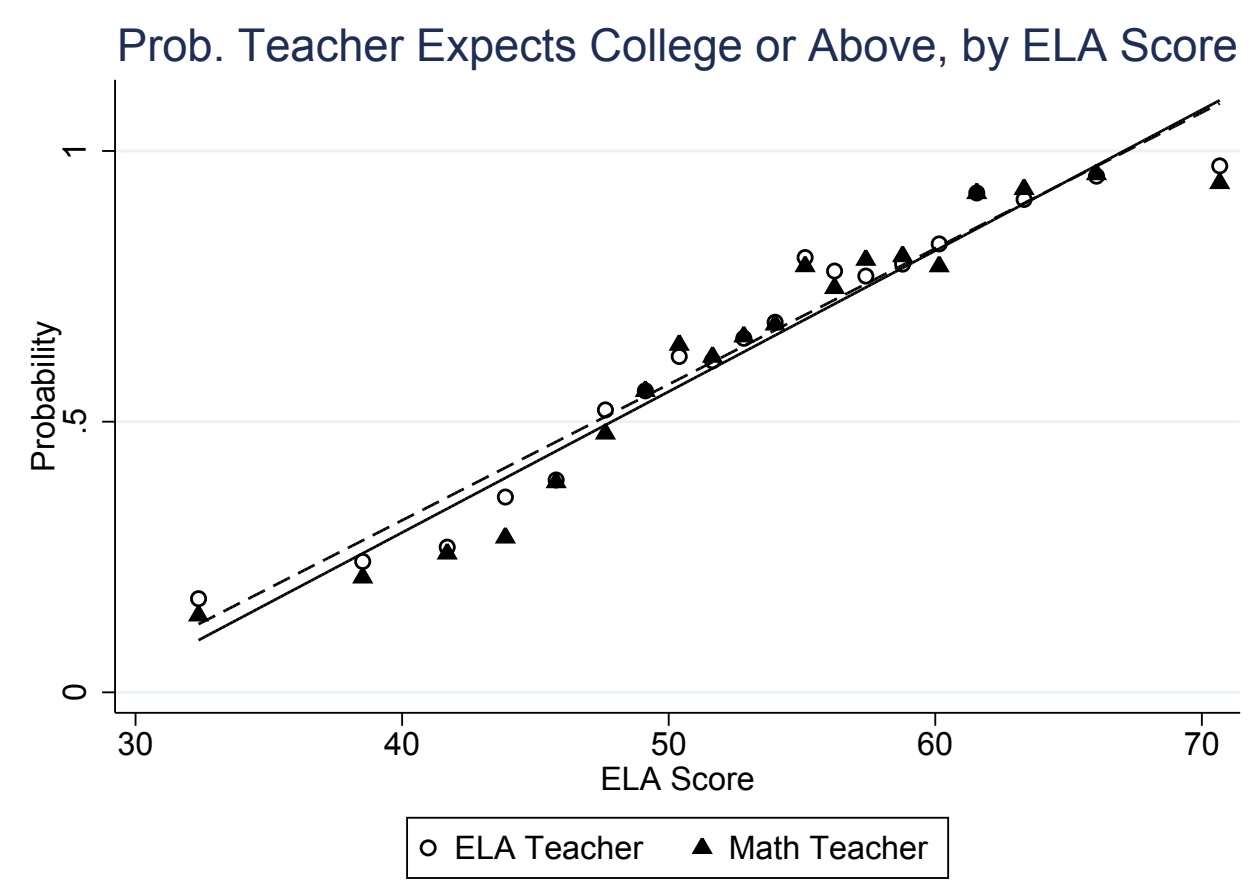

(b)

Figure 3: MATH AND ELA SCORES AND TEACHER EXPECTATIONS. Binned scatterplots, along with the lines of best fit for ELA (dashed lines) and math teacher expectations (solid lines), by math and ELA score, respectively. 

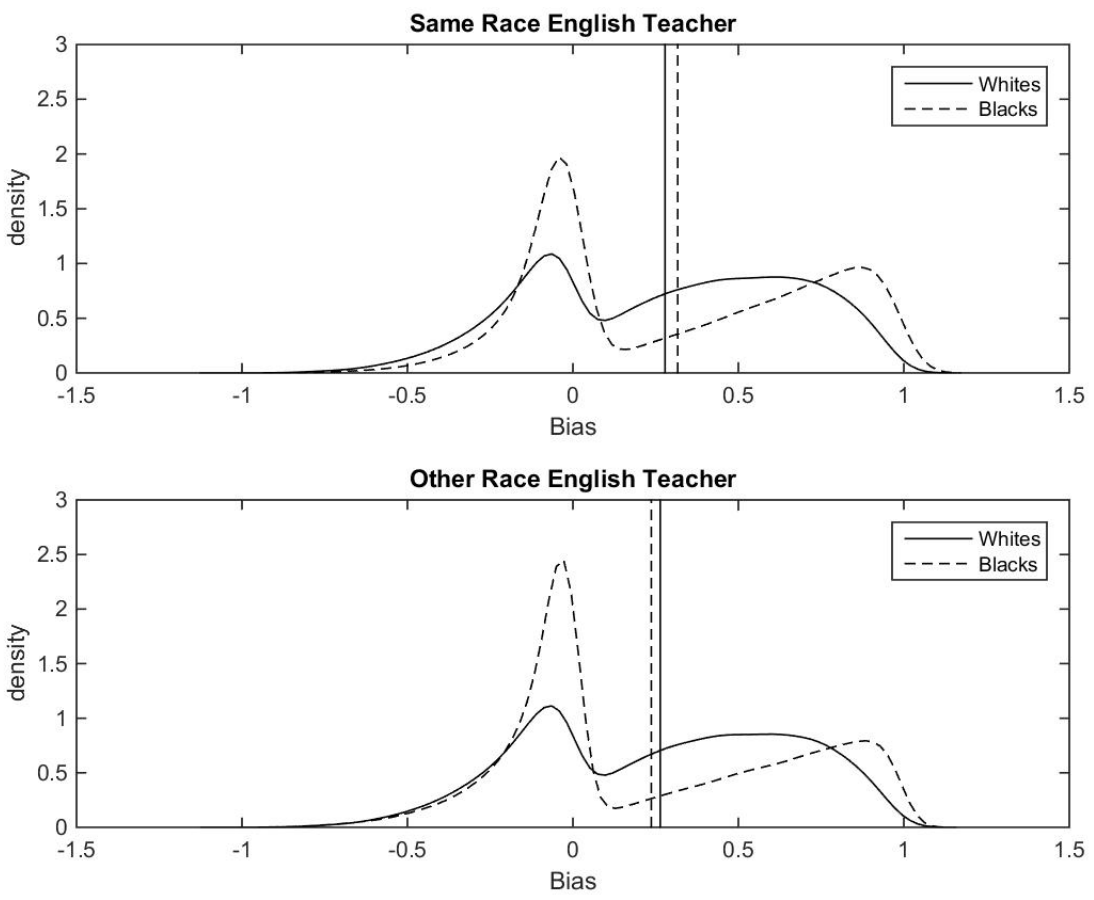

(a)
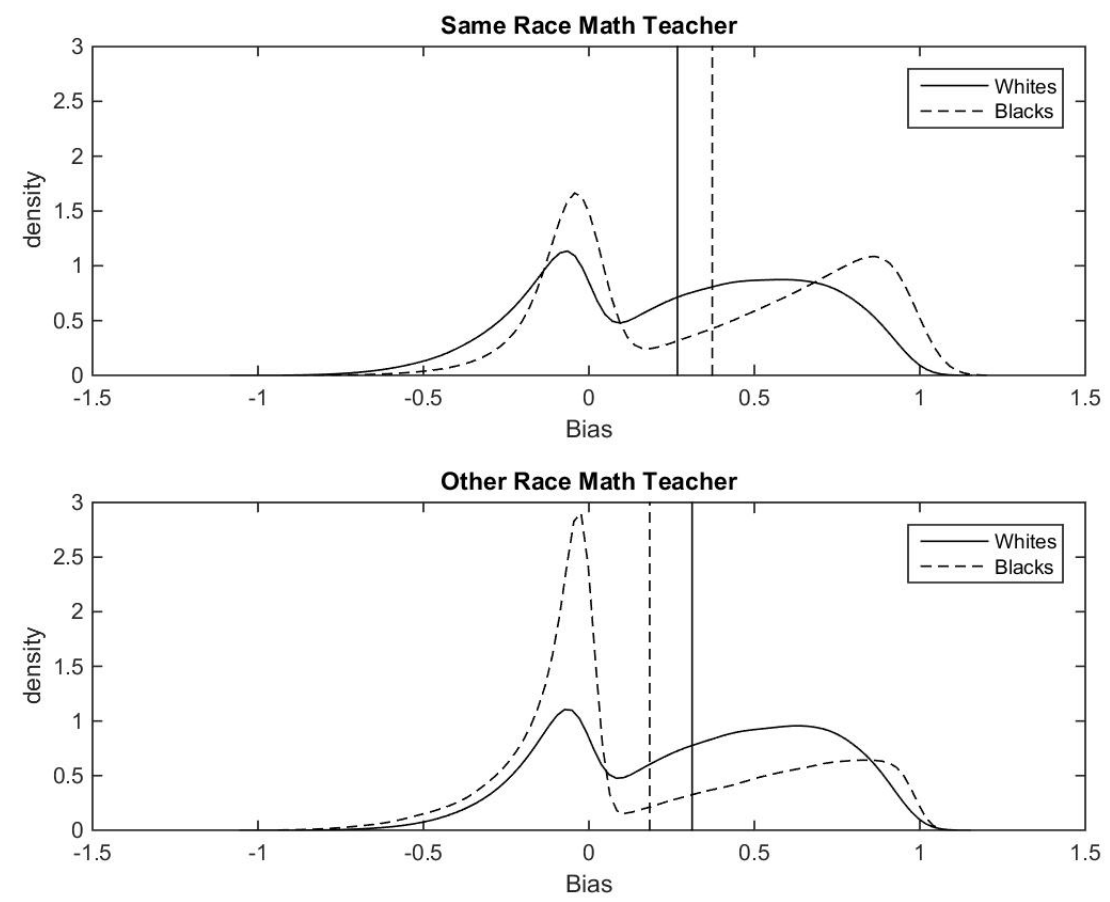

(b)

Figure 4: Distribution of bias by student Race.. PDFs of teacher bias are plotted. Vertical lines represent mean bias. Panel 4(a) shows distribution of bias for white and black students with same and other race ELA teacher. Panel 4(b) shows respective distributions of math teacher bias. Bias is defined in equation (6). 


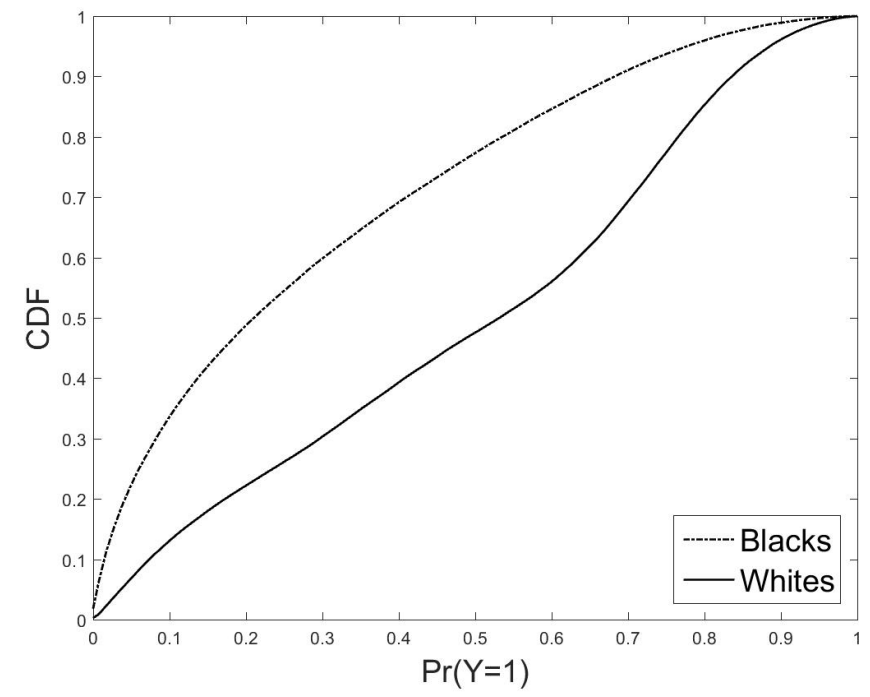

(a)

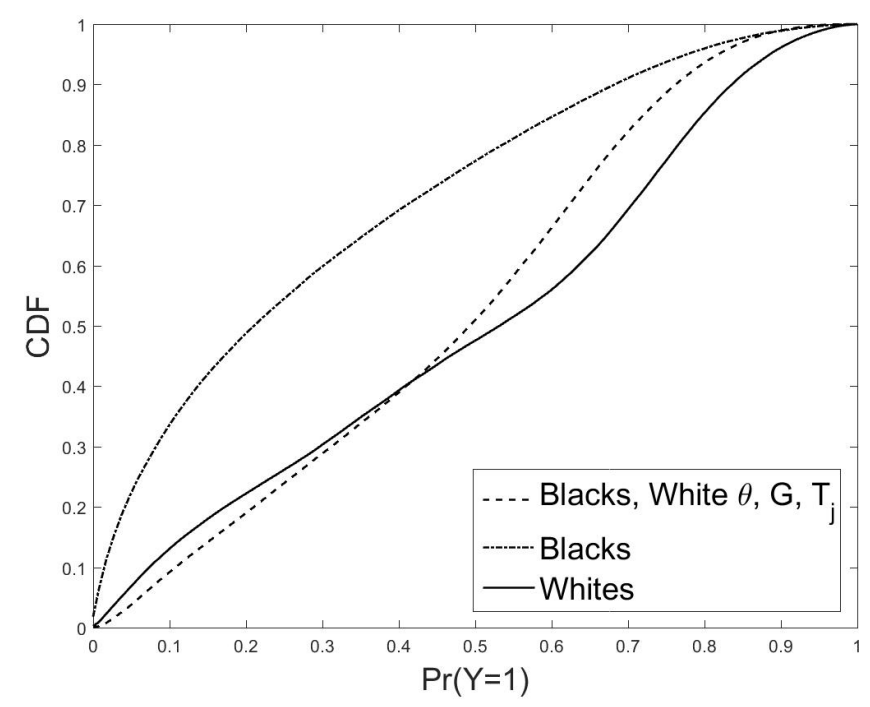

(c)

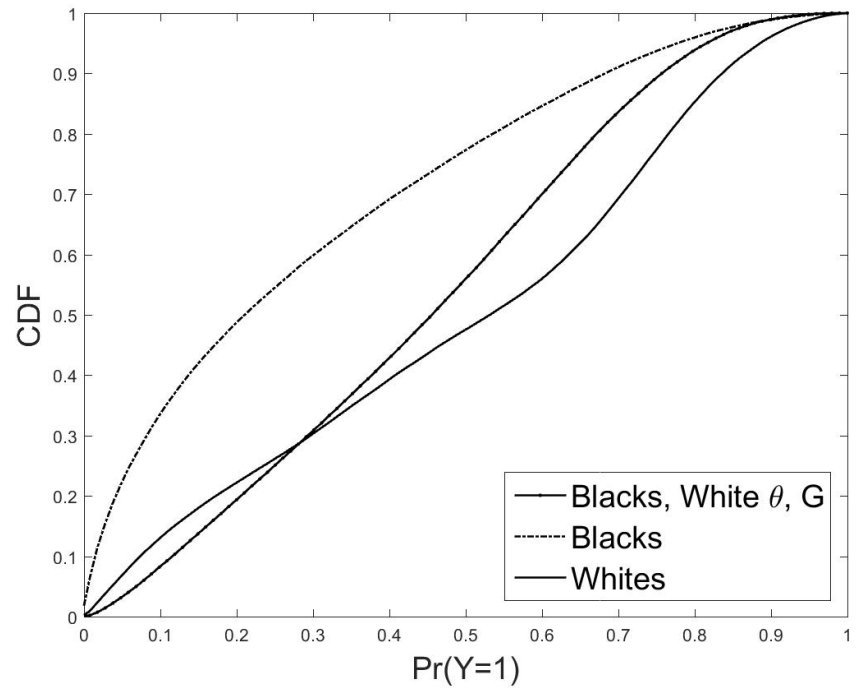

(b)

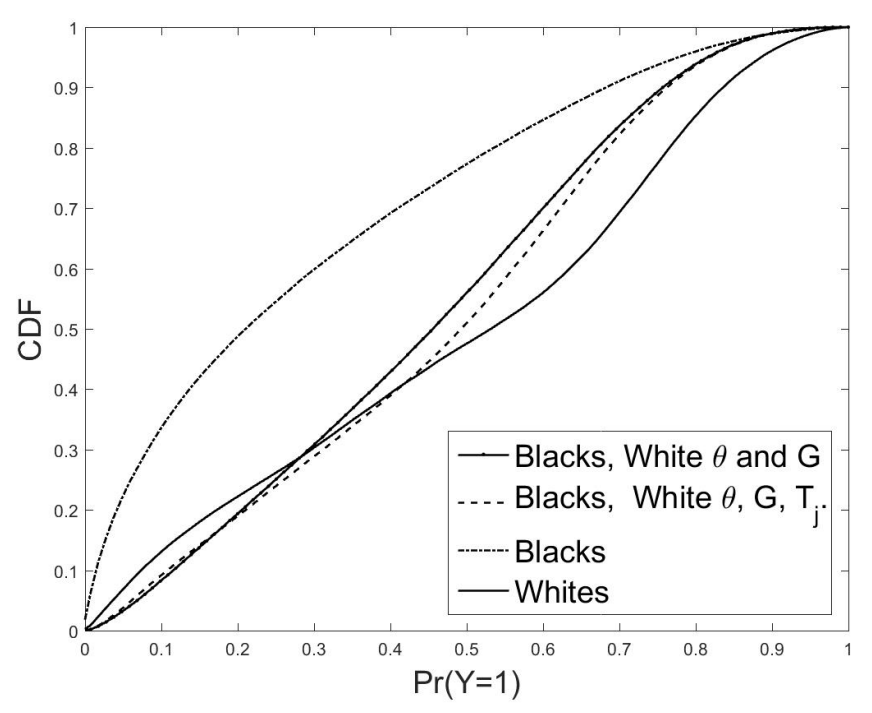

(d)

Figure 5: CDFs of COllege COMPLEtion PRobability for STUDENTS of White TEACHERS. Black and white denote student race. $\theta$ is the latent factor that measures the objective probability of completing college (net of GPA and bias), $G$ is 9th-grade GPA, $T_{j}$ is the the expectation of the subject- $j$ teacher, and $Y$ is a binary indicator for college completion. Panel 5(a) plots the actual CDFs of $\operatorname{Pr}(Y=1)$ for black and white students who have white teachers. Panel $5(\mathrm{~b})$ plots the distribution under the counterfactual in which black students have the same $\theta$ and $G$ as white students. Panel 5(c) plots the distribution under the counterfactual in which black students face the same teacher-expectation production function and the same $\theta$ and $G$ as white students. Panel $5(\mathrm{~d})$ combines the three previous plots. The largest difference between the two CDFs occurs at $\operatorname{Pr}(Y=1)=0.50$, with the magnitude of difference being 0.05. 


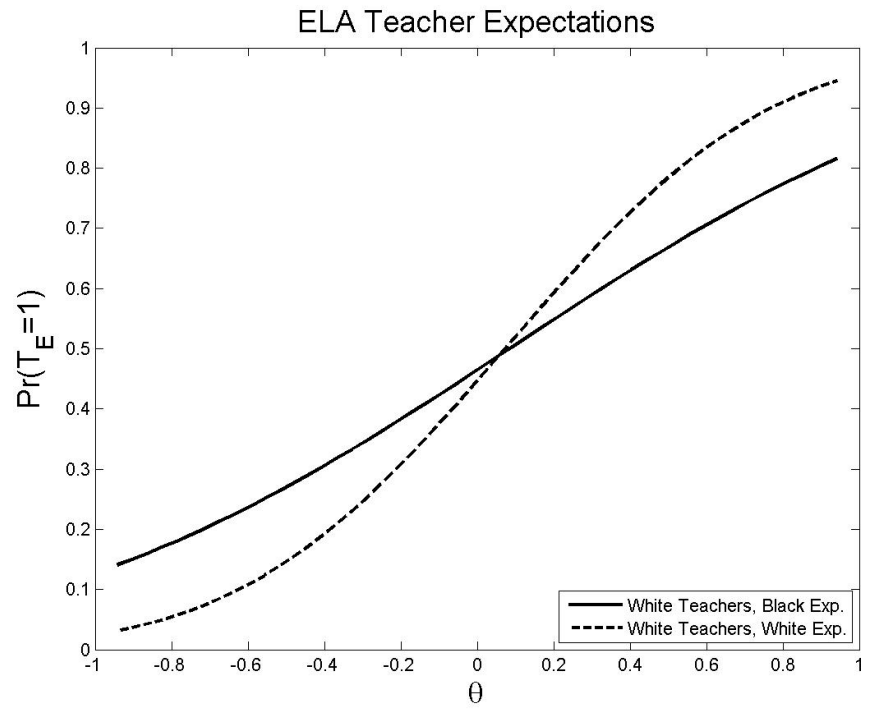

(a)

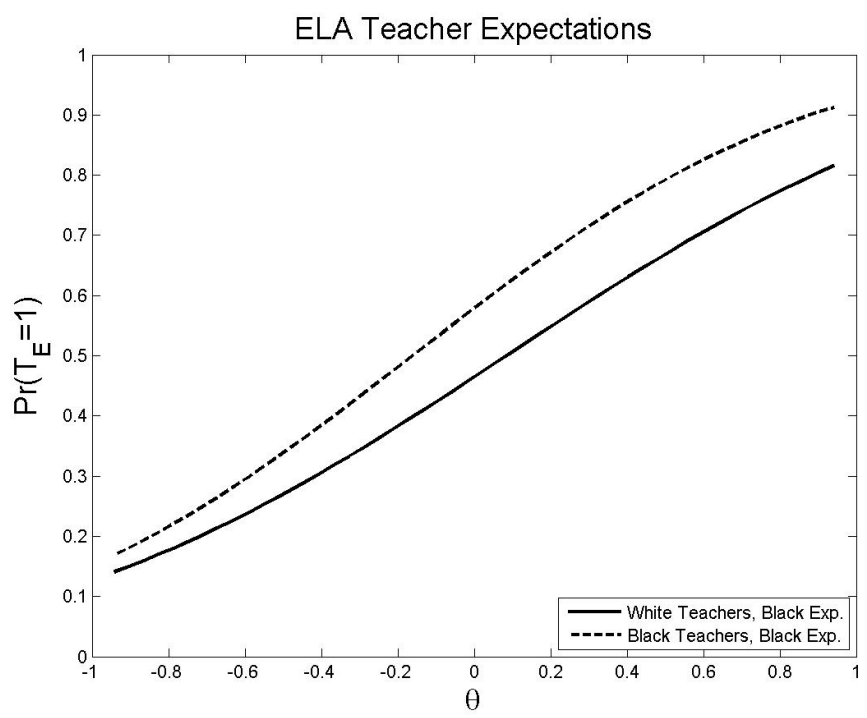

(c)

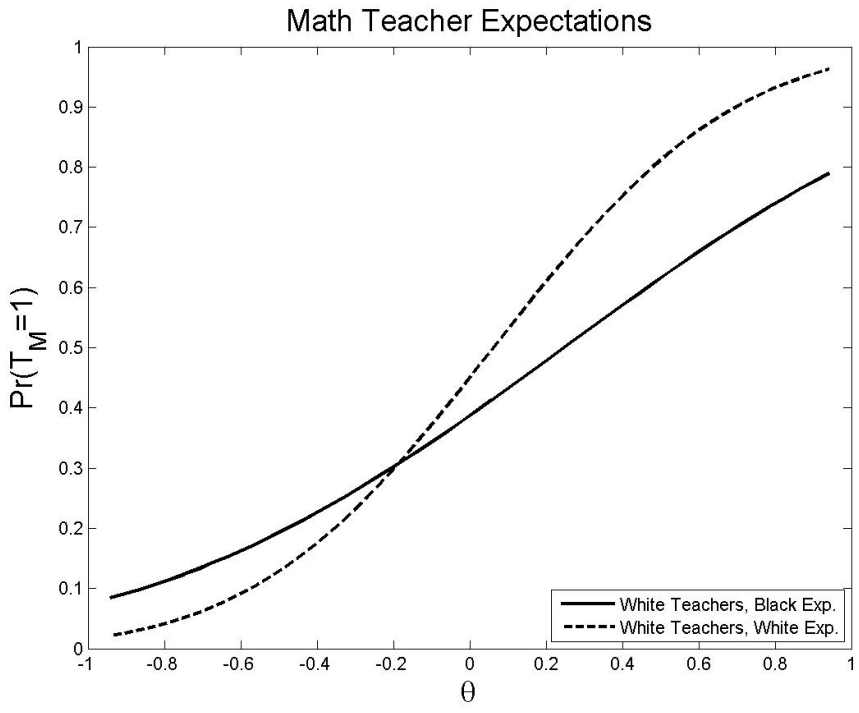

(b)

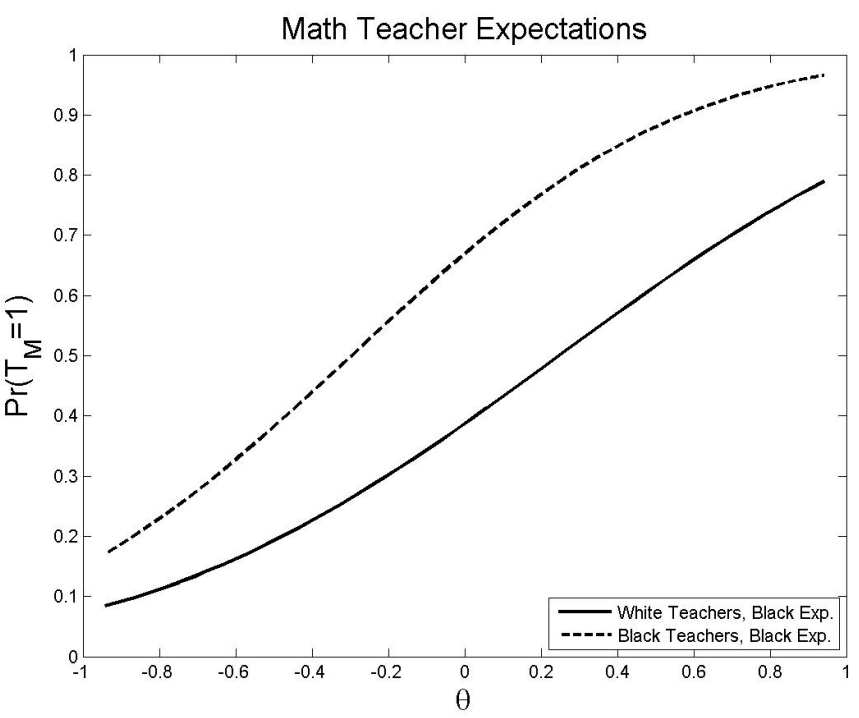

(d)

Figure 6: TEACHER EXPECTATIONS FOR BLACK STUDENTS. $\theta$ is the latent factor that measures the objective probability of completing college (net of GPA and bias) and $T_{j}$ is the expectation of the subject- $j$ teacher. Panel 6(a) shows how teacher expectations change when black students face the same expectation production function from white ELA teachers as white students. Panel 6(b) shows how the expectations change in the counterfactual scenario for math teachers. Panels 6(c) and 6(d), respectively, compare white and black ELA and math teachers' expectation for black students with given $\theta$. 


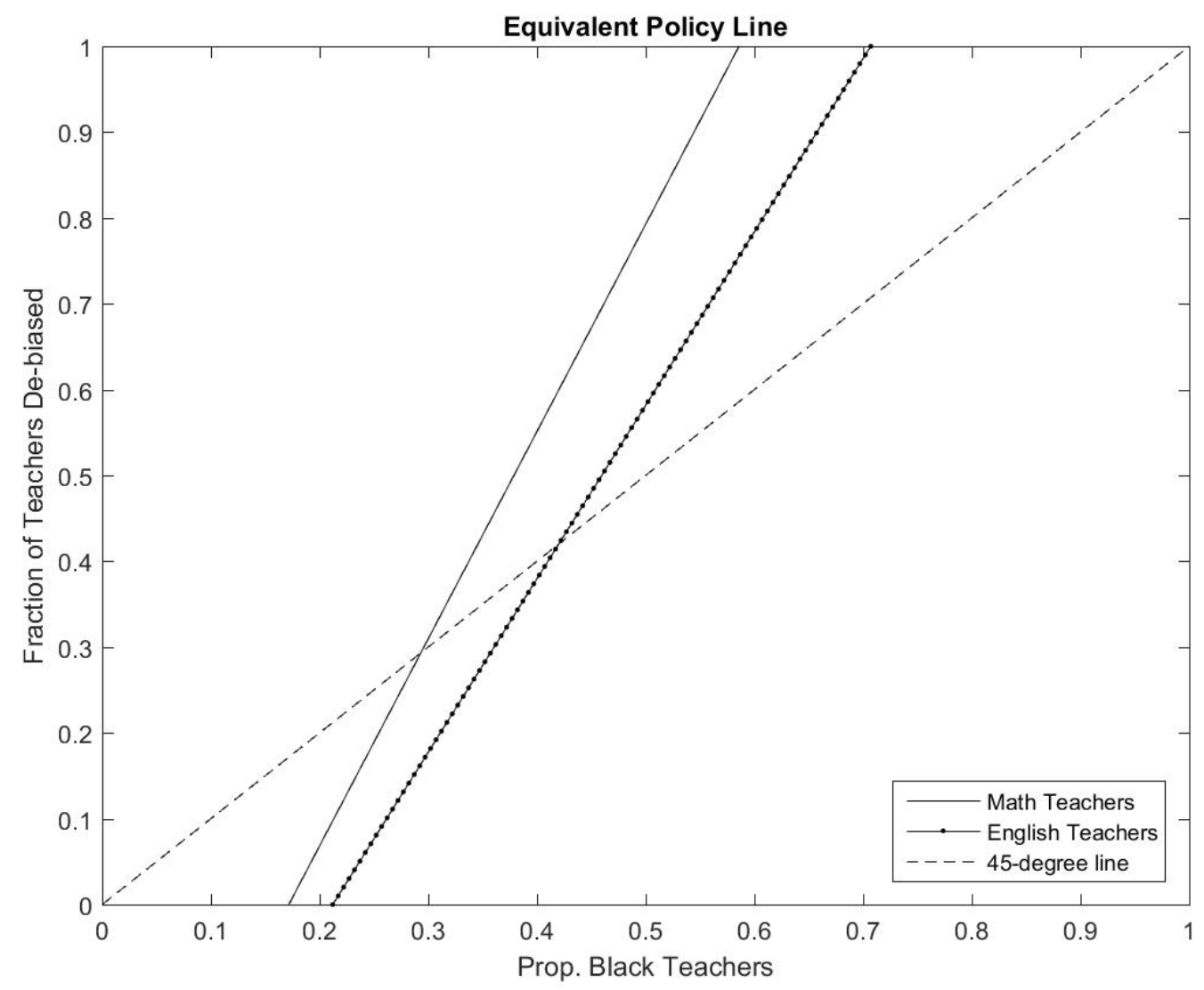

Figure 7: EqUivalent POLICY Line. Level of de-biasing and hiring policies needed to achieve the same college completion rates for blacks is plotted. 


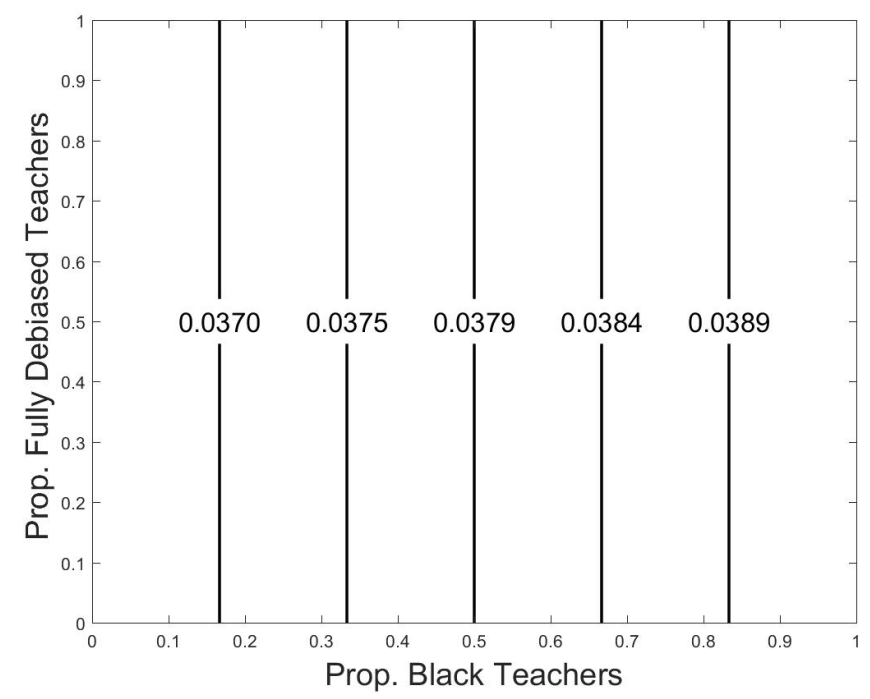

(a)

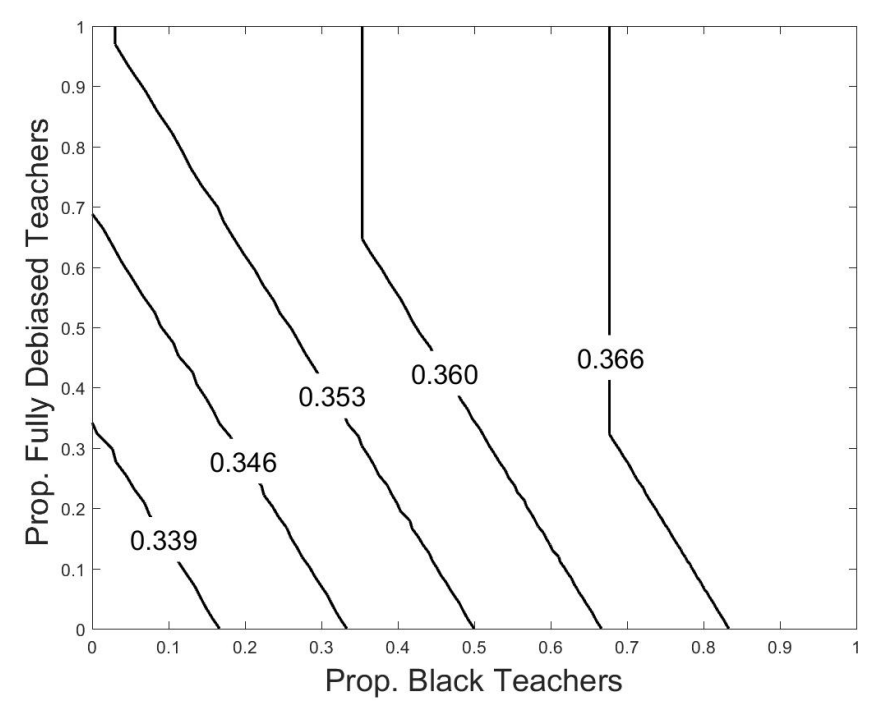

(c)

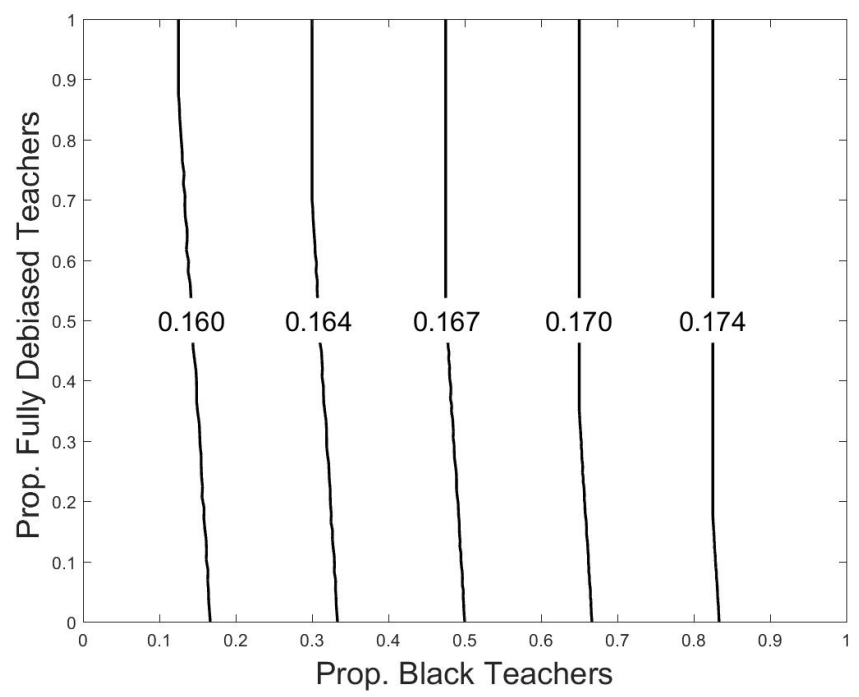

(b)

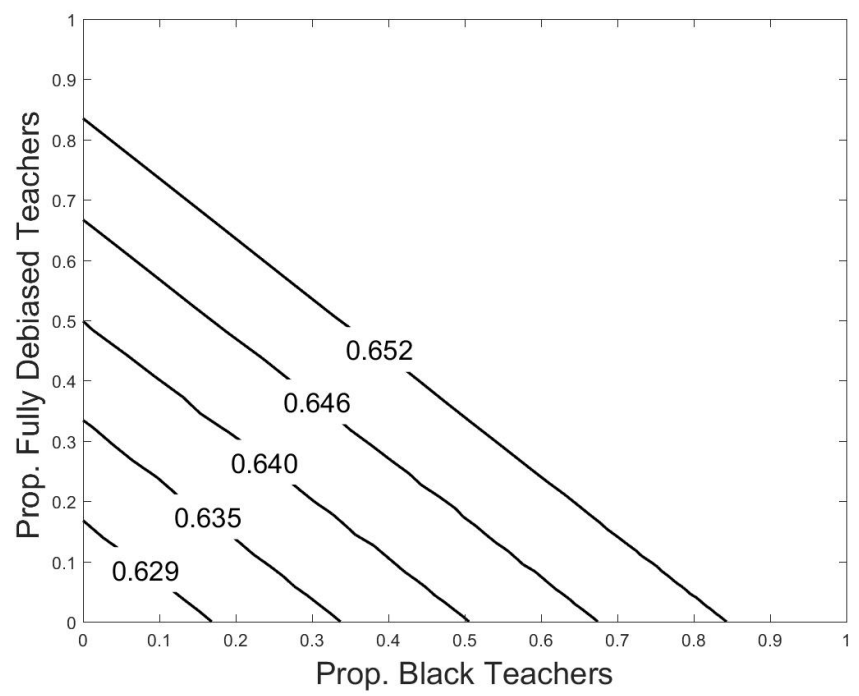

(d)

Figure 8: College COMPletion RATE isoquants. Isoquants with de-biasing and hiring more black teachers as two inputs and black students' college completion rates as outputs. Proportion of debiased teachers are calculated as the number of de-biased white teachers over the number of white teachers of black students when the proportion of black teachers is equal to 0 . Panel $8(\mathrm{a})$ shows isoquants for black students in the first quartile in terms of $\theta$. Panel 8(b) isoquants for individuals in the second quartile, and panel 8(c) and 8(d) respectively show the isoquants for individuals in third and fourth quartiles. Kinks occur when all white teachers of black students are debiased. 


\section{Appendix A Identification Using Parameter Restrictions}

In the main text, we claim that we can identify the impact of bias using data on two teachers' expectations and student outcomes as long as we are willing to make strong functional form assumptions and if we restrict parameters. One of the key reasons we instead opt for using additional data is that it allows us to relax continuity of outcomes. Moreover, we can avoid parameter restrictions. Still, we think it is worth demonstrating that even if we limit ourselves to teacher expectations and student outcomes, we can still achieve identification of the magnitude of bias, its various sources and its impact on outcomes. Moreover, we are able to demonstrate the our results are similar, which suggests that our main results are not driven by the test score data we use to identify additional model parameters.

In what follows, we omit the subscript $i . Y$ is a continuous outcome. $T_{j}$ are teacher expectations for teacher $j \in\{E, M\}$ about the outcome $Y$. We have suppressed student indices. $b_{j}$ are biases about the student for teacher $j$ and will be explained below. We allow teachers to have mean expectations that deviate from each other and also from the true mean, denoted $c$. Teacher means are denoted $c_{j}$. This captures how, on average, teachers can be wrong. Teachers can make a student specific error, which is denoted $e_{j}$. We also allow teachers be wrong about how $\theta$ maps to outcomes, which is captured by $\phi$.

$$
\begin{aligned}
Y & =c+\theta+\left[b_{E}+b_{M}\right] \gamma+e_{Y} \\
T_{E} & =c_{E}+\phi \theta+e_{E} \\
T_{M} & =c_{M}+\phi \theta+e_{M}
\end{aligned}
$$

Notice, we have made parameter restrictions on the model in the main text. In particular, $\phi_{1}=\phi_{2} \equiv \phi$ and $\gamma_{1}=\gamma_{2} \equiv \gamma$. We also assume that the disturbances $e$ and $\theta$ are all normally distributed and independent of one another with mean zero:

$$
\begin{aligned}
\theta & \sim N\left(0, \sigma_{\theta}^{2}\right) \\
e_{y} & \sim N\left(0, \sigma_{Y}^{2}\right) \\
e_{E} & \sim N\left(0, \sigma_{E}^{2}\right) \\
e_{M} & \sim N\left(0, \sigma_{M}^{2}\right)
\end{aligned}
$$

Rewrite the production of expectations to be:

$$
\begin{aligned}
T_{E} & =c+\theta+\left(c_{E}-c\right)+(\phi-1) \theta+e_{E} \\
T_{M} & =c+\theta+\left(c_{M}-c\right)+(\phi-1) \theta+e_{M}
\end{aligned}
$$

Notice teacher expectations are the correct expectations plus a systematic component $c_{j}-c$, 
a component that depends on the objective probability $\theta$ and an idiosyncratic component. Bias is defined as follows:

$$
\begin{aligned}
T_{E}-c-\theta & \equiv b_{E}=\left(c_{E}-c\right)+(\phi-1) \theta+e_{E} \\
T_{M}-c-\theta & \equiv b_{M}=\left(c_{M}-c\right)+(\phi-1) \theta+e_{M}
\end{aligned}
$$

Given the above, we re-write the outcome equation as follows:

$$
\begin{aligned}
Y & =c+\left(c_{E}+c_{M}-2 c\right) \gamma \\
& +\theta(1+2 \gamma(\phi-1)) \\
& +e_{E} \gamma+e_{M} \gamma \\
& +e_{Y}
\end{aligned}
$$

Rewrite again as:

$$
\begin{aligned}
Y & =\bar{c}+\theta \psi+e_{E} \gamma+e_{M} \gamma+e_{Y} \\
T_{E} & =c_{E}+\phi \theta+e_{E} \\
T_{M} & =c_{M}+\phi \theta+e_{M} \\
\bar{c} & =c+\left(c_{E}+c_{M}-2 c\right) \gamma \\
\psi & =1+2 \gamma(\phi-1)
\end{aligned}
$$

Demean, so that $Y-\bar{c}=\tilde{Y}, T_{E}-c_{E}=\tilde{T}_{E}$ and $T_{M}-c_{M}=\tilde{T}_{M}$. Next, independence implies the following:

$$
\begin{aligned}
\operatorname{Cov}\left(\tilde{T}_{E}, \tilde{T}_{M}\right) & =\phi^{2} \operatorname{Var}(\theta) \\
\operatorname{Cov}\left(\tilde{Y}, \tilde{T}_{E}\right) & =\psi \phi \operatorname{Var}(\theta)+\gamma \operatorname{Var}\left(e_{E}\right) \\
\operatorname{Cov}\left(\tilde{Y}, \tilde{T}_{M}\right) & =\psi \phi \operatorname{Var}(\theta)+\gamma \operatorname{Var}\left(e_{M}\right) \\
\operatorname{Var}\left(\tilde{T}_{E}\right) & =\phi^{2} \operatorname{Var}(\theta)+\operatorname{Var}\left(e_{E}\right) \\
\operatorname{Var}\left(\tilde{T}_{M}\right) & =\phi^{2} \operatorname{Var}(\theta)+\operatorname{Var}\left(e_{M}\right)
\end{aligned}
$$

Notice

$$
\begin{aligned}
\operatorname{Var}\left(e_{E}\right) & =\operatorname{Var}\left(\tilde{T}_{E}\right)-\operatorname{Cov}\left(\tilde{T}_{E}, \tilde{T}_{M}\right) \\
\operatorname{Var}\left(e_{M}\right) & =\operatorname{Var}\left(\tilde{T}_{M}\right)-\operatorname{Cov}\left(\tilde{T}_{M}, \tilde{T}_{M}\right) \\
\operatorname{Cov}\left(\tilde{Y}, \tilde{T}_{E}\right)-\operatorname{Cov}\left(\tilde{Y}, \tilde{T}_{M}\right) & =\gamma\left[\operatorname{Var}\left(e_{E}\right)-\operatorname{Var}\left(e_{M}\right)\right]
\end{aligned}
$$

Therefore

$$
\gamma=\frac{\operatorname{Cov}\left(\tilde{Y}, \tilde{T}_{E}\right)-\operatorname{Cov}\left(\tilde{Y}, \tilde{T}_{M}\right)}{\operatorname{Var}\left(\tilde{T}_{E}\right)-\operatorname{Var}\left(\tilde{T}_{M}\right)}
$$


Since we have $\gamma$, we can identify $\phi$ and $\psi$ as follows:

$$
\begin{aligned}
\phi\left[\operatorname{Cov}\left(\tilde{Y}, \tilde{T}_{E}\right)-\gamma \operatorname{Var}\left(e_{E}\right)\right] & =\psi \operatorname{Cov}\left(\tilde{T}_{E}, \tilde{T}_{M}\right)=\psi \phi^{2} \operatorname{Var}(\theta) \\
\Longrightarrow \frac{\phi}{\psi} & =\frac{\operatorname{Cov}\left(\tilde{T}_{E}, \tilde{T}_{M}\right)}{\left[\operatorname{Cov}\left(\tilde{Y}, \tilde{T}_{E}\right)-\gamma \operatorname{Var}\left(e_{E}\right)\right]} \\
& =\frac{\operatorname{Cov}\left(\tilde{T}_{E}, \tilde{T}_{M}\right)}{\left[\operatorname{Cov}\left(\tilde{Y}, \tilde{T}_{E}\right)-\gamma\left(\operatorname{Var}\left(\tilde{T}_{E}\right)-\operatorname{Cov}\left(\tilde{T}_{E}, \tilde{T}_{M}\right)\right)\right]} \\
& \equiv \Lambda
\end{aligned}
$$

We also have that

$$
\psi=1+2 \gamma(\phi-1)
$$

Together, we get that:

$$
\psi=\frac{1-2 \gamma}{1-2 \gamma \Lambda}
$$

When we get results, it will sometimes be interesting to decompose the different effects of bias. To make this clear, re-write the outcome equation as follows:

$$
\begin{array}{rccll}
Y & = & c+\theta & & \text { Explains } Y \\
& + & \left(c_{E}+c_{M}-2 c\right) \gamma & : & \text { Systematic Bias } \\
+ & \theta 2(\phi-1) \gamma & : & \text { Bias as a Function of } \theta \\
+ & \left(e_{E}+e_{M}\right) \gamma & : & \text { Idiosyncratic Bias } \\
+ & e_{y} & : & \text { Disturbance } \\
T_{E} & = & c_{E}+\phi \theta+e_{E} & & \\
T_{M} & = & c_{M}+\phi \theta+e_{M} & &
\end{array}
$$

Estimating this model purely on expectations and outcomes data yields $\hat{\gamma}=0.2620$. This estimate is reassuring as it is fairly similar to parameters we estimate in the main analysis. In other words, the additional data we use to relax continuity and to identify additional model parameters do not appear to drive our main results. 


\section{Appendix B Alternative Definition of Bias}

There are different ways to define bias in our setup. In a linear model, we can think of bias in at least two different ways:

1. $b_{i}=T_{i}-\theta, T_{i} \in\{E, M\}$

2. $b_{i}=\tilde{\theta}_{i}-\theta, \tilde{\theta}_{i}=E\left(T_{i}\right)$

In the non-linear case, we can consider two possible ways to define bias that are similar to the second option:

$$
\begin{gathered}
b_{i}=\Phi\left(c_{i}+\phi \theta+\beta_{i} G P A\right)-\Phi\left(c_{y}+\theta+\beta_{y} G P A\right) \\
b_{i}=\Phi\left(c_{i}+\phi \theta+\beta_{i} G P A+e_{i}\right)-\Phi\left(c_{y}+\theta+\beta_{y} G P A\right)
\end{gathered}
$$

The paper focuses on the first definition of bias. The problem with the alternative definition is that the two teacher expectations, on average, are close to each other, even after introducing nonlinearity by using a probit specification. Therefore, we run into a multicollinearity problem. Here, we define bias as $b_{i}=E\left(Y \mid b_{i}=0, G P A\right)-E\left(T_{i}\right)$ and estimate the model outlined in the main text where the outcome equation is defined as $Y^{*}=\theta+\gamma\left(b_{E}+b_{M}\right) / 2+e_{y}$. The parameter estimates are in Table S6, S7, and S8 for all sample, whites, and blacks, respectively. The results are qualitatively similar to main results. 


\section{Appendix Tables and Figures}

Appendix Table S1: Effect of Expectation on Education, LPM

\begin{tabular}{lccccccccc}
\hline \hline & & \multicolumn{4}{c}{ All Students } & \multicolumn{3}{c}{ White } & $\begin{array}{c}\text { Black } \\
(9)\end{array}$ \\
& $(1)$ & $(2)$ & $(3)$ & $(4)$ & $(5)$ & $(6)$ & $(7)$ & $(8)$ & $(9)$ \\
\hline Expect College, English & $0.42^{* * *}$ & & $0.27^{* * *}$ & $0.27^{* * *}$ & $0.23^{* * *}$ & $0.16^{* * *}$ & $0.14^{* * *}$ & $0.13^{* * *}$ & $0.18^{*}$ \\
& $(0.01)$ & & $(0.02)$ & $(0.02)$ & $(0.02)$ & $(0.02)$ & $(0.02)$ & $(0.02)$ & $(0.08)$ \\
Expect College, Math & & $0.42^{* * *}$ & $0.28^{* * *}$ & $0.28^{* * *}$ & $0.23^{* * *}$ & $0.17^{* * *}$ & $0.13^{* * *}$ & $0.14^{* * *}$ & 0.10 \\
& & $(0.01)$ & $(0.02)$ & $(0.02)$ & $(0.02)$ & $(0.02)$ & $(0.02)$ & $(0.02)$ & $(0.07)$ \\
Teacher Controls & No & No & No & Yes & Yes & Yes & Yes & Yes & Yes \\
Student SES & No & No & No & No & Yes & Yes & Yes & Yes & Yes \\
9th Grade GPA & No & No & No & No & No & Yes & Yes & Yes & Yes \\
School FE & No & No & No & No & No & No & Yes & Yes & Yes \\
\hline Observations & 5320 & 5320 & 5320 & 5320 & 5320 & 5320 & 5320 & 3460 & 550 \\
$R^{2}$ & 0.18 & 0.18 & 0.24 & 0.24 & 0.28 & 0.30 & 0.40 & 0.45 & 0.65 \\
Adj $R^{2}$ & 0.18 & 0.18 & 0.24 & 0.24 & 0.27 & 0.30 & 0.31 & 0.33 & 0.26 \\
\hline \hline
\end{tabular}

Notes: This table reports OLS estimates of equation (1) for the restricted sample of students who did complete high school but did not earn a graduate degree. Otherwise, all specifications are identical to those estimated in Table 3. 
Appendix Table S2: Probit Estimates of Effect of Expectations on Educational Attainment

\begin{tabular}{|c|c|c|c|c|c|c|c|c|c|}
\hline & \multicolumn{7}{|c|}{ All Students } & \multirow{2}{*}{$\begin{array}{c}\text { White } \\
(8)\end{array}$} & \multirow{2}{*}{$\begin{array}{c}\text { Black } \\
(9)\end{array}$} \\
\hline & $(1)$ & $(2)$ & $(3)$ & $(4)$ & $(5)$ & $(6)$ & $(7)$ & & \\
\hline \multirow[t]{2}{*}{ ELA Teacher Coefficient } & $1.39^{* * *}$ & & $0.97^{* * *}$ & $0.97^{* * *}$ & $0.84^{* * *}$ & $0.59^{* * *}$ & $0.57^{* * *}$ & $0.52^{* * *}$ & $1.97^{* * *}$ \\
\hline & $(0.04)$ & & $(0.048)$ & $(0.048)$ & $(0.050)$ & $(0.052)$ & $(0.067)$ & $(0.09)$ & $(0.58)$ \\
\hline \multirow[t]{2}{*}{ Math Teacher Coefficient } & & $1.39^{* * *}$ & $0.97^{* * *}$ & $0.97^{* * *}$ & $0.85^{* * *}$ & $0.60^{* * *}$ & $0.51^{* * *}$ & $0.56^{* * *}$ & $1.18^{* *}$ \\
\hline & & $(0.04)$ & $(0.05)$ & $(0.05)$ & $(0.05)$ & $(0.05)$ & $(0.06)$ & $(0.09)$ & $(0.49)$ \\
\hline \multirow[t]{2}{*}{ ELA Teacher APE } & $0.55^{* * *}$ & & $0.38^{* * *}$ & $0.38^{* * *}$ & $0.33^{* * *}$ & $0.23^{* * *}$ & $0.22^{* * *}$ & $0.12^{* * *}$ & $0.33^{* * *}$ \\
\hline & $(0.04)$ & & & $(0.05)$ & $(0.05)$ & & $(0.07)$ & $(0.02)$ & $(0.11)$ \\
\hline \multirow[t]{2}{*}{ Math Teacher APE } & & $0.54^{* * *}$ & $0.38^{* * *}$ & $0.38^{* * *}$ & $0.33^{* * *}$ & $0.23^{* * *}$ & $0.20^{* * *}$ & $0.13^{* * *}$ & $0.20^{* *}$ \\
\hline & & $(0.04)$ & $(0.05)$ & $(0.05)$ & $(0.05)$ & $(0.05)$ & $(0.06)$ & $(0.02)$ & $(0.09)$ \\
\hline Teacher Controls & No & No & No & Yes & Yes & Yes & Yes & Yes & Yes \\
\hline Student SES & No & No & No & No & Yes & Yes & Yes & Yes & Yes \\
\hline 9th Grade GPA & No & No & No & No & No & Yes & Yes & Yes & Yes \\
\hline School FE & No & No & No & No & No & No & Yes & Yes & Yes \\
\hline Pseudo $R^{2}$ & 0.17 & 0.17 & 0.23 & 0.23 & 0.28 & 0.31 & 0.37 & 0.39 & 0.53 \\
\hline Observations & 6060 & 6060 & 6060 & 6060 & 6060 & 6060 & 5660 & 3550 & 300 \\
\hline
\end{tabular}

This table reports probit coefficient estimates, and corresponding average partial effects (APE), of the "expects college" indicators in equation (1). The dependent variable is a binary indicator equal to one if the student completed a four-year college degree (or more), and zero otherwise. The sample in column (7) is slightly smaller because schools with too few students are removed from the school fixed-effects specification. Otherwise, all specifications are identical to those estimated in Table 3. 
Appendix Table S3: Summary Statistics - Instruments

\begin{tabular}{lcccccc}
\hline \hline & \multicolumn{2}{c}{$(1)$} & \multicolumn{2}{c}{$(2)$} & \multicolumn{2}{c}{$(3)$} \\
& $\begin{array}{c}\text { All Sample } \\
\text { mean }\end{array}$ & \multicolumn{2}{c}{ Whites } & \multicolumn{2}{c}{ Blacks } \\
& 0.12 & 5960 & 0.10 & 3900 & 0.16 & 600 \\
\hline Passive (English) & 0.11 & 5980 & 0.10 & 3930 & 0.14 & 600 \\
Passive (Math) & 0.04 & 5940 & 0.03 & 3890 & 0.07 & 580 \\
Rarely attentive (English) & 0.04 & 5980 & 0.03 & 3930 & 0.07 & 590 \\
Rarely attentive (Math) & 0.17 & 5940 & 0.16 & 3890 & 0.23 & 580 \\
Sometimes attentive (English) & 0.16 & 5980 & 0.15 & 3930 & 0.22 & 590 \\
Sometimes attentive (Math) & 0.46 & 5940 & 0.47 & 3890 & 0.44 & 580 \\
Mostly attentive (English) & 0.45 & 5980 & 0.46 & 3930 & 0.48 & 590 \\
Mostly attentive (Math) & 0.16 & 4850 & 0.17 & 3270 & 0.17 & 420 \\
Strongly agree reading is fun & 0.35 & 4850 & 0.33 & 3270 & 0.41 & 420 \\
Agree reading is fun & 0.35 & 4850 & 0.36 & 3270 & 0.31 & 420 \\
Disagree reading is fun & 0.08 & 4800 & 0.07 & 3240 & 0.11 & 410 \\
Strongly agree math is fun & 0.27 & 4800 & 0.25 & 3240 & 0.32 & 410 \\
Agree math is fun & 0.47 & 4800 & 0.49 & 3240 & 0.39 & 410 \\
Disagree math is fun & \multicolumn{4}{c}{ fun } \\
\hline \hline
\end{tabular}

Appendix Table S4: Summary Statistics - Identification

\begin{tabular}{l|c}
\hline \hline Variable & Mean \\
\hline Ever bullied & 0.1978 \\
Ever bullied missing & 0.0406 \\
Got in Fight & 0.1008 \\
Got in Fight missing & 0.0416 \\
Participated in science fair & 0.1465 \\
Participated in science fair missing & 0.0440 \\
S finds class interesting & 0.5664 \\
S finds class interesting missing & 0.0427 \\
$\mathrm{P}$ thinks S has disability & 0.0881 \\
$\mathrm{P}$ thinks S has disability missing & 0.0605 \\
\hline $\mathrm{N}$ & 6060 \\
\hline \hline
\end{tabular}

Summary tables for variables used to check the exogeneity of teacher bias in Section 3.2 . $\mathrm{S}$ is student and $\mathrm{P}$ is parent. 
Appendix Table S5: Parameter Estimates - Additional Measures

\begin{tabular}{c|rr}
\hline \hline & Whites & Blacks \\
\hline$c_{G}$ & $0.15^{* * *}$ & $-0.63^{* * *}$ \\
& $(0.02)$ & $(0.04)$ \\
$c_{S_{E}}$ & $0.19^{* * *}$ & $-0.63^{* * *}$ \\
& $(0.02)$ & $(0.04)$ \\
$c_{S_{M}}$ & $0.17^{* * *}$ & $-0.75^{* * *}$ \\
& $(0.01)$ & $(0.04)$ \\
$\phi_{G}$ & $1.22^{* * *}$ & $0.67^{* * *}$ \\
& $(0.13)$ & $(0.12)$ \\
$\phi_{S_{E}}$ & $1.53^{* * *}$ & $0.96^{* * *}$ \\
& $(0.16)$ & $(0.17)$ \\
$\phi_{S_{M}}$ & $1.53^{* * *}$ & $1.01^{* * *}$ \\
& $(0.16)$ & $(0.18)$ \\
$\sigma_{G}$ & $0.77^{* * *}$ & $0.83^{* * *}$ \\
& $(0.01)$ & $(0.03)$ \\
$\sigma_{S_{M}}$ & $0.47^{* * *}$ & $0.46^{* * *}$ \\
& $(0.01)$ & $(0.03)$ \\
$\sigma_{S_{R}}$ & $0.54^{* * *}$ & $0.52^{* * *}$ \\
& $(0.01)$ & $(0.02)$ \\
\hline $\mathrm{N}$ & 3970 & 610 \\
\hline \hline
\end{tabular}

Appendix Table S6: All

\begin{tabular}{l|cc}
\hline \hline Variable & Coefficient & Std. Error \\
\hline$\gamma$ & 0.33 & 0.11 \\
$c$ & -0.39 & 0.08 \\
$b_{y}$ & 0.42 & 0.04 \\
$\sigma_{\theta}$ & 0.64 & 0.04 \\
\hline$c_{E}$ & 0.52 & 0.02 \\
$c_{M}$ & 0.50 & 0.02 \\
$\phi_{G}$ & 1.04 & 0.07 \\
$\phi_{E}$ & 1.15 & 0.10 \\
$\phi_{M}$ & 1.30 & 0.10 \\
$b_{E}$ & 0.53 & 0.03 \\
$b_{M}$ & 0.49 & 0.03 \\
\hline$c_{G}$ & 0.02 & 0.01 \\
$c_{S_{M}}$ & -0.00 & 0.01 \\
$c_{S_{R}}$ & -0.00 & 0.01 \\
$\phi_{S_{M}}$ & 1.37 & 0.09 \\
$\phi_{S_{R}}$ & 1.30 & 0.08 \\
$\sigma_{G}$ & 0.80 & 0.01 \\
$\sigma_{S_{M}}$ & 0.49 & 0.01 \\
$\sigma_{S_{R}}$ & 0.56 & 0.01 \\
\hline \hline
\end{tabular}

Parameter estimates of alternative bias definition model in subsection Appendix B for the sample. $N=6060$. 
Appendix Table S7: Whites

\begin{tabular}{l|cc}
\hline \hline Variable & Coefficient & Std. Error \\
\hline$\gamma$ & 0.38 & 0.13 \\
$c$ & -0.31 & 0.09 \\
$b_{y}$ & 0.44 & 0.05 \\
$\sigma_{\theta}$ & 0.61 & 0.05 \\
\hline$c_{E}$ & 0.59 & 0.03 \\
$c_{M}$ & 0.59 & 0.03 \\
$\phi_{E}$ & 1.35 & 0.15 \\
$\phi_{M}$ & 1.56 & 0.16 \\
$b_{E}$ & 0.53 & 0.04 \\
$b_{M}$ & 0.48 & 0.04 \\
\hline$c_{G}$ & 0.15 & 0.02 \\
$c_{S_{M}}$ & 0.17 & 0.01 \\
$c_{S_{R}}$ & 0.19 & 0.02 \\
$\phi_{G}$ & 1.03 & 0.09 \\
$\phi_{S_{M}}$ & 1.27 & 0.11 \\
$\phi_{S_{R}}$ & 1.27 & 0.11 \\
$\sigma_{G}$ & 0.77 & 0.01 \\
$\sigma_{S_{M}}$ & 0.48 & 0.01 \\
$\sigma_{S_{R}}$ & 0.55 & 0.01 \\
\hline \hline
\end{tabular}

Parameter estimates of alternative bias definition model in subsection Appendix B for white subsample. $N=3970$. 
Appendix Table S8: Blacks

\begin{tabular}{l|cc}
\hline \hline Variable & Coefficient & Std. Error \\
\hline$\gamma$ & 0.47 & 0.54 \\
$c$ & -0.91 & 0.48 \\
$b_{y}$ & 0.24 & 0.17 \\
$\sigma_{\theta}$ & 0.84 & 0.16 \\
\hline$c_{E}$ & 0.25 & 0.08 \\
$c_{M}$ & 0.06 & 0.08 \\
$\phi_{E}$ & 0.74 & 0.19 \\
$\phi_{M}$ & 0.85 & 0.21 \\
$b_{E}$ & 0.45 & 0.07 \\
$b_{M}$ & 0.38 & 0.08 \\
\hline$c_{G}$ & -0.63 & 0.04 \\
$c_{S_{M}}$ & -0.75 & 0.04 \\
$c_{S_{R}}$ & -0.63 & 0.04 \\
$\phi_{G}$ & 0.64 & 0.13 \\
$\phi_{S_{R}}$ & 0.91 & 0.17 \\
$\phi_{S_{M}}$ & 0.96 & 0.18 \\
$\sigma_{G}$ & 0.83 & 0.03 \\
$\sigma_{S_{M}}$ & 0.47 & 0.03 \\
$\sigma_{S_{R}}$ & 0.52 & 0.02 \\
\hline \hline
\end{tabular}

Parameter estimates of alternative bias definition model in subsection Appendix B for black sample. $N=670$. 


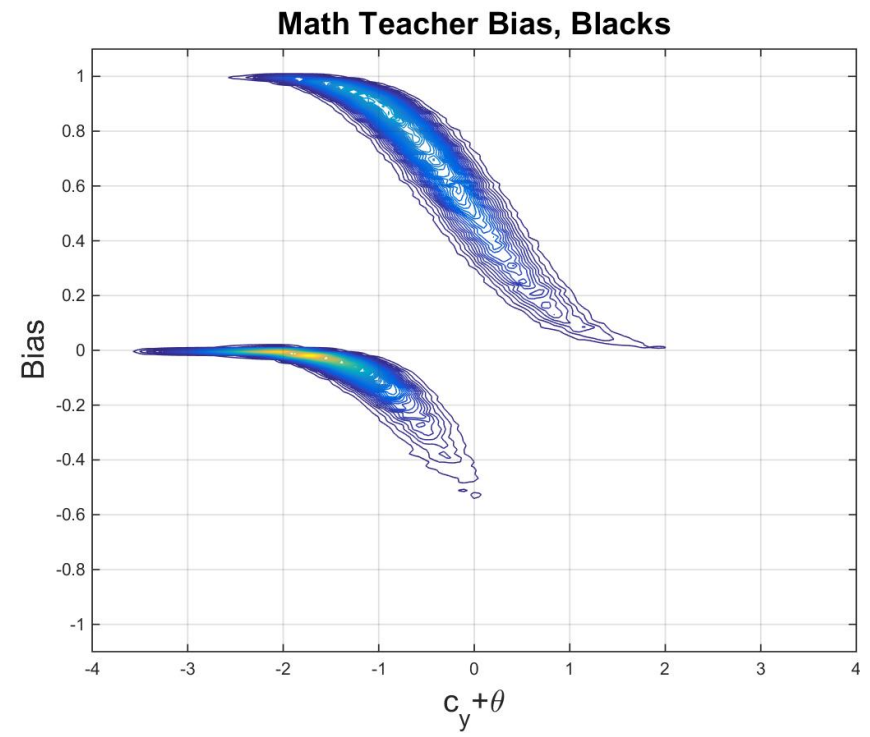

(a)

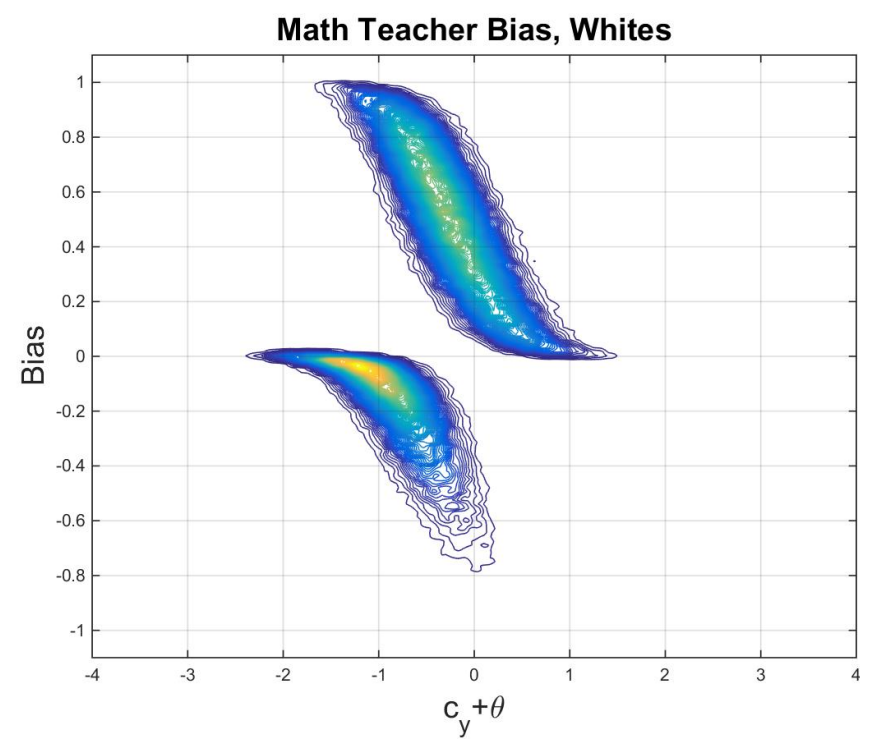

(c)

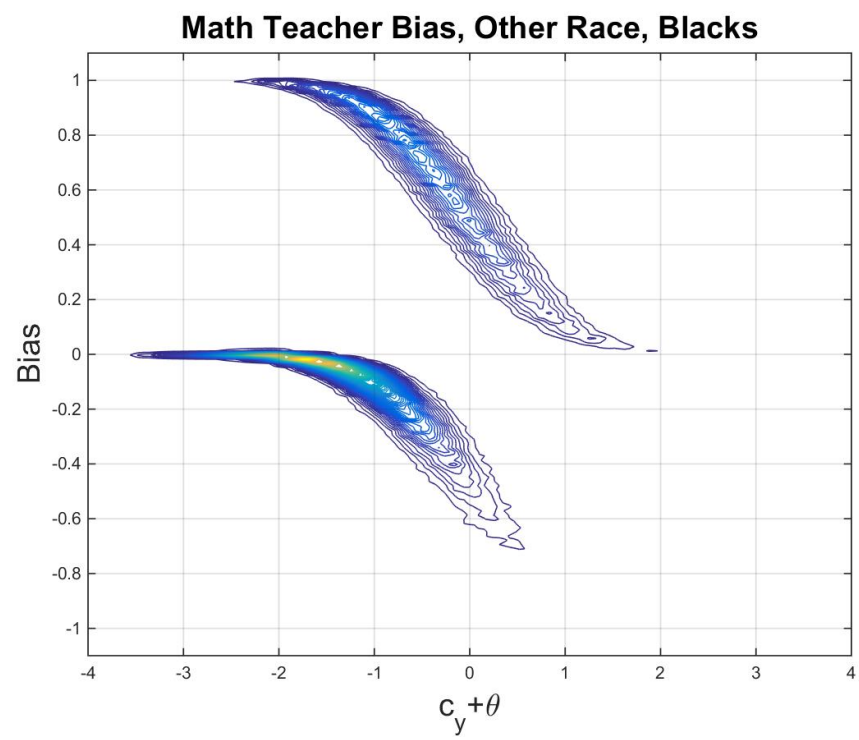

(b)

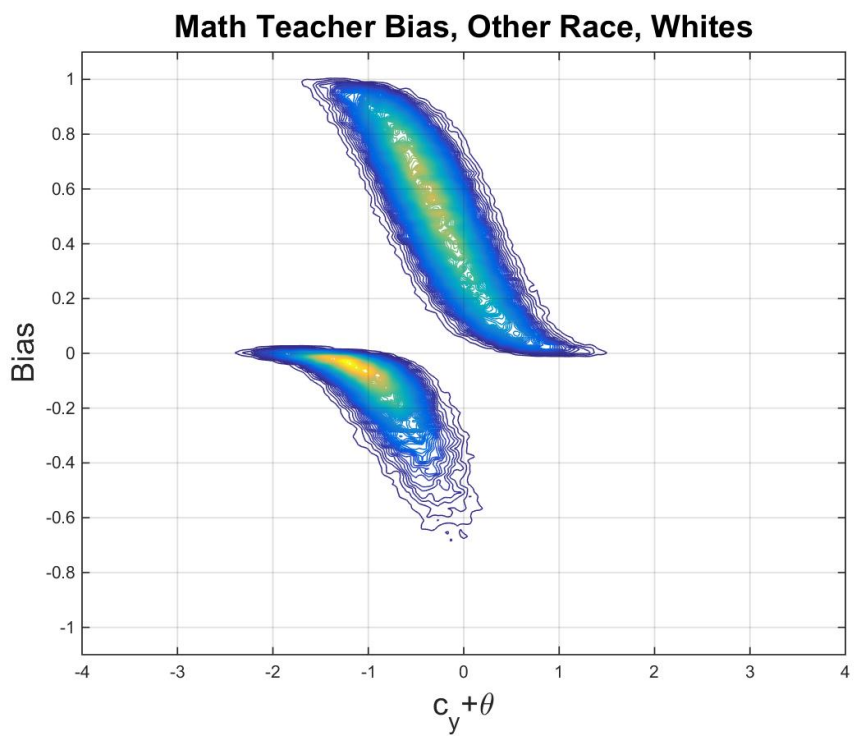

(d)

Appendix Figure S1: Distribution of Bias. Panel 1(a) shows contour plot of black math teachers' bias of black students. Panel 1(b) shows the distribution non-black math teacher bias of black students. Panel $1(\mathrm{c})$ and $1(\mathrm{~d})$ show contour plots of white and non-white teachers' bias, respectively, of white students. 


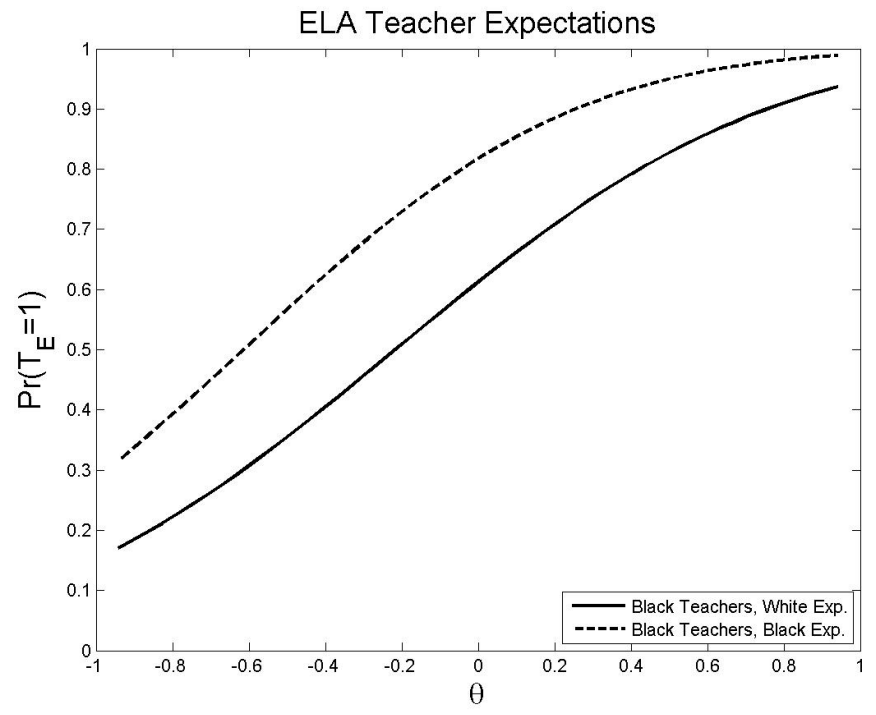

(a)

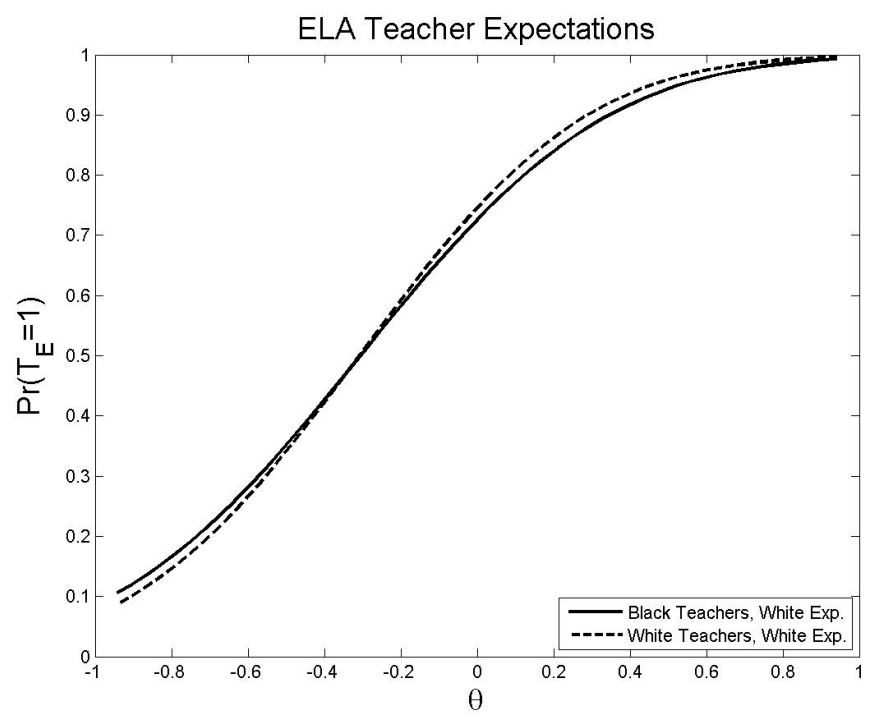

(c)

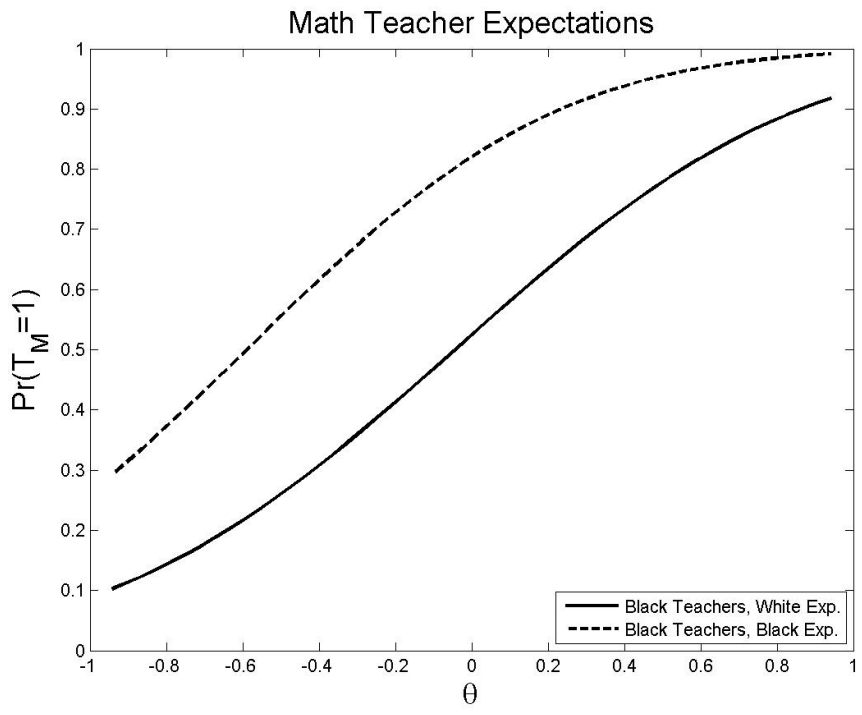

(b)

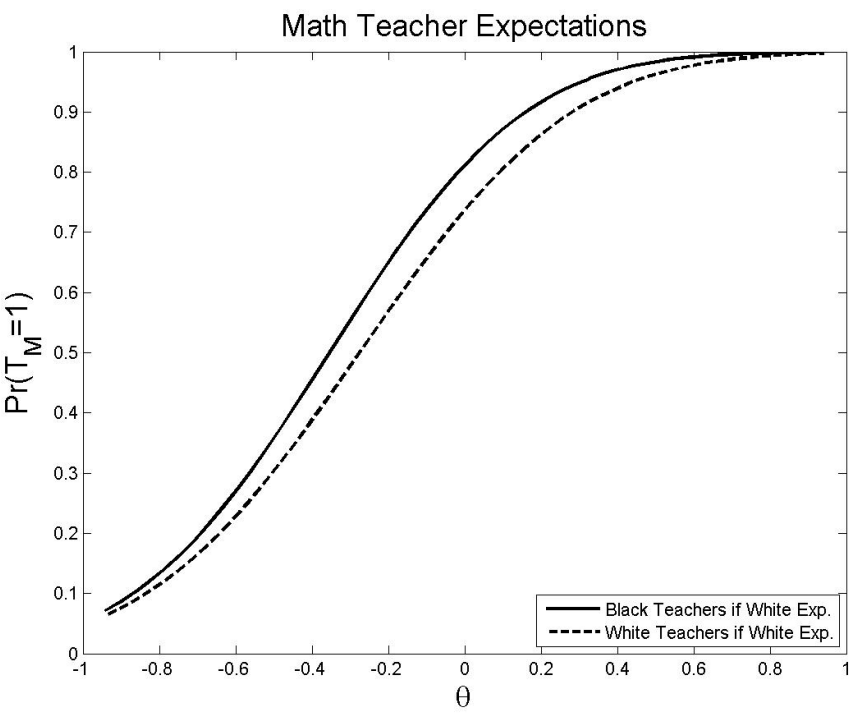

(d)

Appendix Figure S2: Teacher Expectations, White students. Panel 2(a) shows how teacher expectations change when white students face the same expectation production function from black ELA teachers as black students. Panel 2(b) shows how the expectations change in the counter factual scenario for black math teachers.Panels 2(c) and 2(d), respectively, compare white and black ELA and math teachers' expectation for white students with given $\theta$. 